\title{
'An Annotated Bibliography on Screenwriting Manuals Between 2000-2020 that aid in Character Development.'
}

by

\section{Lene Aiono}
Submitted to the School of Information Management, Victoria University of Wellington in partial fulfilment of the requirements for the degree of Master of Information Studies




\section{Contents}

1. Background to Screenwriting Problems and Screenwriting Manuals ........... 3

A. Character Development Problems........................................................ 3

2. Identification of Bibliographic Gap................................................. 4

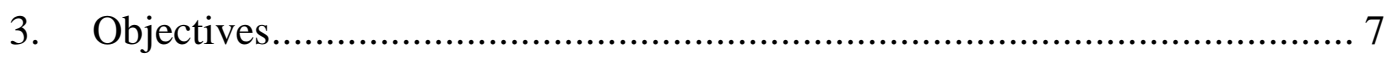

A. Purpose ….............................................................................. 7

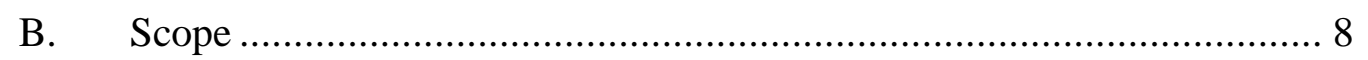

I. Inclusion of items .......................................................................... 8

II. Exclusion of items ............................................................. 9

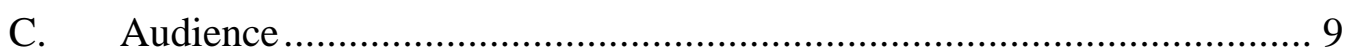

4. Currency and Comprehensiveness .......................................................... 11

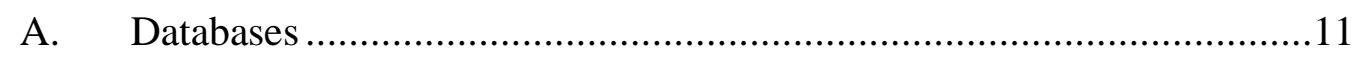

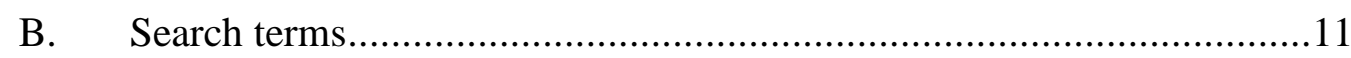

C. Expectations of the number of items...............................................12

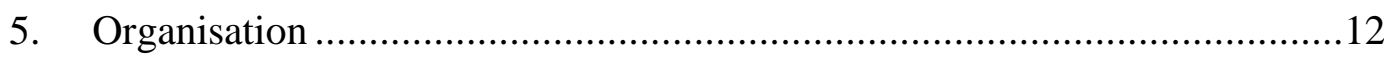

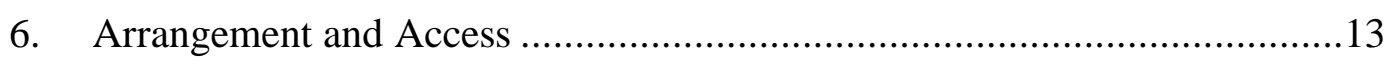

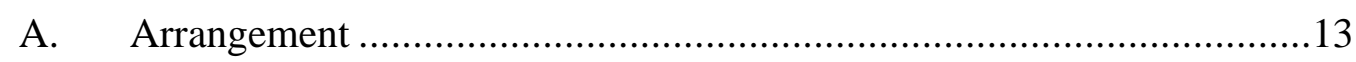

B. Format and Information Fields ...................................................... 13

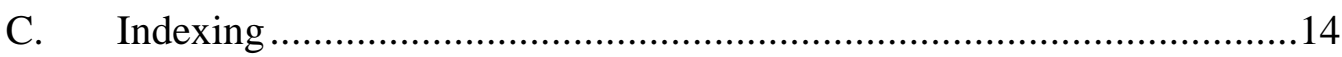

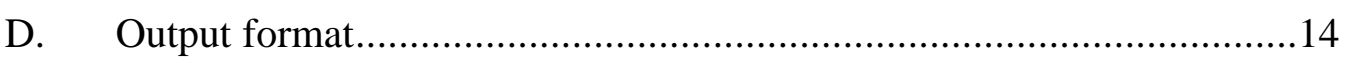

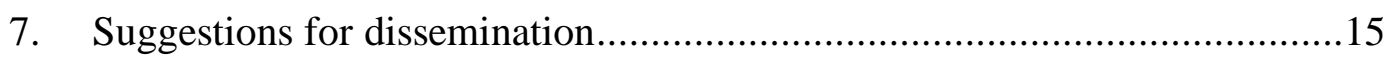

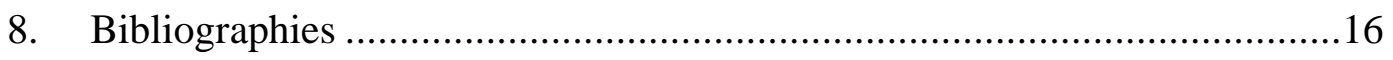

A. Defining the Main Character .............................................................16

B. Developing the Character-arc ...........................................................67

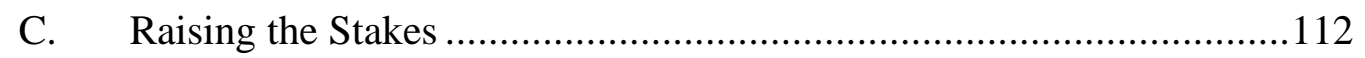

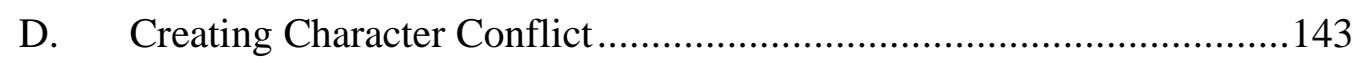

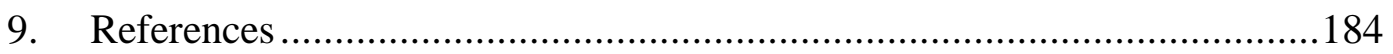

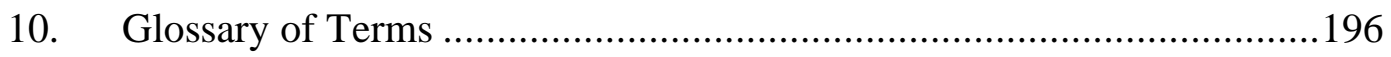

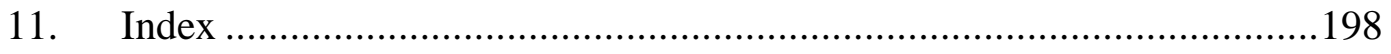

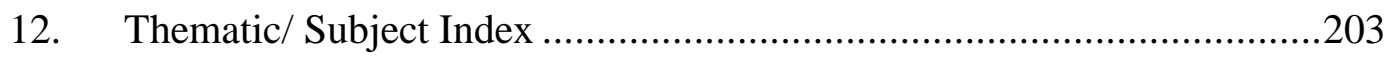




\section{Background to Screenwriting Problems and}

\section{Screenwriting Manuals}

The New Zealand Film Commission (NZFC) is the government organisation that finances films. The NZFC agrees with many screenwriting authors that the most common problems with scripts relate to character development (Batty, 2011, p. 45; Frayne, 2019; Nelmes, 2010, p. 202; NZFC Scriptwriting, 2020). Therefore, a screenwriter needs resources to overcome character development problems in their scripts. However, there are too many screenwriting manuals in publication. Also, an inexperienced amateur screenwriter may not know which manuals would solve their particular character development problems.

In this annotated bibliography, the screenwriter is the author responsible for developing the script. Furthermore, the script serves as a guideline to producing media content: feature film, short film, videogames, radio-play, television (Field, 2005, p. 19; Gallo, 2012a, Chapter 2; Nannicelli, 2013, pp. 11-18). On account of this, this annotated bibliography will focus mainly on screenwriting manuals dealing with feature film scripts. Feature film scripts are 90 minutes or longer in duration (Field, 2005, p. 22). Additionally, since a script encompasses story and character elements, this annotated bibliography will focus only on character development.

A story is unique to their characters (Chamberlain, 2016a, p. 9), and the characters drive the plot (Batty, 2011, p. 24). Therefore, a functioning, script, needs a clearly defined main character, or hero, with a stable character arc, and high stakes for the hero, and character conflict (Ballon, 2005, p. 55; Batty, 2011; L. Lee, 2001; Sublett, 01).

\section{A. Character Development Problems}

Firstly, the hero's emotional conflict is the driving force behind the drama in a script (Ballon, 2005, p. 49). A common problem is a lack of conflict, which derives from a lack of a goal for the hero, and characters opposing that hero (Ballon, 2005, p. 50; Batty, 2011, p. 47; Sublett, 01, p. 26). Secondly, a lack of stakes derives from the screenwriter, not establishing what the hero stands to lose 
if they fail (Batty, 2011, p. 25). Thirdly, a screenwriters failure to clearly define the hero stems from a lack of knowledge of the hero's desires, fears, hopes, and flaws to make the character more emotionally three-dimensional (Ballon, 2005, p. 58). Lastly, a weak character-arc ensues when the hero fails to change from one emotional state to another by the end of the story (Ballon, 2005, p. 64; Batty, 2011, p. 53; L. Lee, 2001, p. 92).

Consequently, a screenwriter only has two ways of learning how to circumvent these character development problems: to learn through an academic institution or reading screenwriting manuals. However, the amateur screenwriter does not have the experience to evaluate what screenwriting manuals are trusted and accurate or the expertise required to navigate the abundance of publications available on screenwriting.

Therefore, an annotated bibliography that collates, and organises these screenwriting manuals to answer these character-development problems could be useful to screenwriters, and those interested in the subject of screenwriting.

\section{Identification of Bibliographic Gap}

The proliferation of Screenwriting literature has increased in the last three decades about learning screenwriting techniques (Conor, 2014, p. 122). Moreover, screenwriting as an avenue for research is likely to grow because of increased interest (Batty \& Baker, 2018, p. 80). Furthermore, the expansion of screenwriting education in universities around the world have increased the demand for content and academic research on screenwriting (Batty, 2016, p. 59). Therefore, with the multitude of screenwriting manuals in publication, and increased interest in learning screenwriting techniques in universities, there is a need for scholarly research on the content and practice of screenwriting, and an annotated bibliography could act as a preliminary overview of screenwriting materials available.

Moreover, knowing what the most common problems are will increase the chance of success for a screenwriter (Frayne, 2019), and most problems are inherent in the construction of characters. Therefore, a bibliographic gap exists for an 
annotated bibliography on screenwriting manuals, for screenwriters to reference, and to provide solutions to the most common character development problems (Ballon, 04, p. 5; Chamberlain, 2016, p. 4; Lee, 2001, p. 89; NZFC Scriptwriting, 2020).

Additionally, Batty argues for more academic research into work designed to assist in writing, such as screenwriting manuals, to generate new knowledge and new approaches to screenwriting (Batty, 2016, p. 60). Therefore, an annotated bibliography on screenwriting manuals would benefit future academic research, and provide a stepping stone into producing more scholarly research into the subject of screenwriting.

Furthermore, Batty believes scholarly research on screenwriting can help academic research but also help screenwriters writing scripts develop better stories (Batty, 2016, p. 61). Therefore, an annotated bibliography on screenwriting manuals can help further academic research which can also help screenwriters produce better quality stories.

In the literature, from the Te Waharoa database, there are film-centric annotated bibliographies available, such as on subjects such as motion pictures that are suitable for a high school curriculum (Dale, 1951). However, Dale's annotations do not offer resources that solve character development problems. Additionally, films had evolved narratively since films in 1951, which is when Dale created his annotations. Therefore, there is a need to learn more about the writing process from more current films.

Furthermore, there is also a study on Taiwanese films that includes screenwriter's biographies and autobiographies (Cheng et al., 2016). Similarly, there is a research guide to Japanese films that analyse scripts and directors from Japan (Nornes, 2009). However, this is not helpful to a screenwriter with specific character development problems as it only describes Taiwanese and Japanese scripts, and they do not offer a critical analysis of the screenwriting techniques. Dale, Cheng, and Nornes are just a few examples of the annotated bibliographies that are currently available, and none of them provides solutions to character development problems. 
Another journal article on Te Waharoa, while searching for critical essays on screenwriting manuals and motion picture authorship, gives guidance on textbooks, critical essays, and software programs that a screenwriting teacher could use for their curriculum (Leff, 1984). However, it only references four scriptwriting manuals, which is not exhaustive or comprehensive in coverage to cover the character development problems that a screenwriter would encounter. Moreover, the year of publication is quite old and lacks the currency needed from screenwriters presently.

The most promising item found on Te Waharoa was Foster's annotated bibliography on literature around the topic of film noir and neo-noir genre (Foster, 2002). Although it does not talk about screenwriting, it does offer ideas on how to conduct a study on film-related subjects which this annotated bibliography on screenwriting manuals can use.

Similarly, on Google Scholar, there are annotated bibliographies related to the film but none that approach the problem of character development in screenwriting. Although Jacey's article does touch on character development using Vogler's paradigm of the hero's journey (Jacey, 2010), it does not offer alternatives to solving other character development problems. Alternatively, there are fantastic books like Grierson's book on professional screenwriters, and how they approach character development problems (Grierson, 2013). However, Jacey and Grierson, only provide insight into solving some character development problems, whereas what is needed is a compilation of resources that could help a screenwriter find the right solution from alternative screenwriting paradigms and conventions.

Alternatively, a screenwriter can learn on their own through the use of books, articles, writers' guilds, even YouTube. However, the NZFC states that there is a multitude of publications to learn from (NZFC Scriptwriting, 2020). Furthermore, there have been numerous screenwriting manuals published since 1911 to the present (Finnegan, 2016, p. 320). Therefore, a self-taught amateur screenwriter may not have the skills to evaluate what screenwriting manuals are reliable or useful. Furthermore, a screenwriter would have to consult with more than one 
screenwriting manual as character development problems are complex, and there is no one-size-fits-all solution. However, a screenwriter may not have the time to read through the plethora of publications available.

Sculley believes research in screenwriting contributes to new knowledge (Batty, 2016, p. 60; S.-J. S. Lee et al., 2016, p. 91). However, Lee believes that there is little PHD lead research to draw upon (S.-J. S. Lee et al., 2016, p. 85).

Additionally, Sawtell argues that most research is based on production research rather than on screenwriting (S.-J. S. Lee et al., 2016, p. 92). Therefore, an annotated bibliography on screenwriting manuals could aid future research and contribute to new knowledge.

On account of the available literature about screenwriting manuals, none of the critical essays, journals, or annotated bibliographies on screenwriting provides a sufficient amount of information for a screenwriter to find a solution on character development. Furthermore, the increase in scholarly interest in screenwriting necessitates more research on screenwriting.

Therefore, an annotated bibliography on screenwriting manuals could help collate and assess the value of these screenwriting manuals and also limit the number of items to those that are current and applicable to the specific questions a screenwriter has in terms of character development. Moreover, an annotated bibliography on screenwriting manuals could aid future research on screenwriting. Subsequently, improving scholarly research on screenwriting could improve the quality of screenplays that screenwriters produce.

\section{Objectives}

\section{A. Purpose}

The purpose of this annotated bibliography is to provide a collection of current, 2000-2020, screenwriting manuals that publicly accessible as books or e-books. Furthermore, screenwriting manuals that can offer solutions to the most common problems: a poorly defined hero, a weak character arc for the hero, a lack of stakes for the hero, and the absence of conflict (NZFC Scriptwriting, 2020). 
Therefore, this annotated bibliography can provide annotations that summarise and evaluate the effectiveness of the screenwriting manual. Additionally, this annotated bibliography can identify if a particular manual provides case studies, exercises, or diagrams that aid in solving character development problems. Furthermore, this annotated bibliography can identify what experience level: novice, intermediate, advanced, the manual is suitable for.

Additionally, annotations are organised in the most effective way for the user to efficiently traverse the plethora of screenwriting manuals to find specific answers to their specific character development problems adherent in their scripts.

\section{B. Scope}

\section{Inclusion of items}

A screenwriting manual will be more appealing if it is relatively current to a screenwriter's needs. Therefore, the annotated bibliography will include books from the years 2000-2020. Furthermore, publications often build upon prior knowledge on screenwriting. Additionally, publications before 2000 may also have outdated information such as Azlant's article on writing for silent films (Azlant, 1997), which is why this annotated bibliography will only assess books between 2000-2020. Moreover, it is more likely for publications between 20002020 to have a digital copy making it more accessible to screenwriters, and most likely to still be in print for screenwriters to obtain.

Secondly, items that are publicly available online are preferable so that screenwriters can have better access to the materials on offer in the annotated bibliography.

The reason for using only databases available online, or in Auckland, is because the catalogue for Wellington, Christchurch, and Dunedin libraries was accessible but not necessarily the hardcopy or digital copy which was inaccessible to those living in Auckland. The reason for resources being inaccessible to those living outside of either Wellington, Christchurch, or Dunedin, is because the user must have a physical address in those respective cities before borrowing. 
Moreover, there is a need to view physical copies as the description in library catalogues are not sufficient to determine if there are relevant sections relating to character development.

On account of this, the annotated bibliography will only include physical copies, or E-books, held at Auckland Libraries as inter-loans are expensive. Moreover, there are more than enough physical copies to sample that would be representative of physical copies held at other repositories.

The annotated bibliography will include creative writing books about fictional authorship that feature character development solutions that a screenwriter can apply in screenwriting.

\section{Exclusion of items}

The annotated bibliography will exclude items dated before 2000 as many screenwriting manuals assimilate and build upon previous publications and knowledge found in books before 2000. Additionally, this annotated bibliography will discard resources that are available in audio format, or video platform in order to limit items to a more manageable size in terms of research. Also, books that are published are usually more reliable and authoritative.

However, there are tens of thousands of articles to research, and due to time and budget limitations will be excluded from this annotated bibliography.

\section{Audience}

The specific audience this annotated bibliography will cater to will be for novice screenwriter that has access to these online resources. However, the annotated bibliography could be of interest to other users that are interested in screenwriting manuals that focus on the subject of character development which include: professional scriptwriters, lecturers, information professionals, and researchers who are specifically looking for books that answer problems relating to character development in feature film scripts.

A screenwriter can attend courses specialising in writing for film: AUT University, International Institute of Modern Letters, NZ writer's college, the Script Factory, South Seas Film School, Southern Institute of Technology, Unitec, 
University of Auckland, Waiariki Institute of Technology, and Whitireia Polytechnic (NZFC Scriptwriting, 2020). Although it is beneficial, it is not necessary to learn how to approach these problems to character development. However, the aforementioned academic institutions could still use screenwriting manuals as an education tool to direct learning in class.

Moreover, universities and a few academic journals give visibility to screenplays (Batty \& Kerrigan, 2018, p. 70). Therefore, an annotated bibliography on the subject can assist students, or researchers, with a focus on screenwriting as a practice and future research on screenwriting as a scholarly pursuit (Batty \& Kerrigan, 2018, p. 74). Moreover, professional screenwriters can use it as a reference; if they come across character problems, they cannot solve for themselves.

Furthermore, an annotated bibliography of resources would be invaluable to an amateur screenwriter that wants to learn without attending an academic institution. Additionally, professional bodies: NZFC or the New Zealand Writer's Guild (NZWG), a government-funded organisation that helps the development of screenwriters with advice, services, and resources (NZ Writers Guild -

Professional Association of Script Writers, 2020), could use the annotated bibliography as a resource to help screenwriters.

Lastly, Information Professionals such as librarians could use it as a reference with customer enquiries. The function of a reference librarian is to act an intermediary between a customer and the library collection using tools and databases to aid in searching (N. J. Smith, 1999, p. 8).

Therefore, an annotated bibliography on screenwriting manuals could be used as a tool by reference librarians to help screenwriters connect with their collection, and perhaps help librarians identify gaps in their collection in terms of resources on screenwriting. 


\section{Currency and Comprehensiveness}

\section{A. Databases}

The main focus will be on items found Auckland Libraries as they are publicly available to screenwriters, and will also be more manageable to get comprehensive coverage of items covering the subject of character development in screenwriting. Furthermore, the Auckland libraries database has useful refining tools that can help limit the number of items, unlike google scholar that has rudimentary refining tools that are unsuitable to limiting results required by this annotated bibliography.

\section{B. Search terms}

The library of congress has listed variant search terms for Motion-Picture Authorship as the following:

- Film authorship

- Moviemaking

- Film-making (Motion pictures)

- Film scriptwriting

- Filmmaking (Motion pictures)

- Motion picture plays--Authorship

- Motion picture scriptwriting

- Motion picture writing

- Motion picture technique

- Motion pictures--Play-writing
- Moving-picture authorship

- Screenwriting

- Screenplay writing

- $\quad$ Screenwriting

- $\quad$ Scriptwriting, Film

- Scriptwriting, Motion picture (The Library of Congress, 2020)

Additionally, the search terms used in the annotated bibliography will relate to the research question are as follows:

- Character development

- Character stakes
- Character arc

- Conflict 
The search terms can be used in conjunction with each other using Boolean logic such as AND, OR, NOT to help limit results.

The reason for using these search terms is to limit the number of irrelevant items found on databases but also to optimise searches by using the terms developed by the subject matter, being scriptwriting. Additionally, using these search terms could increase the relevant return of items, and their appropriateness to the research question.

\section{Expectations of the number of items}

Preliminary searches, on Te Waharoa, for this annotated bibliography using the search term 'screenwriting' produced over 17,000 results. Refining the search using 'screenwriting manual' produced over 1,000 results, and using the search terms 'screenwriting' and 'character development' produced more than 5,000 results. Although these searches demonstrate a result with more than 1000 using search terms, many items did not sufficiently cover character development. However, by refining the numbers to published books, using the search term 'screenwriting manual,' there was a return of 94 items. However, at least 20 of the 94 items were irrelevant.

In summary, the preliminary research discovered 100 reliable physical books and e-books from Auckland Libraries that are relevant to character development problems, using the parameters of inclusion and exclusion in the scope of this annotated bibliography.

\section{Organisation}

This annotated bibliography will reference citations using Zotero in order for more accurate citation. Google-forms were used to input annotations and citations and other information relating to format, useful learning aids, and what particular character development problem each annotation attempts to answer. Google-forms organises entries alphabetically, and also by subject, or theme, which is useful to organising the annotations into themed sections relating to one of the four common character problems that screenwriters encounter. Google forms can also export entries into an excel spreadsheet for information to be re-organised easily. Subsequently, results can be exported into PDF, or Word, and Excel format in order to be re-arranged into Word. 


\section{Arrangement and Access}

\section{A. Arrangement}

The bibliography will be arranged into four subject categories:
A. Define the Main Character
B. Create a Character-Arc
C. Raise Stakes
D. Create Conflict

Subsequently, making it easier for users of this annotated bibliography to find solutions to their specific characterisation problems.

\section{B. Format and Information Fields}

An American Psychological Association (APA) citation style is applied to all annotations in the bibliography. The item will be arranged alphabetically by the author's last name, and the initial of their first name, in bold for clarity.

Furthermore, the annotation will follow the citation with roughly 150 words or less describing the content of the manual, and how well it performs in aiding screenwriters with particular character-development problems. Moreover, the annotations will include the format: a physical book, or an e-book, for screenwriters.

The critical assessment of items will give the user an idea of the item's main points and how well it answers the character development problems, and whether it provides case studies, exercises, or diagrams. Furthermore, the annotations will note the manuals suitability to screenwriting experience-level: novice, intermediate, or advanced. For example, a screenwriting manual suitable for a novice user would include books that require little to no prior knowledge of screenwriting techniques. However, a screenwriting manual for an intermediate user would be more suitable to a screenwriter with experience or preferably finished the first draft. Moreover, a screenwriting manual for advanced users would include content that delves into techniques that require knowledge of basic screenwriting techniques. Additionally, the annotation will be presented in a Microsoft Word Document. 


\section{Indexing}

A general index will be arranged alphabetically for the ease of the user. The index will include the author's name displayed with the last name, and then the first name of the author, and then the page number. The index is arranged this way so that the user can locate a particular resource

Additionally, the index will also include the title of a book. It will alphabetically arrange items by italicised to differentiate between indexed items, followed by the page numbers that it appears in the bibliography. Therefore, italicising will help the user to locate a particular resource with ease.

Furthermore, a thematic, or subject, index will be presented, and include themes or specific character problems: Creating character conflict, Defining the Main Character, Developing the Character-Arc, and Raising the Stakes. Additionally, the annotation sub-entries of case studies, exercises, diagrams, the format will follow each theme. The indexing of subjects and examples is useful to the user especially if they want to find annotations relating to a specific topic such as 'character-arc' but also if they want to find examples demonstrating how to approach that subject.

The indexing would be very familiar to screenwriting as it has been a format demonstrated in various other screenwriting manuals such as by Dancyger, Field, and Seger (Dancyger, 2013; Field, 2005; Seger, 1990). Therefore, this indexing format helps screenwriters to locate subjects of interest and would help the user of this annotated bibliography of screenwriting manuals as well as they should be familiar with this format.

\section{Output format}

The annotated bibliography will be available as a digital PDF on Victoria University of Wellington's Te Waharoa database. Additionally, the annotated bibliography can be made available as a hard copy both at the Victoria University of Wellington Library and perhaps as a library guide at public libraries. The annotated bibliography will be circulated as an openaccess library and advisory tool through LIANZA, National Library. Film journals may be interested and perhaps academic institutions such as the IIML (Institute of Modern Letters), which has a screenwriting course. 


\section{Suggestions for dissemination}

- AUT University

- International Institute of Modern Letters

- NZ writer's college

- Script Factory

- Southern Institute of Technology

- Unitec

- University of Auckland

- Waiariki Institute of Technology

- Victoria University of Wellington

- The New Zealand Film Commission

- New Zealand Writer's Guild

- Auckland Libraries

- University Libraries

- LIANZA, Library review

- Film Journal International

- Millennium Film Journal

- American Film Institute Journal

- Journal of Screenwriting 


\section{Bibliographies}

\section{A. Defining the Main Character}

Abushwesha, F. (2014). Rocliffe notes: A professional approach for screenwriters \& writerdirectors. Kamera Books.

Subject: Define Hero, Create Conflict.

Format: Physical.

Audience: Intermediate.

Useful things: Case Study, Exercises

Abushwesha interviews various filmmakers on how they approach problems with character development (Abushwesha, 2014). Moreover, this manual provides the screenwriter with multiple real-world perspectives on solving a character development problem in their script, such as defining the hero and creating conflict. It provides a checklist, exercises, and case studies to understand the ideas present in the chapters. The manual touches on various topics that are essential learning for screenwriters, such as what is the writing process, and gives tips in finding a producer. Additionally, the manual serves as a quick reference to professional writers stuck or have come across specific development problems with their characters. Furthermore, this manual offers advice on how to overcome procrastination.

Ackerman, A., Puglisi, B., \& Kaufman, C. (2013). The negative trait thesaurus: A writer's guide to character flaws (First print edition). JADD Publishing.

Subject: Define Hero, Develop Character-Arc, Create Stakes, Create Conflict.

Format: Physical.

Audience: Novice.

Useful things: Case Study, Exercises.

Ackerman argues that character flaws are just as crucial in defining a character and making them memorable (A. Ackerman et al., 2013). Character flaws are traits that 
can damage character relationships. Character flaws develop through the characterarc. Therefore, it is the flaws of the hero and other secondary characters that can cause conflict. Subsequently, Ackerman provides a thesaurus of character traits and behaviours and character flaws of certain characters to aid a screenwriter in forming believable, credibly, three-dimensional characters. This manual is unlike other screenwriting books as it gives a plethora of character types in detail for the screenwriter to choose and explore.

Ackerman, H. (2017). Write screenplays that sell: The Ackerman way (Revised updated edition). Tallfellow Press

Subject: Define Hero, Develop Character-Arc, Create Stakes, Create Conflict.

Format: Physical.

Audience: Intermediate-Advanced.

Useful things: Case Study, Exercises, Diagrams.

Ackerman demonstrates how a screenwriter introduces a character to the audience by actions, such as introducing them through a scene showing their occupation $(\mathrm{H}$. Ackerman, 2017). It provides examples of how to overcome character and narrative problems by using scene-cards to map out how a character grows and drives the narrative. It also provides exercises for the screenwriter to practice their craft. Ackerman also answers frequently asked questions a screenwriter by exploring why a screenwriter writes or does not write. Additionally, this manual offers a glimpse into the practicality of generating ideas by using scene, or index cards, to create an exciting scene.

Alderson, M., \& Rosenfeld, J. E. (2015). Writing deep scenes: Plotting your story scene by scene through action, emotion, and theme [Electronic resource]. Writer's Digest. http://samples.overdrive.com/?crid=72bc4d2e- ec05-44f1-832f49f366150333\&.epub-sample.overdrive.com

Subject: Define Hero, Develop Character-Arc, Create Stakes, Create Conflict. 
Format: Physical \& E-Book.

Audience: Novice.

Useful things: Case Study, Exercises.

Alderson \& Rosenfeld believes that character problem must propel the hero to achieving a concrete goal which leads to smaller goals (Alderson \& Rosenfeld, 2015). Moreover, a character can change how they achieve smaller goals to complete their primary objective. The book is not easy to navigate and requires the screenwriter to flip through pages to find relevant chapters. However, the manual is logical and easy to read and provides plenty of case studies and exercises for the screenwriter.

Aronson, L. (2000). Scriptwriting updated: New and conventional ways of writing for the screen. Australian Film Television \& Radio School; Allen \& Unwin.

Subject: Define Hero, Develop Character-Arc, Create Stakes, Create Conflict.

Format: Physical.

Audience: Intermediate-Advanced.

Useful things: Case Study, Exercises, Diagrams.

Aronson has been a screenwriter for twenty years, but more importantly, she has been a script assessor and teacher (Aronson, 2000). She has a checklist for identifying who the protagonist is in the story, and it is helpful to any screenwriter to follow and answer, the questions provided to define their main character. The manual is easy to follow, and Aronson organises the manual in a user-friendly way for navigating. It has checklists, exercises, and diagrams and case studies that will illuminate most characterisation problems a screenwriter will encounter. The manual relates ideas about the character to the main beats of a three-act structure. The best part of the book is that it makes use of diagrams to follow.

Aronson, L. (2010). The 21 st century screenplay: A comprehensive guide to writing tomorrow's films. Allen \& Unwin. 
Subject: Define Hero, Develop Character-Arc, Create Conflict.

Format: Physical.

Audience: Novice.

Useful things: Case Study, Diagrams.

Aronson provides obvious development strategies and explores these strategies with exercises which are helpful for character development problems inherent in a screenwriter's script. Additionally, Aronson has visual strategies and checklists on how to create and develop ideas when a screenwriter has writer's block. It provides conventional and alternative methods to narrative structure and how to break out of cliches. It also tackles double protagonist or ensemble casting, like no other screenwriting manual. She tackles innovative narrative designs, such as writing for an anthology film (Aronson, 2010). It is a book that can help novice and professional writers with ordering their ideas into real scripts. Furthermore, the manual aligns how to solve character problems with a strong emphasis on narrative conventions.

Axelrod, M. (2014). Constructing dialogue: From Citizen Kane to Midnight in Paris. Bloomsbury Academic.

Subject: Define Hero, Develop Character-Arc.

Format: Physical.

Audience: Novice.

Useful things: Case Study, Exercises.

Axelrod uses a plethora of films, and fictional works, as exemplars of good screenwriting dialogue. Additionally, Axelrod points out where films have encountered problems relating to defining the hero and developing a character-arc (Axelrod, 2014). Axelrod gives very close attention to dialogue construction within a script. Axelrod's manual layout is challenging for any novice screenwriter to navigate and find sections relating to characterisation problems inherent in their film scripts. However, it does provide close analyses of how dialogue should be written from case studies and offers good exercises on character-arc and how to define the main 
character. Axelrod reminds screenwriters to rewrite the script with particular attention to word-economy. Subsequently, a screenwriter needs to delete unnecessary words in a script.

Bailey, S., \& Blake, M. (2013). Writing the horror movie. Bloomsbury.

Subject: Define Hero, Develop Character-Arc, Create Stakes, Create Conflict.

Format: Physical.

Audience: Novice-Intermediate.

Useful things: Case Study, Exercises.

Bailey \& Blake give direction in how to structure the character's journey but also on how to create tension through the use of 5 tropes: unease, dread, terror, horror, and disgust (Bailey \& Blake, 2013). It provides a checklist for screenwriters to check that their story is on track and writing exercises, interviews with directors and writers on horror films. The manual is an exemplar in defining the antagonist that will be a cause of conflict with a screenwriter's central character. Furthermore, it gives good advice on creating conflict, raising the stakes for the main character, and sustaining tension. Although the manual focuses on writing horror films, a screenwriter can use the same principles in different genres. The style and layout of the manual are easy to follow and navigate and has an appealing readable style.

Batty, C. (2012). Screenplays: How to write and sell them. Creative Essentials.

Subject: Define Hero, Develop Character-Arc.

Format: Physical.

Audience: Novice.

Useful things: Exercises.

Batty's manual focuses on writing the feature film. Batty explains why a characterisation does not work and how to fix these problems. Batty explains that the common problem is that there are not enough characters to help or deter a character's 
journey (Batty, 2012). Batty elaborates on the character's physical and emotional journey and how the two work together to develop a three-dimensional character. In essence, the physical journey is what the character wants, and the emotional journey is what the character needs. Batty's manual is easy to read but would benefit from more exercises and detail in creating tension, stakes. However, the manual empowers screenwriters in their creative processes to tell the stories that they want to tell.

Batty, C., \& Waldeback, Z. (2012). The creative screenwriter: Exercises to expand your craft. Methuen Drama.

Subject: Define Hero, Develop Character-Arc, Create Stakes, Create Conflict.

Format: Physical.

Audience: Novice.

Useful things: Exercises.

Batty and Waldeback provide a useful checklist on pinpointing the main character that a story follows (Batty \& Waldeback, 2012). Additionally, Batty and Waldeback explore how screenwriters generate ideas. The manual emphasises that understanding the characters and their relationship to one another is useful in defining characters and developing their character-arc. It also provides a section on strengthening visual storytelling which is a critical element of scriptwriting. The manual offers exercises to help build solutions to character development problems.

Additionally, there are some checklists for a screenwriter to work through to develop a good character arc. The manual also provides advice post scriptwriting process of pitching an idea, or writing outlines and treatments to distribute to producers. There are extensive exercises provided at the conclusion to help with common story problems, and they list an index to direct the screenwriter to writing exercises found through the beneficial book.

Bauer, I., \& Bauer, V. (2017). Screenwriting fundamentals: The art and craft of visual writing. Routledge. 
Subject: Define Hero, Develop Character-Arc.

Format: Physical.

Audience: Novice.

Useful things: Exercises, Diagrams.

Bauer \& Bauer's manual is fantastic for the novice screenwriter who wants to learn what a script should look like and what to include. There are helpful examples provided of inserts of a fictional script to help illustrate what Bauer \& Bauer are teaching in each section. Although, the manual touches upon how to practically develop ideas on creating a character- arc, it does not provide details for a screenwriter to follow and adjust their work (Bauer \& Bauer, 2017). However, the manual does provide some exercises to help prepare screenwriters for the overwhelming task of completing the first draft.

Bernhardt, W., \& Bernhardt, W. (2017). Creating Character: Bringing Your Story to Life [Electronic resource]. Babylon Books. https://samples.overdrive.com/?crid=134b427a-3b68-4522-97290a449f836c65\&.epub-sample.overdrive.com

Subject: Define Hero, Develop Character-Arc, Create Stakes, Create Conflict.

Format: Physical \& E-Book.

Audience: Novice.

Useful things: Case Study, Exercises.

Bernhardt believes all stories are character-driven, and all stories are about conflict, and all conflict develops over a character-arc (Bernhardt \& Bernhardt, 2017). This manual provides helpful exercises at the end of every chapter. Therefore, navigating each chapter for a particular characterisation problem will inevitably lead a screenwriter to exercises they can use. This manual's focus is on fiction authorship. However, a screenwriter can use this manual for screenwriting as well. 
Bishop, L. S. (2016). Sell your story in a single sentence: Advice from the front lines of Hollywood. The Countryman Press, a division of W.W. Norton \& Company.

Subject: Define Hero, Create Stakes, Create Conflict.

Format: Physical.

Audience: Intermediate.

Useful things: Exercises.

Bishop talks about how the motivation of the hero, drives the story and character arc and creates conflict (Bishop, 2016). Bishop shows examples of how she initially writes things, and then how she would redo a section in her script. Additionally, Bishop emphasises the use of word-economy in writing loglines and screenplays. Therefore, every Word counts and to be succinct as possible, which will also help identify character development problems as there is less clutter on the page. In general, the manual provides tips on character development. However, the manual is more focused on finalising and selling a script to a producer.

Branton, M. (2013). The Creative Writing Workbook [Electronic resource]. Hodder \& Stoughton. http://auckland.lib.overdrive.com/ ContentDetails.htm?ID=6ECFE41B5E99-44FC-9470-8BA8C899F757

Subject: Define Hero, Develop Character-Arc.

Format: Physical \& E-Book.

Audience: Novice.

Useful things: Case Study, Exercises.

Branton believes that the character arc is the real narrative development in any story. Moreover, characterisation and narrative are intertwined as the narrative follows the character-arc closely and that the journey defines a character (Branton, 2013). Therefore, a character starts in one emotional state, or situation, and completely reverses that by the end of the story. Branton's manual provides ample exercises and case studies for the screenwriter. The manual is easy to navigate. However, the 
solutions, or questions posed to the screenwriter, are simplistic and does not give a comprehensive set of solutions for all characterisation problems.

Brooks, L., \& Hauge, M. (2015). Story fix: Transform your novel from broken to brilliant. Writer's Digest Books.

Subject: Define Hero, Develop Character-Arc, Create Stakes, Create Conflict.

Format: Physical \& E-Book.

Audience: Intermediate.

Useful things: Case Study, Exercises.

Brooks believes there are two reasons why a story does not work: the story concept is not strong enough; and, or, the delivery of the story is ineffective (Brooks \& Hauge, 2015). This manual is a study in revising the concept and the delivery and honing the screenwriter's analytical skills in identifying where a narrative has failed, and the process of fixing it. Brooks believes that conflict is at the heart of a good story, and that means having characters with purpose, which is achieved by a screenwriter creating dramatic tension. Dramatic tension is when the hero's goals, or quest, is in jeopardy by other characters, or an antagonistic force. Therefore, increasing audience empathy with the character. Additionally, there are three dimensions to character: backstory, the hero's world view, and the decisions the hero makes under tension. This manual is a laid out, and direct to the point, and easily readable, which makes it a reliably useful tool to any screenwriter.

Callaghan, D. (2012). Script tease: Today's hottest screenwriters bare all. Adams Media. Subject: Define Hero, Develop Character-Arc, Create Stakes, Create Conflict.

Format: Physical.

Audience: Novice.

Useful things: Case Study. 
Callaghan's manual is a collection of interviews from sessions held for the writer's guild of America and include: Darren Aronofsky, Sofia Coppola, Elmore Leonard and many more (Callaghan, 2012). The book provides some insight into characterisation, but there is no continuity to the questions Callaghan asks, so there are varying degrees of answers from the interviewees. The interview snippets on each guest speaker are also concise. An exciting light read for those interested in the interviewees. However, the manual lacks the necessary sections on characterisation. Moreover, there is a lack of finding aids to help a screenwriter navigate the interviews to find answers to specific questions.

Chamberlain, J. (2016). The nutshell technique: Crack the secret of successful screenwriting (First edition) [Electronic resource]. University of Texas Press. http://samples.overdrive.com/?crid=e97d148d- 9672-4113-be10fc5de8d4393f\&.epub-sample.overdrive.com

Subject: Define Hero, Develop Character-Arc, Create Stakes, Create Conflict.

\section{Format: E-Book.}

Audience: Novice.

Useful things: Case Study, Exercises, Diagrams.

Chamberlain argues that most scripts fail because screenwriters base their narration on a situation rather than a story (Chamberlain, 2016b). Additionally, it is the use of reversals, in which a character's path leads one way and then completely turns around. Therefore, making the story less predictable and more entertaining. Screenwriters can use the nutshell technique as a worksheet to identify their hero and eight essential story elements required for that protagonist. The manual uses case studies different type of protagonist and the story elements that a screenwriter needs to include for the hero to progress with their character arc. The manual is straight to the point with what a screenwriter is required to do to have a satisfying story and interesting characters. 
Chitlik, P. (2013). Rewrite: A step-by-step guide to strengthen structure, characters, and drama in your screenplay (Second edition). Michael Wiese Productions.

Subject: Define Hero, Develop Character-Arc, Create Stakes, Create Conflict.

Format: Physical.

Audience: Novice.

Useful things: Case Study, Exercises, Diagrams.

Chitlik believes in matching the character with the premise or dramatic theme (Chitlik, 2013). The character needs a goal to drive the story. Chitlik demonstrates how characters can be more three dimensional with fatal flaws that stop them from reaching their goals. Therefore, to develop a good character-arc, the audience needs to follow the hero in attaining, or not, their intended purpose. Chitlik provides a detailed checklist for the screenwriter to create a good character arc. Moreover, there is a checklist for a screenwriter to create tension and conflict. The book is well used in US film schools and is a practical manual for revealing the hidden structures in scenes, stories, characters, and scripts.

Coleman, J. J., \& Peditto, P. (2012). Writing screenplays. Self-Counsel Press.

Subject: Define Hero, Develop Character-Arc.

Format: Physical.

Audience: Novice.

Useful things: Case Study, Exercises.

Coleman \& Peditto focus on something mostly absent from other manuals which are creating characters that are sympathetic and unsympathetic to the audience (Coleman $\&$ Peditto, 2012). A hero, at the beginning of the script, can be un-sympathetic, and through the course of their character journey become very sympathetic, and vice versa. This book offers insight into creating antiheroes. Furthermore, the manual provides insights into creating fleshed-out characters with an exciting character-arc for the audience to follow. This manual includes worksheets that get a screenwriter thinking about their characters, and for revising their overall character-arc. Coleman 
\& Peditto cover most aspects of screenwriting from creating ideas to selling the story. Lastly, these manuals emphasis on feedback illustrates that a second opinion is also crucial in crafting and finalising a script.

Cooper, P., \& Dancyger, K. (2005). Writing the short film (3rd ed). Elsevier/Focal Press.

Subject: Define Hero, Create Conflict.

Format: Physical.

Audience: Novice.

Useful things: Case Study, Exercises.

Cooper \& Dancyger comment on behaviour defining the character from character ticks, appearance, but more importantly, on actions and motivations. It also talks about dramatic action and how that motivates character and creates stakes and conflict with the antagonist of the story (Cooper \& Dancyger, 2005). It gives various exercises for the screenwriter to learn and develop a strategy for tackling most character development problems. This manual covers the entire process of screenwriting, and although its main focus is on short film making the same principles can be applied to a feature-length film.

Corbett, D. (2013). The art of character: Creating memorable characters for fiction, film, and $T V$.

Subject: Define Hero, Develop Character-Arc, Create Stakes, Create Conflict.

Format: Physical.

Audience: Novice.

Useful things: Case Study, Exercises.

Corbett offers a plethora of exercises on characterisation. Additionally, this manual covers every detail to creating characters, to formatting the script, and what to include in describing the character (Corbett, 2013). Furthermore, this manual is easy to read and comprehend for and level of the screenwriter. Moreover, Corbett satisfyingly 
covers all aspects of defining a character, developing character-arc, and raising the stakes for a character, and creating conflict. The exercises are beneficial, and the depth of discussion on characterisation in scripts is impressive, considering that Corbett designed the format for better readability.

Corder, N. (2014). Creating convincing characters. Compass Books.

Subject: Define Hero, Develop Character-Arc, Create Conflict.

Format: Physical.

Audience: Novice.

Useful things: Case Study, Exercises.

Corder offers an excellent introductory overview into creating characters for creative writing which a screenwriter can use. Corder provides and end of chapter summary and set of exercises for the writer to practice what they have learned in each chapter. On account of this, the screenwriter can practice their craft. However, more could be done in solving particular characterisation problems found in scripts. One of the most exciting aspects of Corder's manual is the treatment of info-dumping and the use of psychological profiles. Corder advises the screenwriter to slowly reveal character rather than info-dumping everything about that character in one scene (Corder, 2014). Furthermore, the psychological profiles, help provide a more convincing character with ticks, and traits, that are interesting and may play a part in the overall narrative of the script.

Cowgill, L. J. (2008). The art of plotting: How to add emotion, excitement, and depth to your writing [Electronic resource]. Back Stage Books. http://excerpts.cdn.overdrive.com/FormatType- 410/0111-1/406/071/7B/ ArtofPlottingAddEmotionSuspenseandDep9780307875136.epub

Subject: Define Hero, Develop Character-Arc, Create Stakes, Create Conflict.

Format: E-Book. 
Audience: Novice.

Useful things: Case Study.

Cowgill believes the character conflict and desire are interdependent. Therefore, knowing the character's goal is crucial to creating obstacles that prevent that character from reaching that goal. Furthermore, conflict reveals character, and this is where a screenwriter can externalise and define who the main character is, and chart their character arc (Cowgill, 2008). This manual is excellent at finding solutions to character problems and strikes a balance between plotting and characterisation. However, it could do more with exercises, so that screenwriters could use them to find problems in their scripts.

Cron, L. (2016). Story genius: How to use brain science to go beyond outlining and write a riveting novel (before you waste three years writing 327 pages that go nowhere) (First edition) [Electronic resource]. Ten Speed Press. http://samples.overdrive.com/?crid=825acba2- 5676-4cdd-b52c697102dd5a43\&.epub-sample.overdrive.com

Subject: Define Hero, Develop Character-Arc, Create Stakes.

Format: E-Book.

Audience: Novice.

Useful things: Case Study, Exercises.

Cron's manual focuses on fiction authorship more than screenwriting. However, the same principles and problems exist in both disciplines. Cron argues that character comes first, and plot acts as a framework for that character progression through their character-arc (Cron, 2016). Cron also touches on the issue of multiple protagonists but insists that there is always one character favoured as the main character. The manual has simple exercises at the end of each chapter prompting the writer to delve into their characters. The organisation of the manual is easy to follow and navigate. 
Cron, L. (2012). Wired for story: The writer's guide to using brain science to hook readers from the very first sentence (1st ed) [Electronic resource]. Ten Speed Press. http://excerpts.cdn.overdrive.com/FormatType- 410/0111-1/973/3AE/4B/ WiredforStoryTheWritersGuidetoUsingBr9781607742463.epub

Subject: Define Hero, Develop Character-Arc, Create Stakes, Create Conflict.

Format: E-Book.

Audience: Novice.

Useful things: Case Study, Exercises.

Cron's manual focuses on fiction authorship. However, a screenwriter can still use ideas in characterisation in their scripts. The section, in particular regarding character goals, is comprehensive and covers a lot of characterisation problems (Cron, 2012). Cron's manual is easy to navigate to exciting chapters but also generally good advice on creative writing matters. It delves into character problems and their possible solutions using exercises and case studies.

Davis, R. (2016). Creating compelling characters for film, TV, theatre and radio (2nd edition). Bloomsbury Academic.

Subject: Define Hero, Develop Character-Arc, Create Stakes, Create Conflict.

Format: Physical.

Audience: Intermediate.

Useful things: Case Study.

Davis delves into character on a writing level but also offers an understanding of how an actor interprets the script with various acting methods. It is written for the novice to understand relatively complex issues regarding characterisation in stories. It is a good starting point in understanding what shapes characters and what motivates characters to propel the story. Davis provides a manual that covers characterisation indepth and encompasses many examples of how characters move the plot. The plethora of entertaining and intriguing choices a character must make, which makes a story 
interesting. Lastly, Davis explores how screenwriters can use secondary characters to make the main character's journey more attractive to the audience (Davis, 2016).

De Paul, G. (2017). Bring the funny: The essential companion for the comedy screenwriter. Routledge.

Subject: Define Hero, Create Stakes, Create Conflict.

Format: Physical.

Audience: Novice.

Useful things: Case Study.

DePaul does offer solutions to character development problems. DePaul injects humour into this manual. However, this can be time-consuming. De Paul provides a necessary lesson to any screenwriter, and that is to learn scriptwriting by deconstructing or analysing existing film and scripts (De Paul, 2017). De Paul also has a section on the screenwriter and how to keep on track with writing and keep motivated to produce a final draft.

Diamond, D., \& Weissman, D. (2019). Bulletproof: Writing scripts that don't get shot down. Michael Wiese Productions.

Subject: Define Hero, Develop Character-Arc, Create Stakes.

Format: Physical.

Audience: Novice.

Useful things: Case Study, Exercises.

Diamond \& Weissman believe a screenplay centres on the three C's: concept, character, and context (Diamond \& Weissman, 2019). The manual provides useful insights into the creative process from logline to finished script and in an easy to read format. The contents page is easy to navigate for users that are unfamiliar with film terms. It provides summary points to all the chapters in the manual. However, it does not offer a comprehensive look into solving characterisation problems. The manual 
promises to help maximise screenwriting talent and increase the odds of producer picking up the script. The manual provides straightforward and time-tested advice on characterisation.

Duncan, S. V. (2008). Genre screenwriting: How to write popular screenplays that sell. Continuum.

Subject: Define Hero, Develop Character-Arc, Create Stakes, Create Conflict.

Format: Physical.

Audience: Novice, Intermediate.

Useful things: Case Study, Exercises, Diagrams.

Duncan provides a comprehensive manual on the rules of genre writing: Actionadventure, thriller, sci-fi and fantasy, horror-fantasy, Romantic comedies, and popgenre (Duncan, 2008). It defines characters through the use of relationship triangles. It also touches on character-arc and also how it relates to subtext. Duncan treats suspense for thrillers as screenwriters can apply the same methods to other genres. An exciting book that sufficiently answers characterisation questions within the genre's Duncan mentions.

Dunnigan, B. (2019). Screenwriting is filmmaking: The theory and practice of writing for the screen. The Crowood Press.

Subject: Define Hero, Develop Character-Arc, Create Conflict.

Format: Physical.

Audience: Novice.

Useful things: Case Study, Exercises.

Dunnigan provides an excellent overview of most of the character problems that a screenwriter would encounter. The manual is easy to navigate to relevant sections such as chapters on character, structure, scene writing and dialogue, and development. Dunnigan provides exercises at the end of each chapter for convenience. It is an 
excellent resource for the complete novice screenwriter. Dunnigan encourages the screenwriter to find their voice and incorporate their beliefs in their writing (Dunnigan, 2019). The most important sections this manual gives is on subtext and how characters can be revealed by what they say, and do not say. Secondly, the manual provides insight on how to keep a script visually appealing through the use of words rather than intellectual exercises more commonly associated with novel writing.

Edelstein, L. N. (2004). The writer's guide to character traits: Includes profiles of human behaviors and personality types. Writer's Digest; David \& Charles.

Subject: Define Hero, Develop Character-Arc, Create Stakes, Create Conflict.

Format: Physical.

Audience: Intermediate.

Useful things: Case Study.

Edelstein studies character traits in-depth to provide screenwriters with the tools to create convincing characters. Edelstein delves into criminal types, sexual issues, relationships, family, past trauma, body disorders, influences, career choices, and physical appearances (Edelstein, 2004). This manual is useful for developing empathy in a character, or hero. Additionally, this manual can help create a vile antagonist, and give convincing character traits that explain why that character is a villain. Edelstein's manual is comprehensive and exciting for screenwriters wanting to develop their character and engage the audience with exciting character traits and backstory. On account of this, navigating is made more comfortable with the detailed index.

Egri, L. (2009). The art of dramatic writing: Its basis in the creative interpretation of human motives. Wildside $\mathrm{P}$

Subject: Define Hero, Develop Character-Arc, Create Conflict.

Format: Physical \& E-Book. 
Audience: Intermediate.

Useful things: Case Study, Exercises.

Egri believes that all good writing stems from human motives. Therefore, characterisation is essential to novels and screenplays. Egri covers all aspects of characterisation: physiology, sociology, psychology. Additionally, Egri believes that a screenwriter can reveal a character-arc through conflict, and decisions on how to handle that conflict (Egri, 2009). Egri focuses on literary and writing for plays rather than screenwriting.

Moreover, the case studies, and examples, come from a literary and theatrical background and can be jarring for a screenwriter that may be more familiar with films. Therefore, it would take an intermediate screenwriter to learn more from the examples given in this manual than an amateur knew to storytelling. Egri writes little to no jargon, and the contents page makes it easy to navigate to relevant sections.

Eszterhas, J. (2006). The devil's guide to Hollywood: The screenwriter as God! (1st ed). St. Martin's Press.

Subject: Define Hero, Develop Character-Arc, Create Stakes, Create Conflict.

Format: Physical.

Audience: Novice.

Useful things: Case Study.

Eszterhas has some practical advice, and exercises, on writer's block, which could help with character development ideas. Eszterhas has an alternative take on letting the characters develop overwriting the plot, and the choices that they make should be interesting. It is better to reveal character than to have significant exposition explaining backstory; in fact, the backstory is a hindrance and not necessary (Eszterhas, 2006). He also recognises that conflict is at the heart of a compelling script. The advice he gives is almost conversational but does deliver on common problems that he has faced that a screenwriter would inevitably experience with character development. 
Evenson, J. M. (2013). Shakespeare for screenwriters: timeless writing tips from the master of drama. Michael Wiese Productions.

Subject: Define Hero, Create Stakes, Create Conflict.

Format: Physical.

Audience: Intermediate.

Useful things: Case Study, Exercises.

Evenson uses Shakespeare as a framework for understanding and creating a film script. Evenson uses the psychology of Hamlet to understand how to construct a threedimensional character (Evenson, 2013). Evenson provides exercises, case studies, and a summary of the chapter, which helps screenwriters digest what they have learned in every chapter.

Fancher, H., \& Lethem, J. (2019). The wall will tell you: The forensics of screenwriting. Melville House.

Subject: Define Hero, Create Stakes, Create Conflict.

Format: Physical.

Audience: Novice.

Useful things: None.

Fancher \& Lethem have constructed a short and concise book that reveals much in its economy of words and pages (Fancher \& Lethem, 2019). It is more contemplative borderline philosophical than practical as the answer to character development problems are dispersed throughout the text in what appears to be a random order of free thought.

Field, S. (2005). Screenplay: The foundations of screenwriting (Rev. ed.). Delta Trade Paperbacks.

Subject: Define Hero, Develop Character-Arc, Create Stakes, Create Conflict.

Format: Physical. 
Audience: Novice.

Useful things: Case Study.

Field explores character problems in script with exercises, case studies, and diagrams to illustrates his points. The design and format prevent the screenwriter from navigating quickly to solve particular character problems unless they use index. However, Field's manual is comprehensive in exploring the problems in characterisation that a screenwriter would encounter. Field's manual centres on the three-act structure in conjunction with three sections on creating and building character, and story and character (Field, 2005).

Fink, E. J. (2014). Dramatic story structure: A primer for screenwriters. Routledge. Subject: Define Hero, Develop Character-Arc, Create Conflict.

Format: Physical.

Audience: Novice.

Useful things: Case Study, Exercises, Diagrams.

Fink clearly defines the main hero as the one that undergoes the most change from the start to the end of the script. Fink uses case studies from films to illustrate his point. Fink argues that a screenwriter needs to create narratives that are about an extraordinary person in an ordinary situation and an ordinary person in an extraordinary world (Fink, 2014). Additionally, Fink explores conflict and other significant character development problems and uses diagrams, case studies, and a checklist of exercises to perform. Fink's manual provides the building blocks of screenwriting but also a refresher for intermediate screenwriters.

Frey, J. N. (2010). How to write a damn good thriller: A step-by-step guide for novelists and screenwriters (1st ed). St. Martin's Press.

Subject: Define Hero, Develop Character-Arc, Create Stakes, Create Conflict.

Format: Physical. 
Audience: Novice.

Useful things: Case Study.

According to Frey, a good character is one that has an impossible task and the wit to overcome it (Frey, 2010). Additionally, a character should stand to lose a lot if they cannot overcome their obstacles, and a ticking clock to compound tension in a story. Furthermore, the hero must face a moral dilemma at every turn to demonstrate the complexity of the character. Frey's manual is easy to navigate and have exciting sections for screenwriters interested in developing both character and plot specifically for crime thrillers. However, it could benefit from exercises.

Gallo, G. (2012). The screenwriter's compass: Character as true North. Focal Press.

Subject: Define Hero, Develop Character-Arc, Create Stakes, Create Conflict.

Format: Physical.

Audience: Novice.

Useful things: Case Study.

Gallo believes that the audience is not seduced by plot but by characters (Gallo, 2012b). Subsequently, Gallo believes that character development problems are tied to plot problems. Gallo provides case studies on how to structure a script. However, this manual does not have enough exercises for a writer to work out complex character development-problems.

Garant, R. B., \& Lennon, T. (2011). Writing movies for fun and profit! How we made a billion dollars at the box office and you can, too! Touchstone.

Subject: Define Hero, Develop Character-Arc, Create Stakes, Create Conflict.

Format: Physical.

Audience: Intermediate.

Useful things: Case Study. 
Garant and Lennon advise on how to be successful in screenwriting and attract attention from producers (Garant \& Lennon, 2011). However, the manual's format is more akin to reading a magazine, and navigating through the book is cumbersome at times. Garant and Lennon delve into characterisation problems briefly but not sufficiently enough for a screenwriter with serious characterisation problems in their script.

Gilford, J. (2015). Why does the screenwriter cross the road? + other screenwriting secrets. Michael Wiese Productions.

Subject: Define Hero, Develop Character-Arc, Create Conflict.

Format: Physical.

Audience: Novice.

Useful things: Case Study, Exercises.

Gilford talks about character arc as being the plot. The character both enters an unfamiliar world or learns a less by the end of it, which sums up what character arc is for a screenwriter (Gilford, 2015). Additionally, Gilford provides exercises for the screenwriter to follow to help develop a better character arc in their scripts. This manual is for teachers, students, and screenwriters. Furthermore, Gilford provides exercises for screenwriters to overcome writer's block, and how to manage self-doubt that prevents scripts from being finished.

Grove, E. (2009). Beginning filmmaking: 100 easy steps from script to screen (1st ed). Methuen Drama.

Subject: Define Hero, Develop Character-Arc, Create Conflict.

Format: Physical.

Audience: Novice.

Useful things: Exercises. 
Grove gives a comprehensive overview of filmmaking to introduce concepts to filmmakers (Grove, 2009). There is a small section dedicated to screenwriting that dives into characterisation. However, they are more prompts to get a complete novice to think about characterisation. Although there are some exercises to help the screenwriter to come up with solutions, and to begin writing, they are not of the quality or quantity expected in a screenwriting manual. Moreover, the manual is fundamental and more informative of the entire process of filmmaking that on the craft of screenwriting.

Hamand, M. (2009). Creative writing for dummies [Electronic resource]. Wiley. http://link.overdrive.com/?websiteID=262\&titleID=531571

Subject: Define Hero, Create Conflict.

Format: Physical \& E-Book.

Audience: Novice.

Useful things: Exercises.

Hamand provides a manual geared more towards literary than screenwriting. However, a screenwriter can still use Hamand's principles in both disciplines. The most exciting aspect of this manual is its focus on revealing the characters through actions. However, the section on characterisation is short and is suitable for any writer regardless of ability (Hamand, 2009).

Hauge, M. (2011). Writing screenplays that sell (New twentieth anniversary ed). Methuen Drama.

Subject: Define Hero, Develop Character-Arc, Create Stakes, Create Conflict.

Format: Physical.

Audience: Novice.

Useful things: Case Study, Exercises, Diagrams. 
Hauge has an interesting take in that a character flaw could play as the main obstacle to achieving a story goal. Hauge also details how a screenwriter gets the audience to empathise with a character by putting them in jeopardy. Hauge also demonstrates that a protagonist needs inner motivation for every action or in-action they have. Hauge gives case studies to illustrate how conflict is made either by the character or other supporting characters. Therefore, a character must have outer motivation and conflict to create a definable character that an audience can follow (Hauge, 2011). Hauge's manual is suitable for the intermediate screenwriter interested in re-learning crucial characterisation points.

Hay, L. V. (2017). Writing diverse characters for fiction, TV or film [Electronic resource]. Kamera Books. https://samples.overdrive.com/?crid=a4f88304-2f10-45c3-abfd269b4df98fce\&.epub-sample.overdrive.com

Subject: Define Hero, Develop Character-Arc, Create Stakes, Create Conflict.

Format: E-Book.

Audience: Novice.

Useful things: Case Study, Exercises.

Hay talks about diversity in television and film and the inclusion of different ethnicities and religions in screenwriting. Hay defines good characterisation as characters having flaws and complications regardless of their diverse background (Hay, 2017). Hay believes that good characters do not have to change like characters that inspire other characters to change but not necessarily the hero of the story. In general, this manual is excellent at identifying stereotypes, tropes, and cliches. Furthermore, this manual is a good start for any novice screenwriter has it explains why they exist and how to subvert expectations.

Hockrow, R. (2014). Storytelling techniques for digital filmmakers: Plot structure, camera movement, lens selection, and more [Electronic resource]. Amherst Media Press. http://link.overdrive.com/?websiteID=262\&titleID=1408846 
Subject: Define Hero, Create Conflict.

Format: Physical and E-Book.

Audience: Novice.

Useful things: Case Study.

Hockrow has a concise passage on character development. It illustrates the importance of character but does not delve deeply into answering questions on how to circumvent character development problems. However, it does give an overview of different types of conflict: relational, situational, inner, paranormal, cosmic, and social (Hockrow, 2014), that a story can have.

Horne, J. (2018). Dramatic techniques for creative writers: Turbo-charge your writing (1st ed). Method Writing.

Subject: Define Hero, Create Stakes, Create Conflict.

Format: Physical.

Audience: Novice.

Useful things: Case Study, Exercises.

Horne suggests that there are dramatic guidelines that a screenwriter must follow and that characterisation in terms of conflict and tension are interrelated (Horne, 2018). The manual provides fair use of exercises and case studies. However, the manual is not comprehensive in covering the problems of characterisation.

Howard, D. (2005). How to build a great screenplay: A master class in storytelling for film. Souvenir.

Subject: Define Hero, Develop Character-Arc, Create Stakes, Create Conflict.

Format: Physical.

Audience: Novice.

Useful things: Case Study. 
Howard's approach is to tie the theme of the screenplay closely with the hero; in other words, the theme defines the hero. It mentions that whatever weakness is inherent in the hero, are flaws that are exploited by the antagonist or strengths that they possess, which create conflict. Howard also explains how tension captures audience attention and retains it through the story (Howard, 2005). It provides examples of how to overcome problems with tension, conflict, and stakes through case studies of other films. Howard asks the questions of where the hero should be by the end of the film to create and convincing character arc. Pivotal actions can be as simple as decisions, and this is what involves an audience to care about the character development in the story. Howard's book delves deeply into all facets of the screenplay, and character development is no exception.

Hoxter, J. (2011). Write what you don't know: An accessible manual for screenwriters. Continuum.

Subject: Define Hero, Develop Character-Arc, Create Stakes, Create Conflict.

Format: Physical.

Audience: Novice.

Useful things: Case Study, Diagrams.

Hoxter covers many relevant topics to screenwriters, such as gathering ideas, cinematic storytelling, the writing process, and character development. Hoxter offers an alternative to just using checklists and background exercises as it becomes irrelevant if the character does not match up with the cinematic theme. Therefore, it is better to come up with a theme that will oppose the character (Hoxter, 2011). Hoxter provides a few generic choices and action that a hero and a villain or antihero will make during their character arc, which could be useful to the screenwriter.

Hurbis-Cherrier, M., \& Rabiger, M. (2013). Directing: Film techniques and aesthetics $\left(5^{\text {th }}\right.$ ed). Focal Press.

Subject: Define Hero, Develop Character-Arc, Create Stakes, Create Conflict. 
Format: Physical.

Audience: Novice.

Useful things: Case Study, Diagrams.

Hurbis-Cherrier \& Rabiger have crafter a manual that is comprehensive from gathering ideas to writing the script, to planning production, post-production (HurbisCherrier \& Rabiger, 2013). In terms of scriptwriting, it covers most facets of screenwriting, including all of the character development problems of defining, character-arc, stakes, and conflict. A must-read for any screenwriter and it is easy to use and in a logical arrangement.

Iglesias, K. (2005). Writing for emotional impact: Advanced dramatic techniques to attract, engage, and fascinate the reader from beginning to end (1st ed). WingSpan Press.

Subject: Define Hero, Develop Character-Arc, Create Stakes, Create Conflict.

Format: Physical.

Audience: Novice.

Useful things: Case Study.

Iglesias cares more about the emotional impact a script can have than the usual by the numbers script development process provided in most screenwriting manuals. In character development chapter, Iglesias talks about character flaw as a need that should be fulfilled, or not, by the end, which creates character arc. Including what is at stake for the hero if they fail and Iglesias provides case studies to show how character wants and needs can develop character arc, tension, and stakes. It also delves into how to make a character appealing through the use of being recognisable, fascinating, and being a mystery, which usually captures an audience (Iglesias, 2005). Iglesias Manual is an easy read and covers the basics, and also the norm for professional screenwriters. 
Indick, W. (2004). Psychology for screenwriters: Building conflict in your script. Michael Wiese Productions.

Subject: Define Hero, Develop Character-Arc, Create Stakes, Create Conflict.

Format: Physical.

Audience: Intermediate.

Useful things: Case Study, Exercises, Diagrams.

Indick uses notable figures in psychology: Freud, Erikson, and Jung and other notable figures to explain the psychology behind constructing characters and creating conflict (Indick, 2004). Indick uses the neurotic complex to explore a character's inner and outer conflict. Additionally. An exciting read for the novice screenwriter to delve more profound than any other book on externalising the inner workings of a character, and developing a deeper understanding of how to form such complex characters. Indick addresses most of the character development problems with such depth that this manual might be more suitable for an advanced screenwriter.

Jessup, L. Z. (2014). Getting it write: An insider's guide to a screenwriting career. Michael Wiese Productions.

Subject: Define Hero, Create Stakes, Create Conflict.

Format: Physical.

Audience: Novice.

Useful things: None.

Jessup has practical advice for writers, but there is not enough to fully explain how to develop characterisation to a particular problem a screenwriter would encounter. However, the book provides tips on how to make screenwriting career, and what to expect. Additionally, Jessup offers tips on the process of starting and selling as a script than on the craft itself (Jessup, 2014). Jessup offers a practical guide on surviving a screenwriting career. 
Johnson, C. (2010). Crafting short screenplays that connect (3rd ed., rev.expanded). Focal Press.

Subject: Define Hero, Develop Character-Arc.

Format: Physical.

Audience: Novice.

Useful things: Case Study, Exercises.

Johnson believes that connection and compassion are crucial in developing unique, three-dimensional characters (Johnson, 2010). Johnson does not give an analysis of how to overcome character problems. Johnson designs this manual as a learning aid for students and novice screenwriters.

Johnson, C., \& Stevens, M. (2002). Script partners: What makes film and TV writing teams work. Michael Wiese Productions.

Subject: Define Hero, Develop Character-Arc.

Format: Physical.

Audience: Novice.

Useful things: Case Study.

Johnson \& Stevens delve into character conflict by using case studies from movies (Johnson \& Stevens, 2002). Although the manual centres on co-creating characters, it still offers insight on how to write for actors as well. However, the manual is more about relationships in collaborating than a detail exploration on characterisation in scripts.

Klick, T. (2016). Beat by beat: A cheat sheet for screenwriters. Michael Wiese Productions.

Subject: Define Hero, Develop Character-Arc, Create Stakes, Create Conflict.

Format: Physical.

Audience: Intermediate. 
Useful things: Case Study, Exercises, Diagrams.

Klick organises sections that follow a four-act structure and lists the requirements for each act. It provides a comprehensive checklist for a screenwriter to keep track of essential beats in the story that are crucial for a coherent script. Its emphasis on a visual checklist is constructive for a writer to navigate and consume information, especially in a pinch. It uses six different movies: Skyfall, Avengers, Hangover, Beautiful Mind, Conjuring, and Gone Girl (Klick, 2016). Klick tackles all character development problems and emphasises the visual form.

Kress, N. (2005). Characters, emotion, \& viewpoint: Techniques and exercises for creating dynamic characters and effective viewpoints (1st ed). Writer's Digest Books.

Subject: Define Hero, Develop Character-Arc, Create Conflict.

Format: Physical.

Audience: Novice.

Useful things: Case Study, Exercises, Diagrams.

Kress believes that character motivation is key to the narrative structure. Kress advises the screenwriter to write characters with more than one goal. Furthermore, a screenwriter should include smaller goals that the character may want to achieve towards their primary objective. For example, a small goal could include repairing a character flaw, or a relationship, or getting revenge, as long as the smaller goals apply to the main objective and narrative structure (Kress, 2005). Furthermore, Kress delves into revealing information slowly through the narrative and not info-dumping exposition, which is information crucial to understanding the plot or character. This manual is a good start for a novice screenwriter in understanding how to construct characters and how to reveal their objectives naturally.

Lake, D. (2017). The screenwriter's path: From idea to script to sale. Focal Press.

Subject: Define Hero, Develop Character-Arc. 


\section{Format: E-Book.}

Audience: Novice.

Useful things: Case Study, Exercises, Diagrams.

Lake believes character arc is separate from the narrative structure but closely related in the sense that the character learns from overcoming plot obstacles (Lake, 2017). Lake's manual explores a seven-step narrative structure and develops characters with this as a framework. The manual is easy to navigate and easy to read, and there are exercises available in the form of questions for the screenwriter. The manual informs the screenwriter how to pace a script, and answers why specific points in the narrative structure lag, or fail.

Landau, N. (2013). The screenwriter's roadmap: 21 ways to jumpstart your story. Focal Press.

Subject: Define Hero, Develop Character-Arc, Create Stakes, Create Conflict.

Format: Physical.

Audience: Intermediate.

Useful things: Case Study, Exercises.

Landau's manual is very comprehensive in dealing with a character as its primary focus. The contents page is convenient, and the headings are designed for quick access for any screenwriter regardless of their working knowledge of the screenwriter's language or terminology. Landau acknowledges that there can be alternatives to the three-act structure (Landau, 2013). However, the fundamental focus of any story is on the character. It provides excellent case studies and exercises in overcoming various character development problems.

Lazarus, T. (2012). The last word: Definitive answers to all your screenwriting questions. Michael Wiese Productions.

Subject: Define Hero, Develop Character-Arc, Create Stakes, Create Conflict. 
Format: Physical.

Audience: Intermediate.

Useful things: Case Study, Exercises.

Lazarus has developed a convenient manual for screenwriters. A screenwriter can look for solutions to specific problems by looking at the contents page. Lazarus' writing style is easy to follow and is organised in alphabetical order by theme. The manual is straightforward and provides some exercises for the screenwriter. It has information for a novice screenwriter to advance to more intermediate or advance. Lazarus provides advice on what producers are looking for in a script; if the screenwriter is an amateur or professional screenwriter (Lazarus, 2012). It provides adequate coverage on character development problems a screenwriter will face.

Lyons, J. (2016). Anatomy of a premise line: How to master premise and story development for writing success. Focal Press.

Subject: Define Hero, Develop Character-Arc.

Format: Physical.

Audience: Novice.

Useful things: Case Study, Exercises, Diagrams.

Lyons provides diagrams of the passive and active protagonist loop (Lyons, 2016), which helps a screenwriter better define their character and character-arc. Lyons offers checklists in the conclusion of the manual that is helpful. However, Lyons focuses on a screenwriter's beginning phase in starting to write the premise and synopsis. However, it is still relevant in thinking about a character at these early stages.

Marlow, J. R. (2012). Make your story a movie: Adapting your book or idea for Hollywood (1st ed). St. Martin's Griffin.

Subject: Define Hero, Develop Character-Arc. 
Format: Physical.

Audience: Novice.

Useful things: Case Study.

Marlow suggests that the hero must be relatable, so the audience understands their motivation but preferably be likeable or else the audience will not care about the story (Marlow, 2012). Hence, why the character is more important than the plot, or at least it shares a symbiotic relationship. Additionally, an emotionally captivating story requires stakes when a character has something to lose, which leads to the hero conflicting with either the environment or opposing characters. A screenwriter creates tension by raising the stakes of the main character or adding a ticking clock. Marlow hits all the main character development problems but fails to provide exercises for the screenwriter to learn and develop their craft.

McBride, J. (2012). Writing in pictures: Screenwriting made (mostly) painless. Vintage Books.

Subject: Create Stakes, Create Conflict.

Format: Physical.

Audience: Novice.

Useful things: None.

McBride believes action is character and character is conflict and conflict is the plot. Additionally, McBride believes the character does not have to be likeable. However, the character needs to drive the action and have clear motives that the audience can understand why the hero wants to accomplish their goal. McBride emphasises the use of word-economy, showing more than telling and does touch on subtext in terms of dialogue and images (McBride, 2012). Sometimes the character development problems encountered by a screenwriter have to do how they have defined character, raised the stakes, created conflict through the use of secondary characters. 
McKee, R. (2016). Dialogue: The art of verbal action for page, stage, screen (First edition). Twelve, an imprint of Grand Central Publishing.

Subject: Define Hero, Develop Character-Arc, Create Conflict.

Format: Physical.

Audience: Novice.

Useful things: Case Study, Exercises.

McKee believes that every character is a walking dictionary with their unique phrases and words (McKee, 2016). McKee offers solutions to creating three-dimensional characters and defining characters using dialogue as a framework. Additionally, McKee explains that there are three types of conflict: social, personal, and inner. Moreover, Social conflict derives from institutional forces. Furthermore, personal conflict arises from relationships, and inner conflict derives from the main character. Therefore, it is essential to fluctuate between the three to create exciting obstacles for the hero to overcome or not overcome. McKee's manual is a seminal work in dialogue for films. It offers comprehensive coverage in all matters of building characters through dialogue.

Mernit, B. (2020). Writing the romantic comedy: The art of crafting funny love stories for the screen (Twentieth anniversary expanded and updated edition). Harper.

Subject: Define Hero

Format: Physical.

Audience: Novice.

Useful things: Case Study.

Mernit proposes that there are four critical elements to characterisation: Purpose, credibility, empathy, and complexity (Mernit, 2020). In defining the character, credibility is achieved by the opening few actions that character makes that is believable to the audience, such as the example Mernit provides in the film Tootsie. The Godfather is used to show the difference between feeling empathetic, not 
sympathetic, to Don Corleone. However, the audience can connect with his devotion to his family. According to Mernit, the use of wants and needs is central to a character arc as a character may want something but ends up with what the hero needs by the end of the script. Mernit lets the screenwriter know the five ways of bringing a character to life: speech, action, appearance, thought, and indirect information from secondary characters which applies to all scripts and not just romantic comedies.

Mukherjee, R. (2014). The art of screenplays: A writer's guide. Kamera Books, an imprint of Oldcastle Books.

Subject: Define Hero.

Format: Physical.

Audience: Novice.

Useful things: Exercises, Diagrams.

Mukherjee elaborates on character development problems by talking about a sense of self, logos/Rationale, Emotions, Thoughts, Speech/Action (Mukherjee, 2014). It does provide a checklist and exercises in expanding a screenwriter's character. According to Mukherjee, character and story are intertwined and are indistinguishable in a script. However, it does not delve deeper into solutions to character development than providing a broad description of character development problems. However, it could be attractive to a novice screenwriter wanting to learn more about how a screenwriter should think, and handle dialogue, and character in general terms.

Munier, P. (2014). Plot Perfect: How to Build Unforgettable Stories Scene by Scene [Electronic resource]. F+W Media. http://auckland.lib.overdrive.com/ ContentDetails.htm?ID=9C683762-4FBF-49F1-9648-643934BDF270

Subject: Define Hero, Develop Character-Arc, Create Conflict.

Format: Physical \& E-Book.

Audience: Novice. 
Useful things: Case Study, Exercises, Diagrams.

Munier provides a manual that is very simplistic in design and some ways content. However, the content that is there is crucial for any novice writer to understand. Additionally, Munier asks the screenwriter a series of questions to both let the screenwriter identify and characterisation problem, and also solve it. Furthermore, Munier encourages the screenwriter to ask questions about their scripts regularly (Munier, 2014). Munier covers areas of defining the hero and structuring the narrative with the character-arc to achieve a character-driven story.

Neipris, J. (2016). A master class in dramatic writing: Theater, film, and television. Routledge.

Subject: Define Hero, Develop Character-Arc, Create Stakes, Create Conflict.

Format: Physical.

Audience: Novice.

Useful things: Case Study.

Neipris has a short but concise look into creating complex characters by providing a checklist of questions for the screenwriter to answer for their particular character problem. Additionally, it tells a screenwriter how to show this complexity through action and interactions with other characters (Neipris, 2016). It also touches on how to raise stakes through the character journey. It also provides exercises on escalating conflicts. However, the manual shines with its section on how to rewrite to refine a script.

Nicolosi, B. R., \& Peterson, V. (2015). Notes to screenwriters: Advancing your story, screenplay, and career with whatever Hollywood throws at you. Michael Wiese Productions.

Subject: Define Hero, Develop Character-Arc.

Format: Physical. 
Audience: Intermediate.

Useful things: Case Study, Exercises.

Nicolosi and Peterson explore how to create relatable characters. A screenwriter must show a hero's selfless actions to gain audience empathy and trust (Nicolosi \& Peterson, 2015). Additionally, the hero must be consistent in their drive towards a goal to be relatable and interesting.

Nicolosi and Peterson believe characterisation is complicated with a paradox and provides a checklist of the question for the screenwriter to ask themselves in regards to developing their characters. Additionally, Nicolosi and Peterson provide exercises such as brainstorming the choices a character can take, which could help shed light on character development problems.

Obstfeld, R. (2002). Fiction first aid: Instant remedies for novels, stories and scripts. Writer's Digest Books.

Subject: Define Hero, Develop Character-Arc, Create Stakes, Create Conflict.

Format: Physical.

Audience: Novice.

Useful things: Case Study, Exercises.

Obstfeld believes that increasing the stakes for the hero means having a goal and subtasks to achieve that goal (Obstfeld, 2002). Additionally, the hero must face unimaginable odds that the audience knows it is close to impossible to overcome. Moreover, Obstfeld believes a character does not have to be likeable. In conclusion, this manual is easy to navigate. It has finding aids inside that will help the user skip to relevant chapters or pages. Furthermore, Obstfeld asks relevant questions that are common problems in characterisation.

Patz, D. S. (2017). Write! Shoot! Edit! The complete guide to filmmaking for teens. Michael Wiese Productions. 
Subject: Define Hero, Develop Character-Arc, Create Conflict.

Format: Physical.

Audience: Novice.

Useful things: Diagrams.

Patz' manual aims to deliver practicable information for teenagers to make films. An example is different strategies such as brainstorming, the use of index cards. It also provides a simple overview of character archetypes, such as the villain and the hero. However, it does touch upon how events or activities that affect a screenwriter's character should either be an emotional up or and emotional downer to show character arc, struggle, and resolution (Patz, 2017). Although it is primarily for short films, the principles can be applied to feature films.

Robinson, J., \& Mungovan, T. (2003). The screenplay workbook: The writing before the writing [Electronic resource]. Lone Eagle. http://auckland.lib.overdrive.com/ ContentDetails.htm?ID=DECC7971-16B0-4648-862C-A9F00653DD2C

Subject: Define Hero, Develop Character-Arc, Create Conflict.

Format: E-Book

Audience: Novice.

Useful things: Case Study, Exercises.

Robinson and Mungovan provide a very simple and easy to use manual. The manual offers sound advice on character development and character arcs. Furthermore, Robinson \& Mungovan provide worksheets for screenwriters to use to flesh out their characters and understand what drives their actions through the narrative structure (Robinson \& Mungovan, 2003). However, the worksheets are very small and hard to look at; it would be beneficial to screenwriters if there were a PDF or a link to download. Despite this, the manual does make an effort to ask the screenwriter questions so the screenwriter can find solutions to their characterisation problems. This manual offers brilliant resources in the appendix. 
Rosenfeld, J. E. (2016). Writing the intimate character: Create unique, compelling characters through mastery of point of view. Writer's Digest Books.

Subject: Define Hero, Develop Character-Arc, Create Stakes.

Format: Physical.

Audience: Intermediate.

Useful things: Case Study, Exercises.

Rosenfeld suggests that screenwriters should put the main character in a situation that is beyond their control to create tension (Rosenfeld, 2016). Rosenfeld's manual is for authors rather than screenwriters. However, the principles of mystery, and developing the character-arc, and creating tension remain the same. The book is not easy to navigate for a novice, mostly a user not used to fictional writing jargon. However, there are essential aspects of writing, such as handling exposition, or extraneous background information to understand the narrative or character, which a screenwriter can use.

Russin, R. U., \& Downs, W. M. (2012). Screenplay: Writing the picture (2nd ed. rev. \& updated). Silman-James Press.

Subject: Define Hero, Develop Character-Arc, Create Stakes, Create Conflict.

Format: Physical.

Audience: Novice.

Useful things: Case Study, Exercises, Diagrams.

Russin \& Down's delves into character development and provides an adequate explanation into character, character arc, conflict, and stakes. Additionally, Russin and Down reference films that have done well, or not well, in developing characters (Russin \& Downs, 2012). The section on stakes is clearly defined and elaborated on, in terms of how to up the stakes. It also provides snapshots of how it would appear in an actual script which is extremely helpful to screenwriters. An exciting chapter on 
power and conflict provides solutions to creating conflict and developing characterarc. Russin \& Down provide advice on smaller things such as formatting that some screenwriting books leave out. Formatting is essential and usually what tells a reader, or producer if the script is worth reading.

Samaroo, M. (2015). The complete guide to writing a successful screenplay: Everything you need to know to write and sell a winning script. Atlantic Publishing Group.

Subject: Define Hero, Develop Character-Arc.

Format: Physical.

Audience: Novice.

Useful things: Case Study, Exercises.

Samaroo has a straightforward checklist for screenwriters with character development problems (Samaroo, 2015), but fails to elaborate more on how these problems can come about and the process of overcoming them. However, Samaroo's manual is an excellent starting point in inspiring writers to start writing and thinking like a screenwriter in terms of simple things to look out for in writing. It is an efficient book aimed for screenwriters who want to make their films on an independent level.

Schimmel, J. (2014). Screenwriting behind enemy lines: Lessons from inside the studio gates. Michael Wiese Productions.

Subject: Define Hero, Develop Character-Arc, Create Stakes, Create Conflict.

Format: Physical.

Audience: Intermediate.

Useful things: Case Study, Exercises.

Schimmel offers a pragmatic look into characterisation (Schimmel, 2014). Schimmel analyses how to define a character and how a character's arc should develop over a standard three-act structure of a script. The exercises force the screenwriter to analyse 
a film and to identify critical elements of characterisation to figure out solutions to their character development problems.

Schmidt, V. (2012). 45 master characters: Mythic models for creating original characters (2nd ed). Writer's Digest Books.

Subject: Define Hero, Develop Character-Arc, Create Conflict.

Format: Physical.

Audience: Intermediate.

Useful things: Exercises.

Schmidt helps writers explore character archetypes using the mythic journeys of heroes and heroines (Schmidt, 2012). The difference with this manual is that it splits up its characterisation by gender. Furthermore, Schmidt believes that the character's goal closely defines character-arc. This manual is an interesting read in terms of archetypes, and the overall design is easy to follow. However, there are terms used in there that a novice would think twice about making it hard to navigate in the contents page.

Seger, L. (2011). Writing subtext: What lies beneath. Michael Wiese Productions.

Subject: Define Hero, Develop Character-Arc, Create Stakes, Create Conflict.

Format: Physical.

Audience: Novice.

Useful things: Case Study, Exercises.

Seger deals with writing dialogue and characterisation in scripts. Moreover, Seger explores subtext: words or gestures that we see that may refer, or infer, a different meaning than the one that a screenwriter wishes to convey (Seger, 2011). Seger offers case studies and exercises for the screenwriter to help develop the use of subtext. 
Selbo, J. (2008). Gardner's guide to screenplay: The rewrite. GGC Pub.

Subject: Define Hero, Develop Character-Arc, Create Stakes, Create Conflict.

Format: Physical.

Audience: Novice.

Useful things: Case Study, Exercises.

Selbo provides useful sections on the basics of rewriting and genre expectations (Selbo, 2008). Selbo delivers great coverage on characterisation and provides numerous checklists of questions, and exercises, to overcome most character development problems. The screenwriter can easily navigate through chapters or use the index to find solutions to their specific needs. Additionally, there are great case studies to demonstrate what Selbo is explaining as well, which is helpful.

Smethurst, W. (2016). How to write for television (7th edition). Robinson.

Subject: Define Hero, Develop Character-Arc.

Format: Physical.

Audience: Novice.

Useful things: None.

Smethurst includes an excellent section on dialogue, and the three functions it serves is to advance the story, to give information, and to reveal character (Smethurst, 2016). It tackles issues such as a script turning into melodrama. It has a checklist, but it is not exhaustive enough to help an intermediate or advance screenwriter. However, the lists are suitable for the novice screenwriter. It does offer websites as resources, as well as potential agents. However, this book is more of an overview of the entire process of filmmaking and television production than a study in character.

Smith, P. J. (2008). The power of the dark side: Creating great villains, dangerous situations, \& dramatic conflict. Michael Wiese Productions.

Subject: Define Hero, Develop Character-Arc, Create Stakes, Create Conflict. 
Format: Physical.

Audience: Novice.

Useful things: Case Study.

Smith understands that conflict is at the heart of a story. Smith focuses on villains, but the screenwriter can apply the concept to any genre. Smith has a good understanding of archetypes found in antagonist and explores how a screenwriter can avoid cliches and why they work in a script. However, Smith's manual design prevents the screenwriter from effortlessly navigating the manual to solve their particular character problem. Smith provides a manual that illustrates the importance of conflict being the centre of a good story, and screenwriters need uncompromising characters to ensure characters are in conflict (P. J. Smith, 2008).

Snyder, B. (2005). Save the cat! The last book on screenwriting you'll ever need. Michael Wiese Productions.

Subject: Define Hero, Develop Character-Arc, Create Conflict.

Format: Physical Book, E-Book.

Audience: Intermediate.

Useful things: Case Study.

Snyder provides a transparent 15-point beat sheet on how a story is structured. He also writes the manual in a manner that asks questions to the screenwriter for them to come up with a solution to their particular script. Snyder demonstrates how to develop a character arc by using his 'transformational machine' diagram, which plots the 15point beats and when and where a character's arc encounters an emotional shift (Snyder, 2005). Snyder provides a useful checklist of questions about the hero's journey.

Steele, A., \& Gotham Writers' Workshop (Eds.). (2006). Writing movies: The practical guide to creating stellar screenplays (1st U.S. ed). Bloomsbury. 
Subject: Define Hero, Create Conflict.

Format: Physical.

Audience: Novice.

Useful things: Case Study.

Steele provides exercises and uses examples from case studies to illustrate how to overcome characterisation problems. Steele says that it is better to like a character but at the very least, respect their intention, or at least find them fascinating (Steele \& Gotham Writers' Workshop, 2006). Steele recommends that the protagonist and antagonist need to be complex three-dimensional characters to create conflict and tension.

Street, K. L. (2013). Writing and selling crime film screenplays. Creative Essentials.

Subject: Define Hero, Develop Character-Arc, Create Stakes, Create Conflict.

Format: Physical.

Audience: Novice.

Useful things: Case Study, Exercises.

Street has dedicated her manual to the crime screenwriter and touches on many popular sub-genres within crime: whodunnit, Prison films, Gangster films, and more (Street, 2013). Street uses Joseph Campbell's mono-myth to construct the hero's journey. Additionally, using a checklist for the antihero journey. Street provides a plethora of exercises, examples, and case studies that are useful.

Sublett, S. W. (2014). Screenwriting for neurotics: A beginner's guide to writing a featurelength screenplay from start to finish. University of Iowa Press.

Subject: Define Hero, Create Stakes, Create Conflict.

Format: Physical.

Audience: Novice. 
Useful things: Case Study.

Sublett emphasises character conflict where there is a clash of ideologies or competing goals between two or more characters. It talks about external conflict, either environment or secondary characters that oppose the hero, or inner conflict inside the hero with doubts of accomplishing their goals (Sublett, 2014). Sublet provides coverage on externalising conflict. It does well to answer all four-character development problems. However, Sublett disperses the solutions throughout the book, and the screenwriter must consult with the index to find the sections that are relevant to their specific character development problem.

Sykes, C. P. (2012). How to craft a great story: Creating perfect plot and structure. Teach Yourself.

Subject: Define Hero, Create Conflict.

Format: Physical and E-Book.

Audience: Novice.

Useful things: Exercises.

Sykes provides diagrams, case studies, and exercises to illustrate his points. Sykes uses a character ladder diagram to illustrate how a character moves through their journey from one emotional state to another by the end of the script (Sykes, 2012). Sykes offers more tips on creating conflict and tension better than most manuals. Sykes succeeds in providing everything a screenwriter needs to solve complex character development problems.

Sykes, C. P. (2014). Complete creative writing course. Teach Yourself, John Murray Learning.

Subject: Define Hero, Develop Character-Arc, Create Stakes, Create Conflict.

Format: Physical and E-Book.

Audience: Novice. 
Useful things: Case Study, Exercises, Diagrams.

Sykes Manual is for writing fiction and provides tools and exercises to stimulate creativity (Sykes, 2014). However, it does provide useful checklists for character biographies that a screenwriter can use and does touch upon essential topics of defining a character and creating conflict between characters. However, the manual is more suitable for writing novels than scripts.

Trottier, D. (2014). The screenwriter's bible: A complete guide to writing, formatting, and selling your script (6th edition). Silman-James Press.

Subject: Define Hero, Develop Character-Arc, Create Stakes, Create Conflict.

Format: Physical.

Audience: Novice.

Useful things: Case Study.

Trottier provides a comprehensive manual on screenwriting. Trottier covers the mental process and motivation to complete a script, the technical formatting of a script to look aesthetically pleasing to a producer or filmmaker, revising a script, and how to sell it (Trottier, 2014). Trottier provides more than sufficient amount of depth in character development solutions and overall coverage of issues arising in scripts. However, Trottier does not provide exercises; instead, it raises awareness of issues and potential solutions by using questions. However, a screenwriter can efficiently traverse to relevant sections to find solutions.

Truby, J. (2007). The anatomy of story: 22 steps to becoming a master storyteller. Faber and Faber.

Subject: Define Hero, Develop Character-Arc, Create Stakes, Create Conflict.

Format: Physical \& E-Book.

Audience: Novice.

Useful things: Case Study, Exercises, Diagrams. 
Truby argues that secondary characters often define great characters. Additionally, all characters serve a purpose. Therefore, a screenwriter should write all characters in a script like an interconnected web. Truby also argues that any opposition or conflict should be necessary for the growth of the character-arc (Truby, 2007). Truby's manual is well-formatted and designed to be easy to read. A screenwriter can navigate between chapters easily, and there are learning aids such as exercises, case studies, and diagrams that help a reader understand the concepts that underlie characterisation.

Vogler, C., \& Montez, M. (2007). The writer's journey: Mythic structure for writers (3rd ed). Michael Wiese Productions.

Subject: Define Hero, Develop Character-Arc, Create Stakes, Create Conflict.

Format: Physical.

Audience: Novice.

Useful things: Case Study, Exercises, Diagrams.

Vogler is a seminal text for screenwriters as it uses Joseph Campbell's mythic structure and makes it more accessible to screenwriters (Vogler \& Montez, 2007). It gives case studies, checklists, diagrams, and exercises for novice screenwriters to explore the mythic structure. It delves into defining a character, character arc, character stakes, and conflict and more. Film studio executives, creatives, screenwriters and producers in Hollywood use Vogler's manual.

Walker, S. J. (2012). Romantic screenplays 101 [Electronic resource]. Fiction Works. http://auckland.lib.overdrive.com/ ContentDetails.htm?ID=D0961FBB-00E7-4CF6AE53-F5CEC5BCDB52

Subject: Define Hero, Develop Character-Arc, Create Conflict.

Format: E-Book.

Audience: Novice.

Useful things: Case Study, Exercises, Diagrams. 
Walker analyses the principles of romantic fiction and romance's characterisation requirement. Walker recognises that there is a clear narrative progression from a romantic couple going from trust, acceptance, and permission (Walker, 2012). Walker recognises that conflict is handled differently in romance and that complication in the relationship between characters, and jealousy is a crucial device in creating conflict. Walker's account on characterisation does not seem comprehensive. However, a screenwriter can learn archetypes and why they are essential to this particular genre of filmmaking.

Weiland, K. M. (2017). Creating character arcs: The masterful author's guide to uniting story structure, plot, and character development [Electronic resource]. Smashwords Edition. https://samples.overdrive.com/?crid=5c0105b2-3acb-4c91-8322c3b909acd72c\&.epub-sample.overdrive.com

Subject: Define Hero, Develop Character-Arc, Create Stakes, Create Conflict.

Format: E-book.

Audience: Novice.

Useful things: Case Study, Exercises.

Weiland offers a manual that marries story structure and character arc seamlessly. Weiland believes there are three types of character-arcs: Positive change, Flat arc, and negative change (Weiland, 2017). Firstly, Positive arc is when a character is unfulfilled and ends in triumph. The changes to the hero are positive. Secondly, the Flat arc is when a character is unchanged from the start to the end, and they usually spark change in other characters in the narrative. Lastly, negative change is the opposite of positive change. This manual is easy to follow and delves into problems with characterisation very well and offers straight to the point exercises to remedy problems.

Wendig, C. (2017). Damn fine story: Mastering the tools of a powerful narrative. Writer's Digest Books. 
Subject: Define Hero, Develop Character-Arc, Create Stakes, Create Conflict.

Format: Physical

Audience: Intermediate.

Useful things: Case Study.

Wendig believes superficial aspects of the character are meaningless and that what is the most important is the character problem because it defines who they are (Wendig, 2017). The actions they take to solve it and provides narrative beats to answering that character problem. Moreover, both external and internal complications prevent the character from finding a solution to that character problem which creates more threedimensional characters. Therefore, complications raise the stakes on completing the journey to solving that character problem. Wendig puts together an essential overview of what to do with characterisation but also why it is necessary. Wendig presents his ideas in an entertaining and easy to consume way. However, Wendig has a poorly designed contents page. Therefore, making a screenwriter would have difficulty navigating to characterisation problems. However, this manual is perfect for the novice writer as the content is entertaining and relevant to most characterisation problems.

Yorke, J. (2014). Into the woods: How stories work and why we tell them [Electronic resource]. Penguin Books. https://samples.overdrive.com/into-the-woodsacd02d?.epub-sample.overdrive.com

Subject: Define Hero, Develop Character-Arc.

Format: Physical.

Audience: Advanced.

Useful things: Case Study, Diagrams.

Yorke examines the psychological profile of the hero. Subsequently, Yorke uses Maslow's motivational pyramid, Jungian archetypes, and Freudian Ego to explore characterisation (Yorke, 2014). It does answer a few character development problems. 
However, it fails to elaborate on how a screenwriter can create stakes for a character. The roadmaps provided in the appendices are extremely helpful in visually showing screenwriter is how these concepts translate in their characters. 


\section{B. Developing the Character-arc}

Ackerman, A., Puglisi, B., \& Kaufman, C. (2013). The negative trait thesaurus: A writer's guide to character flaws (First print edition). JADD Publishing.

Subject: Define Hero, Develop Character-Arc, Create Stakes, Create Conflict.

Format: Physical.

Audience: Novice.

Useful things: Case Study, Exercises.

Ackerman argues that character flaws are just as crucial in defining a character and making them memorable (A. Ackerman et al., 2013). Character flaws are traits that can damage character relationships. Character flaws develop through the characterarc. Therefore, it is the flaws of the hero and other secondary characters that can cause conflict. Subsequently, Ackerman provides a thesaurus of character traits and behaviours and character flaws of certain characters to aid a screenwriter in forming believable, credibly, three-dimensional characters. This manual is unlike other screenwriting books as it gives a plethora of character types in detail for the screenwriter to choose and explore.

Ackerman, H. (2017). Write screenplays that sell: The Ackerman way (Revised updated edition). Tallfellow Press.

Subject: Define Hero, Develop Character-Arc, Create Stakes, Create Conflict.

Format: Physical.

Audience: Intermediate-Advanced.

Useful things: Case Study, Exercises, Diagrams.

Ackerman demonstrates how a screenwriter introduces a character to the audience by actions, such as introducing them through a scene showing their occupation $(\mathrm{H}$. Ackerman, 2017). It provides examples of how to overcome character and narrative problems by using scene-cards to map out how a character grows and drives the 
narrative. It also provides exercises for the screenwriter to practice their craft. Ackerman also answers frequently asked questions a screenwriter by exploring why a screenwriter writes or does not write. Additionally, this manual offers a glimpse into the practicality of generating ideas by using scene, or index cards, to create an exciting scene.

Alderson, M., \& Rosenfeld, J. E. (2015). Writing deep scenes: Plotting your story scene by scene through action, emotion, and theme [Electronic resource]. Writer's Digest. http://samples.overdrive.com/?crid=72bc4d2e- ec05-44f1-832f49f366150333\&.epub-sample.overdrive.com

Subject: Define Hero, Develop Character-Arc, Create Stakes, Create Conflict.

Format: Physical \& E-Book.

Audience: Novice.

Useful things: Case Study, Exercises.

Alderson \& Rosenfeld believes that character problem must propel the hero to achieving a concrete goal which leads to smaller goals (Alderson \& Rosenfeld, 2015). Moreover, a character can change how they achieve smaller goals to complete their primary objective. The book is not easy to navigate and requires the screenwriter to flip through pages to find relevant chapters. However, the manual is logical and easy to read and provides plenty of case studies and exercises for the screenwriter.

Aronson, L. (2000). Scriptwriting updated: New and conventional ways of writing for the screen. Australian Film Television \& Radio School; Allen \& Unwin.

Subject: Define Hero, Develop Character-Arc, Create Stakes, Create Conflict.

Format: Physical.

Audience: Intermediate-Advanced.

Useful things: Case Study, Exercises, Diagrams. 
Aronson has been a screenwriter for twenty years, but more importantly, she has been a script assessor and teacher (Aronson, 2000). She has a checklist for identifying who the protagonist is in the story, and it is helpful to any screenwriter to follow and answer, the questions provided to define their main character. The manual is easy to follow, and Aronson organises the manual in a user-friendly way for navigating. It has checklists, exercises, and diagrams and case studies that will illuminate most characterisation problems a screenwriter will encounter. The manual relates ideas about the character to the main beats of a three-act structure. The best part of the book is that it makes use of diagrams to follow.

Aronson, L. (2010). The 21st century screenplay: A comprehensive guide to writing tomorrow's films. Allen \& Unwin.

Subject: Define Hero, Develop Character-Arc, Create Conflict.

Format: Physical.

Audience: Novice.

Useful things: Case Study, Diagrams.

Aronson provides obvious development strategies and explores these strategies with exercises which are helpful for character development problems inherent in a screenwriter's script. Additionally, Aronson has visual strategies and checklists on how to create and develop ideas when a screenwriter has writer's block. It provides conventional and alternative methods to narrative structure and how to break out of cliches. It also tackles double protagonist or ensemble casting, like no other screenwriting manual. She tackles innovative narrative designs, such as writing for an anthology film (Aronson, 2010). It is a book that can help novice and professional writers with ordering their ideas into real scripts. Furthermore, the manual aligns how to solve character problems with a strong emphasis on narrative conventions.

Axelrod, M. (2014). Constructing dialogue: From Citizen Kane to Midnight in Paris. Bloomsbury Academic.

Subject: Define Hero, Develop Character-Arc. 
Format: Physical.

Audience: Novice.

Useful things: Case Study, Exercises.

Axelrod uses a plethora of films, and fictional works, as exemplars of good screenwriting dialogue. Additionally, Axelrod points out where films have encountered problems relating to defining the hero and developing a character-arc (Axelrod, 2014). Axelrod gives very close attention to dialogue construction within a script. Axelrod's manual layout is challenging for any novice screenwriter to navigate and find sections relating to characterisation problems inherent in their film scripts. However, it does provide close analyses of how dialogue should be written from case studies and offers good exercises on character-arc and how to define the main character. Axelrod reminds screenwriters to rewrite the script with particular attention to word-economy. Subsequently, a screenwriter needs to delete unnecessary words in a script.

Bailey, S., \& Blake, M. (2013). Writing the horror movie. Bloomsbury.

Subject: Define Hero, Develop Character-Arc, Create Stakes, Create Conflict.

Format: Physical.

Audience: Novice-Intermediate.

Useful things: Case Study, Exercises.

Bailey \& Blake give direction in how to structure the character's journey but also on how to create tension through the use of 5 tropes: unease, dread, terror, horror, and disgust (Bailey \& Blake, 2013). It provides a checklist for screenwriters to check that their story is on track and writing exercises, interviews with directors and writers on horror films. The manual is an exemplar in defining the antagonist that will be a cause of conflict with a screenwriter's central character. Furthermore, it gives good advice on creating conflict, raising the stakes for the main character, and sustaining tension. Although the manual focuses on writing horror films, a screenwriter can use the same 
principles in different genres. The style and layout of the manual are easy to follow and navigate and has an appealing readable style.

Batty, C. (2012). Screenplays: How to write and sell them. Creative Essentials.

Subject: Define Hero, Develop Character-Arc.

Format: Physical.

Audience: Novice.

Useful things: Exercises.

Batty's manual focuses on writing the feature film. Batty explains why a characterisation does not work and how to fix these problems. Batty explains that the common problem is that there are not enough characters to help or deter a character's journey (Batty, 2012). Batty elaborates on the character's physical and emotional journey and how the two work together to develop a three-dimensional character. In essence, the physical journey is what the character wants, and the emotional journey is what the character needs. Batty's manual is easy to read but would benefit from more exercises and detail in creating tension, stakes. However, the manual empowers screenwriters in their creative processes to tell the stories that they want to tell.

Batty, C., \& Waldeback, Z. (2012). The creative screenwriter: Exercises to expand your craft. Methuen Drama.

Subject: Define Hero, Develop Character-Arc, Create Stakes, Create Conflict.

Format: Physical.

Audience: Novice.

Useful things: Exercises.

Batty and Waldeback provide a useful checklist on pinpointing the main character that a story follows (Batty \& Waldeback, 2012). Additionally, Batty and Waldeback explore how screenwriters generate ideas. The manual emphasises that understanding the characters and their relationship to one another is useful in defining characters and 
developing their character-arc. It also provides a section on strengthening visual storytelling which is a critical element of scriptwriting. The manual offers exercises to help build solutions to character development problems.

Additionally, there are some checklists for a screenwriter to work through to develop a good character arc. The manual also provides advice post scriptwriting process of pitching an idea, or writing outlines and treatments to distribute to producers. There are extensive exercises provided at the conclusion to help with common story problems, and they list an index to direct the screenwriter to writing exercises found through the beneficial book.

Bauer, I., \& Bauer, V. (2017). Screenwriting fundamentals: The art and craft of visual writing. Routledge.

Subject: Define Hero, Develop Character-Arc.

Format: Physical.

Audience: Novice.

Useful things: Exercises, Diagrams.

Bauer \& Bauer's manual is fantastic for the novice screenwriter who wants to learn what a script should look like and what to include. There are helpful examples provided of inserts of a fictional script to help illustrate what Bauer \& Bauer are teaching in each section. Although, the manual touches upon how to practically develop ideas on creating a character- arc, it does not provide details for a screenwriter to follow and adjust their work (Bauer \& Bauer, 2017). However, the manual does provide some exercises to help prepare screenwriters for the overwhelming task of completing the first draft.

Bell, J. S. (2011). Conflict \& suspense [Electronic resource]. Writers Digest Books. http://excerpts.cdn.overdrive.com/FormatType- 410/1705-1/715/9B4/61/ ElementsofFictionWritingConflictandSu9781599632759.epub

Subject: Develop Character-Arc, Create Stakes, Create Conflict. 


\section{Format: E-Book.}

Audience: Intermediate.

Useful things: Exercises, Diagrams.

Bell's manual focuses on fiction-authorship. However, Bell offers tips on

characterisation that a screenwriter can use. Bell provides a comprehensive look into character and conflict. Moreover, Bell also uses the narrative structure to frame characterisation and conflict and lets the screenwriter know when and where conflict should appear (Bell, 2011). In conclusion, this manual is useful to screenwriters as it explores conflict very well. However, more case studies could help the reader know what examples of good and bad writing in terms of characterisation are. Additionally, this manual is easy to read and easy to navigate due to the design.

Bernhardt, W., \& Bernhardt, W. (2017). Creating Character: Bringing Your Story to Life [Electronic resource]. Babylon Books. https://samples.overdrive.com/?crid=134b427a- 3b68-4522-97290a449f836c65\&.epub-sample.overdrive.com

Subject: Define Hero, Develop Character-Arc, Create Stakes, Create Conflict.

Format: Physical \& E-Book.

Audience: Novice.

Useful things: Case Study, Exercises.

Bernhardt believes all stories are character-driven, and all stories are about conflict, and all conflict develops over a character-arc (Bernhardt \& Bernhardt, 2017). This manual provides helpful exercises at the end of every chapter. Therefore, navigating each chapter for a particular characterisation problem will inevitably lead a screenwriter to exercises they can use. This manual's focus is on fiction authorship. However, a screenwriter can use this manual for screenwriting as well. 
Branton, M. (2013). The Creative Writing Workbook [Electronic resource]. Hodder \& Stoughton. http://auckland.lib.overdrive.com/ ContentDetails.htm?ID=6ECFE41B5E99-44FC-9470-8BA8C899F757

Subject: Define Hero, Develop Character-Arc.

Format: Physical \& E-Book.

Audience: Novice.

Useful things: Case Study, Exercises.

Branton believes that the character arc is the real narrative development in any story. Moreover, characterisation and narrative are intertwined as the narrative follows the character-arc closely and that the journey defines a character (Branton, 2013). Therefore, a character starts in one emotional state, or situation, and completely reverses that by the end of the story. Branton's manual provides ample exercises and case studies for the screenwriter. The manual is easy to navigate. However, the solutions, or questions posed to the screenwriter, are simplistic and does not give a comprehensive set of solutions for all characterisation problems.

Brooks, L., \& Hauge, M. (2015). Story fix: Transform your novel from broken to brilliant. Writer's Digest Books.

Subject: Define Hero, Develop Character-Arc, Create Stakes, Create Conflict.

Format: Physical \& E-Book.

Audience: Intermediate.

Useful things: Case Study, Exercises.

Brooks believes there are two reasons why a story does not work: the story concept is not strong enough; and, or, the delivery of the story is ineffective (Brooks \& Hauge, 2015). This manual is a study in revising the concept and the delivery and honing the screenwriter's analytical skills in identifying where a narrative has failed, and the process of fixing it. Brooks believes that conflict is at the heart of a good story, and that means having characters with purpose, which is achieved by a screenwriter 
creating dramatic tension. Dramatic tension is when the hero's goals, or quest, is in jeopardy by other characters, or an antagonistic force. Therefore, increasing audience empathy with the character. Additionally, there are three dimensions to character: backstory, the hero's world view, and the decisions the hero makes under tension. This manual is a laid out, and direct to the point, and easily readable, which makes it a reliably useful tool to any screenwriter.

Callaghan, D. (2012). Script tease: Today's hottest screenwriters bare all. Adams Media. Subject: Define Hero, Develop Character-Arc, Create Stakes, Create Conflict.

Format: Physical.

Audience: Novice.

Useful things: Case Study.

Callaghan's manual is a collection of interviews from sessions held for the writer's guild of America and include: Darren Aronofsky, Sofia Coppola, Elmore Leonard and many more (Callaghan, 2012). The book provides some insight into characterisation, but there is no continuity to the questions Callaghan asks, so there are varying degrees of answers from the interviewees. The interview snippets on each guest speaker are also concise. An exciting light read for those interested in the interviewees. However, the manual lacks the necessary sections on characterisation. Moreover, there is a lack of finding aids to help a screenwriter navigate the interviews to find answers to specific questions.

Chamberlain, J. (2016). The nutshell technique: Crack the secret of successful screenwriting (First edition) [Electronic resource]. University of Texas Press. http://samples.overdrive.com/?crid=e97d148d- 9672-4113-be10fc5de8d4393f\&.epub-sample.overdrive.com

Subject: Define Hero, Develop Character-Arc, Create Stakes, Create Conflict.

Format: E-Book. 
Audience: Novice.

Useful things: Case Study, Exercises, Diagrams.

Chamberlain argues that most scripts fail because screenwriters base their narration on a situation rather than a story (Chamberlain, 2016b). Additionally, it is the use of reversals, in which a character's path leads one way and then completely turns around. Therefore, making the story less predictable and more entertaining. Screenwriters can use the nutshell technique as a worksheet to identify their hero and eight essential story elements required for that protagonist. The manual uses case studies different type of protagonist and the story elements that a screenwriter needs to include for the hero to progress with their character arc. The manual is straight to the point with what a screenwriter is required to do to have a satisfying story and interesting characters.

Chitlik, P. (2013). Rewrite: A step-by-step guide to strengthen structure, characters, and drama in your screenplay (Second edition). Michael Wiese Productions.

Subject: Define Hero, Develop Character-Arc, Create Stakes, Create Conflict.

Format: Physical.

Audience: Novice.

Useful things: Case Study, Exercises, Diagrams.

Chitlik believes in matching the character with the premise or dramatic theme (Chitlik, 2013). The character needs a goal to drive the story. Chitlik demonstrates how characters can be more three dimensional with fatal flaws that stop them from reaching their goals. Therefore, to develop a good character-arc, the audience needs to follow the hero in attaining, or not, their intended purpose. Chitlik provides a detailed checklist for the screenwriter to create a good character arc. Moreover, there is a checklist for a screenwriter to create tension and conflict. The book is well used in US film schools and is a practical manual for revealing the hidden structures in scenes, stories, characters, and scripts. 
Coleman, J. J., \& Peditto, P. (2012). Writing screenplays. Self-Counsel Press.

Subject: Define Hero, Develop Character-Arc.

Format: Physical.

Audience: Novice.

Useful things: Case Study, Exercises.

Coleman \& Peditto focus on something mostly absent from other manuals which are creating characters that are sympathetic and unsympathetic to the audience (Coleman $\&$ Peditto, 2012). A hero, at the beginning of the script, can be un-sympathetic, and through the course of their character journey become very sympathetic, and vice versa. This book offers insight into creating antiheroes. Furthermore, the manual provides insights into creating fleshed-out characters with an exciting character-arc for the audience to follow. This manual includes worksheets that get a screenwriter thinking about their characters, and for revising their overall character-arc. Coleman \& Peditto cover most aspects of screenwriting from creating ideas to selling the story. Lastly, these manuals emphasis on feedback illustrates that a second opinion is also crucial in crafting and finalising a script.

Corbett, D. (2013). The art of character: Creating memorable characters for fiction, film, and $T V$.

Subject: Define Hero, Develop Character-Arc, Create Stakes, Create Conflict.

Format: Physical.

Audience: Novice.

Useful things: Case Study, Exercises.

Corbett offers a plethora of exercises on characterisation. Additionally, this manual covers every detail to creating characters, to formatting the script, and what to include in describing the character (Corbett, 2013). Furthermore, this manual is easy to read and comprehend for and level of the screenwriter. Moreover, Corbett satisfyingly covers all aspects of defining a character, developing character-arc, and raising the 
stakes for a character, and creating conflict. The exercises are beneficial, and the depth of discussion on characterisation in scripts is impressive, considering that Corbett designed the format for better readability.

Corder, N. (2014). Creating convincing characters. Compass Books.

Subject: Define Hero, Develop Character-Arc, Create Conflict.

Format: Physical.

Audience: Novice.

Useful things: Case Study, Exercises.

Corder offers an excellent introductory overview into creating characters for creative writing which a screenwriter can use. Corder provides and end of chapter summary and set of exercises for the writer to practice what they have learned in each chapter. On account of this, the screenwriter can practice their craft. However, more could be done in solving particular characterisation problems found in scripts. One of the most exciting aspects of Corder's manual is the treatment of info-dumping and the use of psychological profiles. Corder advises the screenwriter to slowly reveal character rather than info-dumping everything about that character in one scene (Corder, 2014). Furthermore, the psychological profiles, help provide a more convincing character with ticks, and traits, that are interesting and may play a part in the overall narrative of the script.

Cowgill, L. J. (2008). The art of plotting: How to add emotion, excitement, and depth to your writing [Electronic resource]. Back Stage Books.

http://excerpts.cdn.overdrive.com/FormatType- 410/0111-1/406/071/7B/ ArtofPlottingAddEmotionSuspenseandDep9780307875136.epub

Subject: Define Hero, Develop Character-Arc, Create Stakes, Create Conflict.

Format: E-Book.

Audience: Novice. 
Useful things: Case Study.

Cowgill believes the character conflict and desire are interdependent. Therefore, knowing the character's goal is crucial to creating obstacles that prevent that character from reaching that goal. Furthermore, conflict reveals character, and this is where a screenwriter can externalise and define who the main character is, and chart their character arc (Cowgill, 2008). This manual is excellent at finding solutions to character problems and strikes a balance between plotting and characterisation. However, it could do more with exercises, so that screenwriters could use them to find problems in their scripts.

Cron, L. (2016). Story genius: How to use brain science to go beyond outlining and write a riveting novel (before you waste three years writing 327 pages that go nowhere) (First edition) [Electronic resource]. Ten Speed Press. http://samples.overdrive.com/?crid=825acba2- 5676-4cdd-b52c697102dd5a43\&.epub-sample.overdrive.com

Subject: Define Hero, Develop Character-Arc, Create Stakes.

Format: E-Book.

Audience: Novice.

Useful things: Case Study, Exercises.

Cron's manual focuses on Fiction Authorship more than screenwriting. However, the same principles and problems exist in both disciplines. Cron argues that character comes first, and plot acts as a framework for that character progression through their character-arc (Cron, 2016). Cron also touches on the issue of multiple protagonists but insists that there is always one character favoured as the main character. The manual has simple exercises at the end of each chapter prompting the writer to delve into their characters. The organisation of the manual is easy to follow and navigate. 
Cron, L. (2012). Wired for story: The writer's guide to using brain science to hook readers from the very first sentence (1st ed) [Electronic resource]. Ten Speed Press. http://excerpts.cdn.overdrive.com/FormatType- 410/0111-1/973/3AE/4B/ WiredforStoryTheWritersGuidetoUsingBr9781607742463.epub

Subject: Define Hero, Develop Character-Arc, Create Stakes, Create Conflict.

Format: E-Book.

Audience: Novice.

Useful things: Case Study, Exercises.

Cron's manual focuses on fiction authorship. However, a screenwriter can still use ideas in characterisation in their scripts. The section, in particular regarding character goals, is comprehensive and covers a lot of characterisation problems (Cron, 2012). Cron's manual is easy to navigate to exciting chapters but also generally good advice on creative writing matters. It delves into character problems and their possible solutions using exercises and case studies.

Davis, R. (2016). Creating compelling characters for film, TV, theatre and radio (2nd edition). Bloomsbury Academic.

Subject: Define Hero, Develop Character-Arc, Create Stakes, Create Conflict.

Format: Physical.

Audience: Intermediate.

Useful things: Case Study.

Davis delves into character on a writing level but also offers an understanding of how an actor interprets the script with various acting methods. It is written for the novice to understand relatively complex issues regarding characterisation in stories. It is a good starting point in understanding what shapes characters and what motivates characters to propel the story. Davis provides a manual that covers characterisation indepth and encompasses many examples of how characters move the plot. The plethora of entertaining and intriguing choices a character must make, which makes a story 
interesting. Lastly, Davis explores how screenwriters can use secondary characters to make the main character's journey more attractive to the audience (Davis, 2016).

Diamond, D., \& Weissman, D. (2019). Bulletproof: Writing scripts that don't get shot down. Michael Wiese Productions.

Subject: Define Hero, Develop Character-Arc, Create Stakes.

Format: Physical.

Audience: Novice.

Useful things: Case Study, Exercises.

Diamond \& Weissman believe a screenplay centres on the three C's: concept, character, and context (Diamond \& Weissman, 2019). The manual provides useful insights into the creative process from logline to finished script and in an easy to read format. The contents page is easy to navigate for users that are unfamiliar with film terms. It provides summary points to all the chapters in the manual. However, it does not offer a comprehensive look into solving characterisation problems. The manual promises to help maximise screenwriting talent and increase the odds of producer picking up the script. The manual provides straightforward and time-tested advice on characterisation.

Duncan, S. V. (2008). Genre screenwriting: How to write popular screenplays that sell. Continuum.

Subject: Define Hero, Develop Character-Arc, Create Stakes, Create Conflict.

Format: Physical.

Audience: Novice, Intermediate.

Useful things: Case Study, Exercises, Diagrams.

Duncan provides a comprehensive manual on the rules of genre writing: Actionadventure, thriller, sci-fi and fantasy, horror-fantasy, Romantic comedies, and popgenre (Duncan, 2008). It defines characters through the use of relationship triangles. It 
also touches on character-arc and also how it relates to subtext. Duncan treats suspense for thrillers as screenwriters can apply the same methods to other genres. An exciting book that sufficiently answers characterisation questions within the genre's Duncan mentions.

Dunnigan, B. (2019). Screenwriting is filmmaking: The theory and practice of writing for the screen. The Crowood Press.

Subject: Define Hero, Develop Character-Arc, Create Conflict.

Format: Physical.

Audience: Novice.

Useful things: Case Study, Exercises.

Dunnigan provides an excellent overview of most of the character problems that a screenwriter would encounter. The manual is easy to navigate to relevant sections such as chapters on character, structure, scene writing and dialogue, and development. Dunnigan provides exercises at the end of each chapter for convenience. It is an excellent resource for the complete novice screenwriter. Dunnigan encourages the screenwriter to find their voice and incorporate their beliefs in their writing (Dunnigan, 2019). The most important sections this manual gives is on subtext and how characters can be revealed by what they say, and do not say. Secondly, the manual provides insight on how to keep a script visually appealing through the use of words rather than intellectual exercises more commonly associated with novel writing.

Edelstein, L. N. (2004). The writer's guide to character traits: Includes profiles of human behaviors and personality types. Writer's Digest ; David \& Charles.

Subject: Define Hero, Develop Character-Arc, Create Stakes, Create Conflict.

Format: Physical.

Audience: Intermediate. 
Useful things: Case Study.

Edelstein studies character traits in-depth to provide screenwriters with the tools to create convincing characters. Edelstein delves into criminal types, sexual issues, relationships, family, past trauma, body disorders, influences, career choices, and physical appearances (Edelstein, 2004). This manual is useful for developing empathy in a character, or hero. Additionally, this manual can help create a vile antagonist, and give convincing character traits that explain why that character is a villain. Edelstein's manual is comprehensive and exciting for screenwriters wanting to develop their character and engage the audience with exciting character traits and backstory. On account of this, navigating is made more comfortable with the detailed index.

Egri, L. (2009). The art of dramatic writing: Its basis in the creative interpretation of human motives. Wildside $\mathrm{P}$

Subject: Define Hero, Develop Character-Arc, Create Conflict.

Format: Physical \& E-Book.

Audience: Intermediate.

Useful things: Case Study, Exercises.

Egri believes that all good writing stems from human motives. Therefore, characterisation is essential to novels and screenplays. Egri covers all aspects of characterisation: physiology, sociology, psychology. Additionally, Egri believes that a screenwriter can reveal a character-arc through conflict, and decisions on how to handle that conflict (Egri, 2009). Egri focuses on literary and writing for plays rather than screenwriting.

Moreover, the case studies, and examples, come from a literary and theatrical background and can be jarring for a screenwriter that may be more familiar with films. Therefore, it would take an intermediate screenwriter to learn more from the examples given in this manual than an amateur knew to storytelling. Egri writes little to no jargon, and the contents page makes it easy to navigate to relevant sections. 
Eszterhas, J. (2006). The devil's guide to Hollywood: The screenwriter as God! (1st ed). St. Martin's Press.

Subject: Define Hero, Develop Character-Arc, Create Stakes, Create Conflict.

Format: Physical.

Audience: Novice.

Useful things: Case Study.

Eszterhas has some practical advice, and exercises, on writer's block, which could help with character development ideas. Eszterhas has an alternative take on letting the characters develop overwriting the plot, and the choices that they make should be interesting. It is better to reveal character than to have significant exposition explaining backstory; in fact, the backstory is a hindrance and not necessary (Eszterhas, 2006). He also recognises that conflict is at the heart of a compelling script. The advice he gives is almost conversational but does deliver on common problems that he has faced that a screenwriter would inevitably experience with character development.

Field, S. (2005). Screenplay: The foundations of screenwriting (Rev. ed.). Delta Trade Paperbacks.

Subject: Define Hero, Develop Character-Arc, Create Stakes, Create Conflict.

Format: Physical.

Audience: Novice.

Useful things: Case Study.

Field explores character problems in script with exercises, case studies, and diagrams to illustrates his points. The design and format prevent the screenwriter from navigating quickly to solve particular character problems unless they use index. However, Field's manual is comprehensive in exploring the problems in characterisation that a screenwriter would encounter. Field's manual centres on the three-act structure in conjunction with three sections on creating and building character, and story and character (Field, 2005). 
Fink, E. J. (2014). Dramatic story structure: A primer for screenwriters. Routledge.

Subject: Define Hero, Develop Character-Arc, Create Conflict.

Format: Physical.

Audience: Novice.

Useful things: Case Study, Exercises, Diagrams.

Fink clearly defines the main hero as the one that undergoes the most change from the start to the end of the script. Fink uses case studies from films to illustrate his point. Fink argues that a screenwriter needs to create narratives that are about an extraordinary person in an ordinary situation and an ordinary person in an extraordinary world (Fink, 2014). Additionally, Fink explores conflict and other significant character development problems and uses diagrams, case studies, and a checklist of exercises to perform. Fink's manual provides the building blocks of screenwriting but also a refresher for intermediate screenwriters.

Frey, J. N. (2010). How to write a damn good thriller: A step-by-step guide for novelists and screenwriters (1st ed). St. Martin's Press.

Subject: Define Hero, Develop Character-Arc, Create Stakes, Create Conflict.

Format: Physical.

Audience: Novice.

Useful things: Case Study.

According to Frey, a good character is one that has an impossible task and the wit to overcome it (Frey, 2010). Additionally, a character should stand to lose a lot if they cannot overcome their obstacles, and a ticking clock to compound tension in a story. Furthermore, the hero must face a moral dilemma at every turn to demonstrate the complexity of the character. Frey's manual is easy to navigate and have exciting sections for screenwriters interested in developing both character and plot specifically for crime thrillers. However, it could benefit from exercises. 
Gaines, T. (2017). So you want to write a screenplay: A step-by-step guide to writing for film, video, and television. Atlantic Publishing Group, Inc.

Subject: Develop Character Arc.

Format: Physical.

Audience: Novice.

Useful things: Case Study, Diagrams.

Gaines provides casual insight into writing characters and its aimed primarily at teen screenwriters looking to making a script. However, it is written and is easily accessible language. The case study and exercises do provide an opportunity to expand. However, the book is more about raising awareness of specific character development problems such as making secondary characters more interesting than the hero and how character arc works (Gaines, 2017). It sufficiently tells a young screenwriter was is needed to get started but hardly suitable for an intermediate or professional screenwriter.

Gallo, G. (2012). The screenwriter's compass: Character as true North. Focal Press. Subject: Define Hero, Develop Character-Arc, Create Stakes, Create Conflict.

Format: Physical.

Audience: Novice.

Useful things: Case Study.

Gallo believes that the audience is not seduced by plot but by characters (Gallo, 2012b). Subsequently, Gallo believes that character development problems are tied to plot problems. Gallo provides case studies on how to structure a script. However, this manual does not have enough exercises for a writer to work out complex character development-problems. 
Garant, R. B., \& Lennon, T. (2011). Writing movies for fun and profit! How we made a billion dollars at the box office and you can, too! Touchstone.

Subject: Define Hero, Develop Character-Arc, Create Stakes, Create Conflict.

Format: Physical.

Audience: Intermediate.

Useful things: Case Study.

Garant and Lennon advise on how to be successful in screenwriting and attract attention from producers (Garant \& Lennon, 2011). However, the manual's format is more akin to reading a magazine, and navigating through the book is cumbersome at times. Garant and Lennon delve into characterisation problems briefly but not sufficiently enough for a screenwriter with serious characterisation problems in their script.

Gilford, J. (2015). Why does the screenwriter cross the road? + other screenwriting secrets. Michael Wiese Productions.

Subject: Define Hero, Develop Character-Arc, Create Conflict.

Format: Physical.

Audience: Novice.

Useful things: Case Study, Exercises.

Gilford talks about character arc as being the plot. The character both enters an unfamiliar world or learns a less by the end of it, which sums up what character arc is for a screenwriter (Gilford, 2015). Additionally, Gilford provides exercises for the screenwriter to follow to help develop a better character arc in their scripts. This manual is for teachers, students, and screenwriters. Furthermore, Gilford provides exercises for screenwriters to overcome writer's block, and how to manage self-doubt that prevents scripts from being finished. 
Grace, J. (2013). Directing your destiny: How to become the writer, producer, and director of your dreams (1st edition). Hay House, Inc.

Subject: Develop Character-Arc.

Format: Physical.

Audience: Novice.

Useful things: Exercises.

Grace's manual explores the mental process, awareness, and wellbeing of a writer or filmmaker. Grace provides tips for screenwriters to turn their writing into a lifestyle and to build mental resilience and motivation, and momentum to write and produce a script (J. Grace, 2013). Grace does briefly mention character-arc but only in one sentence. However, Grace's manual is crucial for developing the screenwriter's motivation and positive thinking in overcoming doubt that faces every screenwriter.

Grace, Y. (2014). Writing for television: Series, serials and soaps. Kamera Books, an imprint of Oldcastle Books.

Subject: Develop Character-Arc.

Format: Physical.

Audience: Novice.

Useful things: Exercises.

Grace has a short checklist, short paragraphs, of essential things to think about when writing bout character but does not delve into specifics. However, the book is a fantastic overview of the writing process. Grace demonstrates how storylines are interwoven but not necessarily a fantastic book in regards to solving character development problems (Y. Grace, 2014). However, the manual details Grace's experience in networking with key people and skills a screenwriter needs to develop to thrive in a fast-paced industry. 
Grove, E. (2009). Beginning filmmaking: 100 easy steps from script to screen (1st ed). Methuen Drama.

Subject: Define Hero, Develop Character-Arc, Create Conflict.

Format: Physical.

Audience: Novice.

Useful things: Exercises.

Grove gives a comprehensive overview of filmmaking to introduce concepts to filmmakers (Grove, 2009). There is a small section dedicated to screenwriting that dives into characterisation. However, they are more prompts to get a complete novice to think about characterisation. Although there are some exercises to help the screenwriter to come up with solutions, and to begin writing, they are not of the quality or quantity expected in a screenwriting manual. Moreover, the manual is fundamental and more informative of the entire process of filmmaking that on the craft of screenwriting.

Hauge, M. (2011). Writing screenplays that sell (New twentieth anniversary ed). Methuen Drama.

Subject: Define Hero, Develop Character-Arc, Create Stakes, Create Conflict.

Format: Physical.

Audience: Novice.

Useful things: Case Study, Exercises, Diagrams.

Hauge has an interesting take in that a character flaw could play as the main obstacle to achieving a story goal. Hauge also details how a screenwriter gets the audience to empathise with a character by putting them in jeopardy. Hauge also demonstrates that a protagonist needs inner motivation for every action or in-action they have. Hauge gives case studies to illustrate how conflict is made either by the character or other supporting characters. Therefore, a character must have outer motivation and conflict to create a definable character that an audience can follow (Hauge, 2011). Hauge's 
manual is suitable for the intermediate screenwriter interested in re-learning crucial characterisation points.

Hay, L. V. (2017). Writing diverse characters for fiction, TV or film [Electronic resource]. Kamera Books. https://samples.overdrive.com/?crid=a4f88304-2f10-45c3-abfd269b4df98fce\&.epub-sample.overdrive.com

Subject: Define Hero, Develop Character-Arc, Create Stakes, Create Conflict.

Format: E-Book.

Audience: Novice.

Useful things: Case Study, Exercises.

Hay talks about diversity in television and film and the inclusion of different ethnicities and religions in screenwriting. Hay defines good characterisation as characters having flaws and complications regardless of their diverse background (Hay, 2017). Hay believes that good characters do not have to change like characters that inspire other characters to change but not necessarily the hero of the story. In general, this manual is excellent at identifying stereotypes, tropes, and cliches. Furthermore, this manual is a good start for any novice screenwriter has it explains why they exist and how to subvert expectations.

Howard, D. (2005). How to build a great screenplay: A master class in storytelling for film. Souvenir.

Subject: Define Hero, Develop Character-Arc, Create Stakes, Create Conflict.

Format: Physical.

Audience: Novice.

Useful things: Case Study.

Howard's approach is to tie the theme of the screenplay closely with the hero; in other words, the theme defines the hero. It mentions that whatever weakness is inherent in the hero, are flaws that are exploited by the antagonist or strengths that they possess, 
which create conflict. Howard also explains how tension captures audience attention and retains it through the story (Howard, 2005). It provides examples of how to overcome problems with tension, conflict, and stakes through case studies of other films. Howard asks the questions of where the hero should be by the end of the film to create and convincing character arc. Pivotal actions can be as simple as decisions, and this is what involves an audience to care about the character development in the story. Howard's book delves deeply into all facets of the screenplay, and character development is no exception.

Hoxter, J. (2011). Write what you don't know: An accessible manual for screenwriters. Continuum.

Subject: Define Hero, Develop Character-Arc, Create Stakes, Create Conflict.

Format: Physical.

Audience: Novice.

Useful things: Case Study, Diagrams.

Hoxter covers many relevant topics to screenwriters, such as gathering ideas, cinematic storytelling, the writing process, and character development. Hoxter offers an alternative to just using checklists and background exercises as it becomes irrelevant if the character does not match up with the cinematic theme. Therefore, it is better to come up with a theme that will oppose the character (Hoxter, 2011). Hoxter provides a few generic choices and action that a hero and a villain or antihero will make during their character arc, which could be useful to the screenwriter.

Hurbis-Cherrier, M., \& Rabiger, M. (2013). Directing: Film techniques and aesthetics $\left(5^{\text {th }}\right.$ ed). Focal Press.

Subject: Define Hero, Develop Character-Arc, Create Stakes, Create Conflict.

Format: Physical.

Audience: Novice. 
Useful things: Case Study, Diagrams.

Hurbis-Cherrier \& Rabiger have crafter a manual that is comprehensive from gathering ideas to writing the script, to planning production, post-production (HurbisCherrier \& Rabiger, 2013). In terms of scriptwriting, it covers most facets of screenwriting, including all of the character development problems of defining, character-arc, stakes, and conflict. A must-read for any screenwriter and it is easy to use and in a logical arrangement.

Iglesias, K. (2005). Writing for emotional impact: Advanced dramatic techniques to attract, engage, and fascinate the reader from beginning to end (1st ed). WingSpan Press.

Subject: Define Hero, Develop Character-Arc, Create Stakes, Create Conflict.

Format: Physical.

Audience: Novice.

Useful things: Case Study.

Iglesias cares more about the emotional impact a script can have than the usual by the numbers script development process provided in most screenwriting manuals. In character development chapter, Iglesias talks about character flaw as a need that should be fulfilled, or not, by the end, which creates character arc. Including what is at stake for the hero if they fail and Iglesias provides case studies to show how character wants and needs can develop character arc, tension, and stakes. It also delves into how to make a character appealing through the use of being recognisable, fascinating, and being a mystery, which usually captures an audience (Iglesias, 2005). Iglesias Manual is an easy read and covers the basics, and also the norm for professional screenwriters.

Indick, W. (2004). Psychology for screenwriters: Building conflict in your script. Michael Wiese Productions.

Subject: Define Hero, Develop Character-Arc, Create Stakes, Create Conflict.

Format: Physical. 
Audience: Intermediate.

Useful things: Case Study, Exercises, Diagrams.

Indick uses notable figures in psychology: Freud, Erikson, and Jung and other notable figures to explain the psychology behind constructing characters and creating conflict (Indick, 2004). Indick uses the neurotic complex to explore a character's inner and outer conflict. Additionally. An exciting read for the novice screenwriter to delve more profound than any other book on externalising the inner workings of a character, and developing a deeper understanding of how to form such complex characters. Indick addresses most of the character development problems with such depth that this manual might be more suitable for an advanced screenwriter.

Johnson, C. (2010). Crafting short screenplays that connect (3rd ed., rev.expanded). Focal Press.

Subject: Define Hero, Develop Character-Arc.

Format: Physical.

Audience: Novice.

Useful things: Case Study, Exercises.

Johnson believes that connection and compassion are crucial in developing unique, three-dimensional characters (Johnson, 2010). Johnson does not give an analysis of how to overcome character problems. Johnson designs this manual as a learning aid for students and novice screenwriters.

Johnson, C., \& Stevens, M. (2002). Script partners: What makes film and TV writing teams work. Michael Wiese Productions.

Subject: Define Hero, Develop Character-Arc.

Format: Physical.

Audience: Novice.

Useful things: Case Study. 
Johnson \& Stevens delve into character conflict by using case studies from movies (Johnson \& Stevens, 2002). Although the manual centres on co-creating characters, it still offers insight on how to write for actors as well. However, the manual is more about relationships in collaborating than a detail exploration on characterisation in scripts.

Klick, T. (2016). Beat by beat: A cheat sheet for screenwriters. Michael Wiese Productions. Subject: Define Hero, Develop Character-Arc, Create Stakes, Create Conflict.

Format: Physical.

Audience: Intermediate.

Useful things: Case Study, Exercises, Diagrams.

Klick organises sections that follow a four-act structure and lists the requirements for each act. It provides a comprehensive checklist for a screenwriter to keep track of essential beats in the story that are crucial for a coherent script. Its emphasis on a visual checklist is constructive for a writer to navigate and consume information, especially in a pinch. It uses six different movies: Skyfall, Avengers, Hangover, Beautiful Mind, Conjuring, and Gone Girl (Klick, 2016). Klick tackles all character development problems and emphasises the visual form.

Kress, N. (2005). Characters, emotion, \& viewpoint: Techniques and exercises for creating dynamic characters and effective viewpoints (1st ed). Writer's Digest Books.

Subject: Define Hero, Develop Character-Arc, Create Conflict.

Format: Physical.

Audience: Novice.

Useful things: Case Study, Exercises, Diagrams.

Kress believes that character motivation is key to the narrative structure. Kress advises the screenwriter to write characters with more than one goal. Furthermore, a screenwriter should include smaller goals that the character may want to achieve 
towards their primary objective. For example, a small goal could include repairing a character flaw, or a relationship, or getting revenge, as long as the smaller goals apply to the main objective and narrative structure (Kress, 2005). Furthermore, Kress delves into revealing information slowly through the narrative and not info-dumping exposition, which is information crucial to understanding the plot or character. This manual is a good start for a novice screenwriter in understanding how to construct characters and how to reveal their objectives naturally.

Lake, D. (2017). The screenwriter's path: From idea to script to sale. Focal Press.

Subject: Define Hero, Develop Character-Arc.

Format: E-Book.

Audience: Novice.

Useful things: Case Study, Exercises, Diagrams.

Lake believes character arc is separate from the narrative structure but closely related in the sense that the character learns from overcoming plot obstacles (Lake, 2017). Lake's manual explores a seven-step narrative structure and develops characters with this as a framework. The manual is easy to navigate and easy to read, and there are exercises available in the form of questions for the screenwriter. The manual informs the screenwriter how to pace a script, and answers why specific points in the narrative structure lag, or fail.

Landau, N. (2013). The screenwriter's roadmap: 21 ways to jumpstart your story. Focal Press.

Subject: Define Hero, Develop Character-Arc, Create Stakes, Create Conflict.

Format: Physical.

Audience: Intermediate.

Useful things: Case Study, Exercises. 
Landau's manual is very comprehensive in dealing with a character as its primary focus. The contents page is convenient, and the headings are designed for quick access for any screenwriter regardless of their working knowledge of the screenwriter's language or terminology. Landau acknowledges that there can be alternatives to the three-act structure (Landau, 2013). However, the fundamental focus of any story is on the character. It provides excellent case studies and exercises in overcoming various character development problems.

Lazarus, T. (2012). The last word: Definitive answers to all your screenwriting questions. Michael Wiese Productions.

Subject: Define Hero, Develop Character-Arc, Create Stakes, Create Conflict.

Format: Physical.

Audience: Intermediate.

Useful things: Case Study, Exercises.

Lazarus has developed a convenient manual for screenwriters. A screenwriter can look for solutions to specific problems by looking at the contents page. Lazarus' writing style is easy to follow and is organised in alphabetical order by theme. The manual is straightforward and provides some exercises for the screenwriter. It has information for a novice screenwriter to advance to more intermediate or advance. Lazarus provides advice on what producers are looking for in a script; if the screenwriter is an amateur or professional screenwriter (Lazarus, 2012). It provides adequate coverage on character development problems a screenwriter will face.

Lyons, J. (2016). Anatomy of a premise line: How to master premise and story development for writing success. Focal Press.

Subject: Define Hero, Develop Character-Arc.

Format: Physical.

Audience: Novice. 
Useful things: Case Study, Exercises, Diagrams.

Lyons provides diagrams of the passive and active protagonist loop (Lyons, 2016), which helps a screenwriter better define their character and character-arc. Lyons offers checklists in the conclusion of the manual that is helpful. However, Lyons focuses on a screenwriter's beginning phase in starting to write the premise and synopsis. However, it is still relevant in thinking about a character at these early stages.

Marlow, J. R. (2012). Make your story a movie: Adapting your book or idea for Hollywood (1st ed). St. Martin's Griffin.

Subject: Define Hero, Develop Character-Arc.

Format: Physical.

Audience: Novice.

Useful things: Case Study.

Marlow suggests that the hero must be relatable, so the audience understands their motivation but preferably be likeable or else the audience will not care about the story (Marlow, 2012). Hence, why the character is more important than the plot, or at least it shares a symbiotic relationship. Additionally, an emotionally captivating story requires stakes when a character has something to lose, which leads to the hero conflicting with either the environment or opposing characters. A screenwriter creates tension by raising the stakes of the main character or adding a ticking clock. Marlow hits all the main character development problems but fails to provide exercises for the screenwriter to learn and develop their craft.

McKee, R. (2016). Dialogue: The art of verbal action for page, stage, screen (First edition). Twelve, an imprint of Grand Central Publishing.

Subject: Define Hero, Develop Character-Arc, Create Conflict.

Format: Physical. 
Audience: Novice.

Useful things: Case Study, Exercises.

McKee believes that every character is a walking dictionary with their unique phrases and words (McKee, 2016). McKee offers solutions to creating three-dimensional characters and defining characters using dialogue as a framework. Additionally, McKee explains that there are three types of conflict: social, personal, and inner. Moreover, Social conflict derives from institutional forces. Furthermore, personal conflict arises from relationships, and inner conflict derives from the main character. Therefore, it is essential to fluctuate between the three to create exciting obstacles for the hero to overcome or not overcome. McKee's manual is a seminal work in dialogue for films. It offers comprehensive coverage in all matters of building characters through dialogue.

Munier, P. (2014). Plot Perfect: How to Build Unforgettable Stories Scene by Scene [Electronic resource]. F+W Media. http://auckland.lib.overdrive.com/ ContentDetails.htm?ID=9C683762-4FBF-49F1-9648-643934BDF270

Subject: Define Hero, Develop Character-Arc, Create Conflict.

Format: Physical \& E-Book.

Audience: Novice.

Useful things: Case Study, Exercises, Diagrams.

Munier provides a manual that is very simplistic in design and some ways content. However, the content that is there is crucial for any novice writer to understand. Additionally, Munier asks the screenwriter a series of questions to both let the screenwriter identify and characterisation problem, and also solve it. Furthermore, Munier encourages the screenwriter to ask questions about their scripts regularly (Munier, 2014). Munier covers areas of defining the hero and structuring the narrative with the character-arc to achieve a character-driven story. 
Neipris, J. (2016). A master class in dramatic writing: Theater, film, and television.

Routledge.

Subject: Define Hero, Develop Character-Arc, Create Stakes, Create Conflict.

Format: Physical.

Audience: Novice.

Useful things: Case Study.

Neipris has a short but concise look into creating complex characters by providing a checklist of questions for the screenwriter to answer for their particular character problem. Additionally, it tells a screenwriter how to show this complexity through action and interactions with other characters (Neipris, 2016). It also touches on how to raise stakes through the character journey. It also provides exercises on escalating conflicts. However, the manual shines with its section on how to rewrite to refine a script.

Nicolosi, B. R., \& Peterson, V. (2015). Notes to screenwriters: Advancing your story, screenplay, and career with whatever Hollywood throws at you. Michael Wiese Productions.

Subject: Define Hero, Develop Character-Arc.

Format: Physical.

Audience: Intermediate.

Useful things: Case Study, Exercises.

Nicolosi and Peterson explore how to create relatable characters. A screenwriter must show a hero's selfless actions to gain audience empathy and trust (Nicolosi \& Peterson, 2015). Additionally, the hero must be consistent in their drive towards a goal to be relatable and interesting.

Nicolosi and Peterson believe characterisation is complicated with a paradox and provides a checklist of the question for the screenwriter to ask themselves in regards to developing their characters. Additionally, Nicolosi and Peterson provide exercises 
such as brainstorming the choices a character can take, which could help shed light on character development problems.

Obstfeld, R. (2002). Fiction first aid: Instant remedies for novels, stories and scripts. Writer's Digest Books.

Subject: Define Hero, Develop Character-Arc, Create Stakes, Create Conflict.

Format: Physical.

Audience: Novice.

Useful things: Case Study, Exercises.

Obstfeld believes that increasing the stakes for the hero means having a goal and subtasks to achieve that goal (Obstfeld, 2002). Additionally, the hero must face unimaginable odds that the audience knows it is close to impossible to overcome. Moreover, Obstfeld believes a character does not have to be likeable. In conclusion, this manual is easy to navigate. It has finding aids inside that will help the user skip to relevant chapters or pages. Furthermore, Obstfeld asks relevant questions that are common problems in characterisation.

Patz, D. S. (2017). Write! Shoot! Edit! The complete guide to filmmaking for teens. Michael Wiese Productions.

Subject: Define Hero, Develop Character-Arc, Create Conflict.

Format: Physical.

Audience: Novice.

Useful things: Diagrams.

Patz' manual aims to deliver practicable information for teenagers to make films. An example is different strategies such as brainstorming, the use of index cards. It also provides a simple overview of character archetypes, such as the villain and the hero. However, it does touch upon how events or activities that affect a screenwriter's character should either be an emotional up or and emotional downer to show character 
arc, struggle, and resolution (Patz, 2017). Although it is primarily for short films, the principles can be applied to feature films.

Robinson, J., \& Mungovan, T. (2003). The screenplay workbook: The writing before the writing [Electronic resource]. Lone Eagle. http://auckland.lib.overdrive.com/ ContentDetails.htm?ID=DECC7971-16B0-4648-862C-A9F00653DD2C

Subject: Define Hero, Develop Character-Arc, Create Conflict.

Format: E-Book.

Audience: Novice.

Useful things: Case Study, Exercises.

Robinson and Mungovan provide a very simple and easy to use manual. The manual offers sound advice on character development and character arcs. Furthermore, Robinson \& Mungovan provide worksheets for screenwriters to use to flesh out their characters and understand what drives their actions through the narrative structure (Robinson \& Mungovan, 2003). However, the worksheets are very small and hard to look at; it would be beneficial to screenwriters if there were a PDF or a link to download. Despite this, the manual does make an effort to ask the screenwriter questions so the screenwriter can find solutions to their characterisation problems. This manual offers brilliant resources in the appendix.

Rosenfeld, J. E. (2016). Writing the intimate character: Create unique, compelling characters through mastery of point of view. Writer's Digest Books.

Subject: Define Hero, Develop Character-Arc, Create Stakes.

Format: Physical.

Audience: Intermediate.

Useful things: Case Study, Exercises. 
Rosenfeld suggests that screenwriters should put the main character in a situation that is beyond their control to create tension (Rosenfeld, 2016). Rosenfeld's manual is for authors rather than screenwriters. However, the principles of mystery, and developing the character-arc, and creating tension remain the same. The book is not easy to navigate for a novice, mostly a user not used to fictional writing jargon. However, there are essential aspects of writing, such as handling exposition, or extraneous background information to understand the narrative or character, which a screenwriter can use.

Russin, R. U., \& Downs, W. M. (2012). Screenplay: Writing the picture (2nd ed. rev. \& updated). Silman-James Press.

Subject: Define Hero, Develop Character-Arc, Create Stakes, Create Conflict.

Format: Physical.

Audience: Novice.

Useful things: Case Study, Exercises, Diagrams.

Russin \& Down's delves into character development and provides an adequate explanation into character, character arc, conflict, and stakes. Additionally, Russin and Down reference films that have done well, or not well, in developing characters (Russin \& Downs, 2012). The section on stakes is clearly defined and elaborated on, in terms of how to up the stakes. It also provides snapshots of how it would appear in an actual script which is extremely helpful to screenwriters. An exciting chapter on power and conflict provides solutions to creating conflict and developing characterarc. Russin \& Down provide advice on smaller things such as formatting that some screenwriting books leave out. Formatting is essential and usually what tells a reader, or producer if the script is worth reading.

Samaroo, M. (2015). The complete guide to writing a successful screenplay: Everything you need to know to write and sell a winning script. Atlantic Publishing Group.

Subject: Define Hero, Develop Character-Arc. 
Format: Physical.

Audience: Novice.

Useful things: Case Study, Exercises.

Samaroo has a straightforward checklist for screenwriters with character development problems (Samaroo, 2015), but fails to elaborate more on how these problems can come about and the process of overcoming them. However, Samaroo's manual is an excellent starting point in inspiring writers to start writing and thinking like a screenwriter in terms of simple things to look out for in writing. It is an efficient book aimed for screenwriters who want to make their films on an independent level.

Schimmel, J. (2014). Screenwriting behind enemy lines: Lessons from inside the studio gates. Michael Wiese Productions.

Subject: Define Hero, Develop Character-Arc, Create Stakes, Create Conflict.

Format: Physical.

Audience: Intermediate.

Useful things: Case Study, Exercises.

Schimmel offers a pragmatic look into characterisation (Schimmel, 2014). Schimmel analyses how to define a character and how a character's arc should develop over a standard three-act structure of a script. The exercises force the screenwriter to analyse a film and to identify critical elements of characterisation to figure out solutions to their character development problems.

Schmidt, V. (2012). 45 master characters: Mythic models for creating original characters (2nd ed). Writer's Digest Books.

Subject: Define Hero, Develop Character-Arc, Create Conflict.

Format: Physical.

Audience: Intermediate. 
Useful things: Exercises.

Schmidt helps writers explore character archetypes using the mythic journeys of heroes and heroines (Schmidt, 2012). The difference with this manual is that it splits up its characterisation by gender. Furthermore, Schmidt believes that the character's goal closely defines character-arc. This manual is an interesting read in terms of archetypes, and the overall design is easy to follow. However, there are terms used in there that a novice would think twice about making it hard to navigate in the contents page.

Seger, L. (2011). Writing subtext: What lies beneath. Michael Wiese Productions.

Subject: Define Hero, Develop Character-Arc, Create Stakes, Create Conflict.

Format: Physical.

Audience: Novice.

Useful things: Case Study, Exercises.

Seger deals with writing dialogue and characterisation in scripts. Moreover, Seger explores subtext: words or gestures that we see that may refer, or infer, a different meaning than the one that a screenwriter wishes to convey (Seger, 2011). Seger offers case studies and exercises for the screenwriter to help develop the use of subtext.

Selbo, J. (2008). Gardner's guide to screenplay: The rewrite. GGC Pub.

Subject: Define Hero, Develop Character-Arc, Create Stakes, Create Conflict.

Format: Physical.

Audience: Novice.

Useful things: Case Study, Exercises.

Selbo provides useful sections on the basics of rewriting and genre expectations (Selbo, 2008). Selbo delivers great coverage on characterisation and provides numerous checklists of questions, and exercises, to overcome most character development problems. The screenwriter can easily navigate through chapters or use 
the index to find solutions to their specific needs. Additionally, there are great case studies to demonstrate what Selbo is explaining as well, which is helpful.

Smethurst, W. (2016). How to write for television (7th edition). Robinson.

Subject: Define Hero, Develop Character-Arc.

Format: Physical.

Audience: Novice.

Useful things: None.

Smethurst includes an excellent section on dialogue, and the three functions it serves is to advance the story, to give information, and to reveal character (Smethurst, 2016). It tackles issues such as a script turning into melodrama. It has a checklist, but it is not exhaustive enough to help an intermediate or advance screenwriter. However, the lists are suitable for the novice screenwriter. It does offer websites as resources, as well as potential agents. However, this book is more of an overview of the entire process of filmmaking and television production than a study in character.

Smith, P. J. (2008). The power of the dark side: Creating great villains, dangerous situations, \& dramatic conflict. Michael Wiese Productions.

Subject: Define Hero, Develop Character-Arc, Create Stakes, Create Conflict.

Format: Physical.

Audience: Novice.

Useful things: Case Study.

Smith understands that conflict is at the heart of a story. Smith focuses on villains, but the screenwriter can apply the concept to any genre. Smith has a good understanding of archetypes found in antagonist and explores how a screenwriter can avoid cliches and why they work in a script. However, Smith's manual design prevents the screenwriter from effortlessly navigating the manual to solve their particular character problem. Smith provides a manual that illustrates the importance of conflict being the 
centre of a good story, and screenwriters need uncompromising characters to ensure characters are in conflict (P. J. Smith, 2008).

Snyder, B. (2005). Save the cat! The last book on screenwriting you'll ever need. Michael Wiese Productions.

Subject: Define Hero, Develop Character-Arc, Create Conflict.

Format: Physical Book, E-Book.

Audience: Intermediate.

Useful things: Case Study.

Snyder provides a transparent 15-point beat sheet on how a story is structured. He also writes the manual in a manner that asks questions to the screenwriter for them to come up with a solution to their particular script. Snyder demonstrates how to develop a character arc by using his 'transformational machine' diagram, which plots the 15point beats and when and where a character's arc encounters an emotional shift (Snyder, 2005). Snyder provides a useful checklist of questions about the hero's journey.

Steele, A., \& Gotham Writers' Workshop (Eds.). (2006). Writing movies: The practical guide to creating stellar screenplays (1st U.S. ed). Bloomsbury.

Subject: Define Hero, Create Conflict.

Format: Physical.

Audience: Novice.

Useful things: Case Study.

Steele provides exercises and uses examples from case studies to illustrate how to overcome characterisation problems. Steele says that it is better to like a character but at the very least, respect their intention, or at least find them fascinating (Steele \& Gotham Writers' Workshop, 2006). Steele recommends that the protagonist and 
antagonist need to be complex three-dimensional characters to create conflict and tension.

Street, K. L. (2013). Writing and selling crime film screenplays. Creative Essentials.

Subject: Define Hero, Develop Character-Arc, Create Stakes, Create Conflict.

Format: Physical.

Audience: Novice.

Useful things: Case Study, Exercises.

Street has dedicated her manual to the crime screenwriter and touches on many popular sub-genres within crime: whodunnit, Prison films, Gangster films, and more (Street, 2013). Street uses Joseph Campbell's mono-myth to construct the hero's journey. Additionally, using a checklist for the antihero journey. Street provides a plethora of exercises, examples, and case studies that are useful.

Sykes, C. P. (2012). How to craft a great story: Creating perfect plot and structure. Teach Yourself.

Subject: Define Hero, Create Conflict.

Format: Physical and E-Book.

Audience: Novice.

Useful things: Exercises.

Sykes provides diagrams, case studies, and exercises to illustrate his points. Sykes uses a character ladder diagram to illustrate how a character moves through their journey from one emotional state to another by the end of the script (Sykes, 2012). Sykes offers more tips on creating conflict and tension better than most manuals. Sykes succeeds in providing everything a screenwriter needs to solve complex character development problems. 
Trottier, D. (2014). The screenwriter's bible: A complete guide to writing, formatting, and selling your script (6th edition). Silman-James Press.

Subject: Define Hero, Develop Character-Arc, Create Stakes, Create Conflict.

Format: Physical.

Audience: Novice.

Useful things: Case Study.

Trottier provides a comprehensive manual on screenwriting. Trottier covers the mental process and motivation to complete a script, the technical formatting of a script to look aesthetically pleasing to a producer or filmmaker, revising a script, and how to sell it (Trottier, 2014). Trottier provides more than sufficient amount of depth in character development solutions and overall coverage of issues arising in scripts. However, Trottier does not provide exercises; instead, it raises awareness of issues and potential solutions by using questions. However, a screenwriter can efficiently traverse to relevant sections to find solutions.

Truby, J. (2007). The anatomy of story: 22 steps to becoming a master storyteller. Faber and Faber.

Subject: Define Hero, Develop Character-Arc, Create Stakes, Create Conflict.

Format: Physical \& E-Book.

Audience: Novice.

Useful things: Case Study, Exercises, Diagrams.

Truby argues that secondary characters often define great characters. Additionally, all characters serve a purpose. Therefore, a screenwriter should write all characters in a script like an interconnected web. Truby also argues that any opposition or conflict should be necessary for the growth of the character-arc (Truby, 2007). Truby's manual is well-formatted and designed to be easy to read. A screenwriter can navigate between chapters easily, and there are learning aids such as exercises, case studies, and diagrams that help a reader understand the concepts that underlie characterisation. 
Vogler, C., \& Montez, M. (2007). The writer's journey: Mythic structure for writers (3rd ed). Michael Wiese Productions.

Subject: Define Hero, Develop Character-Arc, Create Stakes, Create Conflict.

Format: Physical.

Audience: Novice.

Useful things: Case Study, Exercises, Diagrams.

Vogler is a seminal text for screenwriters as it uses Joseph Campbell's mythic structure and makes it more accessible to screenwriters (Vogler \& Montez, 2007). It gives case studies, checklists, diagrams, and exercises for novice screenwriters to explore the mythic structure. It delves into defining a character, character arc, character stakes, and conflict and more. Film studio executives, creatives, screenwriters and producers in Hollywood use Vogler's manual.

Walker, S. J. (2012). Romantic screenplays 101 [Electronic resource]. Fiction Works. http://auckland.lib.overdrive.com/ ContentDetails.htm?ID=D0961FBB-00E7-4CF6AE53-F5CEC5BCDB52

Subject: Define Hero, Develop Character-Arc, Create Conflict.

Format: E-Book.

Audience: Novice.

Useful things: Case Study, Exercises, Diagrams.

Walker analyses the principles of romantic fiction and romance's characterisation requirement. Walker recognises that there is a clear narrative progression from a romantic couple going from trust, acceptance, and permission (Walker, 2012). Walker recognises that conflict is handled differently in romance and that complication in the relationship between characters, and jealousy is a crucial device in creating conflict. Walker's account on characterisation does not seem comprehensive. However, a 
screenwriter can learn archetypes and why they are essential to this particular genre of filmmaking.

Weiland, K. M. (2017). Creating character arcs: The masterful author's guide to uniting story structure, plot, and character development [Electronic resource]. Smashwords Edition. https://samples.overdrive.com/?crid=5c0105b2- 3acb-4c91-8322c3b909acd72c\&.epub-sample.overdrive.com

Subject: Define Hero, Develop Character-Arc, Create Stakes, Create Conflict.

Format: E-book.

Audience: Novice.

Useful things: Case Study, Exercises.

Weiland offers a manual that marries story structure and character arc seamlessly. Weiland believes there are three types of character-arcs: Positive change, Flat arc, and negative change (Weiland, 2017). Firstly, Positive arc is when a character is unfulfilled and ends in triumph. The changes to the hero are positive. Secondly, the Flat arc is when a character is unchanged from the start to the end, and they usually spark change in other characters in the narrative. Lastly, negative change is the opposite of positive change. This manual is easy to follow and delves into problems with characterisation very well and offers straight to the point exercises to remedy problems.

Wendig, C. (2017). Damn fine story: Mastering the tools of a powerful narrative. Writer's Digest Books.

Subject: Define Hero, Develop Character-Arc, Create Stakes, Create Conflict.

Format: Physical.

Audience: Intermediate.

Useful things: Case Study. 
Wendig believes superficial aspects of the character are meaningless and that what is the most important is the character problem because it defines who they are (Wendig, 2017). The actions they take to solve it and provides narrative beats to answering that character problem. Moreover, both external and internal complications prevent the character from finding a solution to that character problem which creates more threedimensional characters. Therefore, complications raise the stakes on completing the journey to solving that character problem. Wendig puts together an essential overview of what to do with characterisation but also why it is necessary. Wendig presents his ideas in an entertaining and easy to consume way. However, Wendig has a poorly designed contents page. Therefore, making a screenwriter would have difficulty navigating to characterisation problems. However, this manual is perfect for the novice writer as the content is entertaining and relevant to most characterisation problems.

Yorke, J. (2014). Into the woods: How stories work and why we tell them [Electronic resource]. Penguin Books. https://samples.overdrive.com/into-the-woodsacd02d?.epub-sample.overdrive.com

Subject: Define Hero, Develop Character-Arc.

Format: Physical.

Audience: Advanced.

Useful things: Case Study, Diagrams.

Yorke examines the psychological profile of the hero. Subsequently, Yorke uses Maslow's motivational pyramid, Jungian archetypes, and Freudian Ego to explore characterisation (Yorke, 2014). It does answer a few character development problems. However, it fails to elaborate on how a screenwriter can create stakes for a character. The roadmaps provided in the appendices are extremely helpful in visually showing screenwriter is how these concepts translate in their characters. 


\section{Raising the Stakes}

Ackerman, A., Puglisi, B., \& Kaufman, C. (2013). The negative trait thesaurus: A writer's guide to character flaws (First print edition). JADD Publishing.

Subject: Define Hero, Develop Character-Arc, Create Stakes, Create Conflict.

Format: Physical.

Audience: Novice.

Useful things: Case Study, Exercises.

Ackerman argues that character flaws are just as crucial in defining a character and making them memorable (A. Ackerman et al., 2013). Character flaws are traits that can damage character relationships. Character flaws develop through the characterarc. Therefore, it is the flaws of the hero and other secondary characters that can cause conflict. Subsequently, Ackerman provides a thesaurus of character traits and behaviours and character flaws of certain characters to aid a screenwriter in forming believable, credibly, three-dimensional characters. This manual is unlike other screenwriting books as it gives a plethora of character types in detail for the screenwriter to choose and explore.

Ackerman, H. (2017). Write screenplays that sell: The Ackerman way (Revised updated edition). Tallfellow Press.

Subject: Define Hero, Develop Character-Arc, Create Stakes, Create Conflict.

Format: Physical.

Audience: Intermediate-Advanced.

Useful things: Case Study, Exercises, Diagrams.

Ackerman demonstrates how a screenwriter introduces a character to the audience by actions, such as introducing them through a scene showing their occupation $(\mathrm{H}$. Ackerman, 2017). It provides examples of how to overcome character and narrative problems by using scene-cards to map out how a character grows and drives the 
narrative. It also provides exercises for the screenwriter to practice their craft. Ackerman also answers frequently asked questions a screenwriter by exploring why a screenwriter writes or does not write. Additionally, this manual offers a glimpse into the practicality of generating ideas by using scene, or index cards, to create an exciting scene.

Alderson, M., \& Rosenfeld, J. E. (2015). Writing deep scenes: Plotting your story scene by scene through action, emotion, and theme [Electronic resource]. Writer's Digest. http://samples.overdrive.com/?crid=72bc4d2e- ec05-44f1-832f49f366150333\&.epub-sample.overdrive.com

Subject: Define Hero, Develop Character-Arc, Create Stakes, Create Conflict.

Format: Physical \& E-Book.

Audience: Novice.

Useful things: Case Study, Exercises.

Alderson \& Rosenfeld believes that character problem must propel the hero to achieving a concrete goal which leads to smaller goals (Alderson \& Rosenfeld, 2015). Moreover, a character can change how they achieve smaller goals to complete their primary objective. The book is not easy to navigate and requires the screenwriter to flip through pages to find relevant chapters. However, the manual is logical and easy to read and provides plenty of case studies and exercises for the screenwriter.

Aronson, L. (2010). The 21 st century screenplay: A comprehensive guide to writing tomorrow's films. Allen \& Unwin.

Subject: Define Hero, Develop Character-Arc, Create Conflict.

Format: Physical.

Audience: Novice.

Useful things: Case Study, Diagrams. 
Aronson provides obvious development strategies and explores these strategies with exercises which are helpful for character development problems inherent in a screenwriter's script. Additionally, Aronson has visual strategies and checklists on how to create and develop ideas when a screenwriter has writer's block. It provides conventional and alternative methods to narrative structure and how to break out of cliches. It also tackles double protagonist or ensemble casting, like no other screenwriting manual. She tackles innovative narrative designs, such as writing for an anthology film (Aronson, 2010). It is a book that can help novice and professional writers with ordering their ideas into real scripts. Furthermore, the manual aligns how to solve character problems with a strong emphasis on narrative conventions.

Bailey, S., \& Blake, M. (2013). Writing the horror movie. Bloomsbury.

Subject: Define Hero, Develop Character-Arc, Create Stakes, Create Conflict.

Format: Physical.

Audience: Novice-Intermediate.

Useful things: Case Study, Exercises.

Bailey \& Blake give direction in how to structure the character's journey but also on how to create tension through the use of 5 tropes: unease, dread, terror, horror, and disgust (Bailey \& Blake, 2013). It provides a checklist for screenwriters to check that their story is on track and writing exercises, interviews with directors and writers on horror films. The manual is an exemplar in defining the antagonist that will be a cause of conflict with a screenwriter's central character. Furthermore, it gives good advice on creating conflict, raising the stakes for the main character, and sustaining tension. Although the manual focuses on writing horror films, a screenwriter can use the same principles in different genres. The style and layout of the manual are easy to follow and navigate and has an appealing readable style.

Batty, C., \& Waldeback, Z. (2012). The creative screenwriter: Exercises to expand your craft. Methuen Drama.

Subject: Define Hero, Develop Character-Arc, Create Stakes, Create Conflict. 
Format: Physical.

Audience: Novice.

Useful things: Exercises.

Batty and Waldeback provide a useful checklist on pinpointing the main character that a story follows (Batty \& Waldeback, 2012). Additionally, Batty and Waldeback explore how screenwriters generate ideas. The manual emphasises that understanding the characters and their relationship to one another is useful in defining characters and developing their character-arc. It also provides a section on strengthening visual storytelling which is a critical element of scriptwriting. The manual offers exercises to help build solutions to character development problems.

Additionally, there are some checklists for a screenwriter to work through to develop a good character arc. The manual also provides advice post scriptwriting process of pitching an idea, or writing outlines and treatments to distribute to producers. There are extensive exercises provided at the conclusion to help with common story problems, and they list an index to direct the screenwriter to writing exercises found through the beneficial book.

Bell, J. S. (2011). Conflict \& suspense [Electronic resource]. Writers Digest Books. http://excerpts.cdn.overdrive.com/FormatType- 410/1705-1/715/9B4/61/ ElementsofFictionWritingConflictandSu9781599632759.epub

Subject: Develop Character-Arc, Create Stakes, Create Conflict.

Format: E-Book.

Audience: Intermediate.

Useful things: Exercises, Diagrams.

Bell's manual focuses on fiction-authorship. However, Bell offers tips on characterisation that a screenwriter can use. Bell provides a comprehensive look into character and conflict. Moreover, Bell also uses the narrative structure to frame characterisation and conflict and lets the screenwriter know when and where conflict 
should appear (Bell, 2011). In conclusion, this manual is useful to screenwriters as it explores conflict very well. However, more case studies could help the reader know what examples of good and bad writing in terms of characterisation are. Additionally, this manual is easy to read and easy to navigate due to the design.

Bernhardt, W., \& Bernhardt, W. (2017). Creating Character: Bringing Your Story to Life [Electronic resource]. Babylon Books. https://samples.overdrive.com/?crid=134b427a- 3b68-4522-97290a449f836c65\&.epub-sample.overdrive.com

Subject: Define Hero, Develop Character-Arc, Create Stakes, Create Conflict.

Format: Physical \& E-Book.

Audience: Novice.

Useful things: Case Study, Exercises.

Bernhardt believes all stories are character-driven, and all stories are about conflict, and all conflict develops over a character-arc (Bernhardt \& Bernhardt, 2017). This manual provides helpful exercises at the end of every chapter. Therefore, navigating each chapter for a particular characterisation problem will inevitably lead a screenwriter to exercises they can use. This manual's focus is on fiction authorship. However, a screenwriter can use this manual for screenwriting as well.

Bishop, L. S. (2016). Sell your story in a single sentence: Advice from the front lines of Hollywood. The Countryman Press, a division of W.W. Norton \& Company.

Subject: Define Hero, Create Stakes, Create Conflict.

Format: Physical.

Audience: Intermediate.

Useful things: Exercises.

Bishop talks about how the motivation of the hero, drives the story and character arc and creates conflict (Bishop, 2016). Bishop shows examples of how she initially 
writes things, and then how she would redo a section in her script. Additionally, Bishop emphasises the use of word-economy in writing loglines and screenplays. Therefore, every word counts and to be succinct as possible, which will also help identify character development problems as there is less clutter on the page. In general, the manual provides tips on character development. However, the manual is more focused on finalising and selling a script to a producer.

Brooks, L., \& Hauge, M. (2015). Story fix: Transform your novel from broken to brilliant. Writer's Digest Books.

Subject: Define Hero, Develop Character-Arc, Create Stakes, Create Conflict.

Format: Physical \& E-Book.

Audience: Intermediate.

Useful things: Case Study, Exercises.

Brooks believes there are two reasons why a story does not work: the story concept is not strong enough; and, or, the delivery of the story is ineffective (Brooks \& Hauge, 2015). This manual is a study in revising the concept and the delivery and honing the screenwriter's analytical skills in identifying where a narrative has failed, and the process of fixing it. Brooks believes that conflict is at the heart of a good story, and that means having characters with purpose, which is achieved by a screenwriter creating dramatic tension. Dramatic tension is when the hero's goals, or quest, is in jeopardy by other characters, or an antagonistic force. Therefore, increasing audience empathy with the character. Additionally, there are three dimensions to character: backstory, the hero's world view, and the decisions the hero makes under tension. This manual is a laid out, and direct to the point, and easily readable, which makes it a reliably useful tool to any screenwriter.

Callaghan, D. (2012). Script tease: Today's hottest screenwriters bare all. Adams Media.

Subject: Define Hero, Develop Character-Arc, Create Stakes, Create Conflict.

Format: Physical. 
Audience: Novice.

Useful things: Case Study.

Callaghan's manual is a collection of interviews from sessions held for the writer's guild of America and include: Darren Aronofsky, Sofia Coppola, Elmore Leonard and many more (Callaghan, 2012). The book provides some insight into characterisation, but there is no continuity to the questions Callaghan asks, so there are varying degrees of answers from the interviewees. The interview snippets on each guest speaker are also concise. An exciting light read for those interested in the interviewees. However, the manual lacks the necessary sections on characterisation. Moreover, there is a lack of finding aids to help a screenwriter navigate the interviews to find answers to specific questions.

Chamberlain, J. (2016). The nutshell technique: Crack the secret of successful screenwriting (First edition) [Electronic resource]. University of Texas Press.

http://samples.overdrive.com/?crid=e97d148d- 9672-4113-be10fc5de8d4393f\&.epub-sample.overdrive.com

Subject: Define Hero, Develop Character-Arc, Create Stakes, Create Conflict.

Format: E-Book.

Audience: Novice.

Useful things: Case Study, Exercises, Diagrams.

Chamberlain argues that most scripts fail because screenwriters base their narration on a situation rather than a story (Chamberlain, 2016b). Additionally, it is the use of reversals, in which a character's path leads one way and then completely turns around. Therefore, making the story less predictable and more entertaining. Screenwriters can use the nutshell technique as a worksheet to identify their hero and eight essential story elements required for that protagonist. The manual uses case studies different type of protagonist and the story elements that a screenwriter needs to include for the hero to progress with their character arc. The manual is straight to the point with what a screenwriter is required to do to have a satisfying story and interesting characters. 
Chitlik, P. (2013). Rewrite: A step-by-step guide to strengthen structure, characters, and drama in your screenplay (Second edition). Michael Wiese Productions.

Subject: Define Hero, Develop Character-Arc, Create Stakes, Create Conflict.

Format: Physical.

Audience: Novice.

Useful things: Case Study, Exercises, Diagrams.

Chitlik believes in matching the character with the premise or dramatic theme (Chitlik, 2013). The character needs a goal to drive the story. Chitlik demonstrates how characters can be more three dimensional with fatal flaws that stop them from reaching their goals. Therefore, to develop a good character-arc, the audience needs to follow the hero in attaining, or not, their intended purpose. Chitlik provides a detailed checklist for the screenwriter to create a good character arc. Moreover, there is a checklist for a screenwriter to create tension and conflict. The book is well used in US film schools and is a practical manual for revealing the hidden structures in scenes, stories, characters, and scripts.

Corbett, D. (2013). The art of character: Creating memorable characters for fiction, film, and $T V$.

Subject: Define Hero, Develop Character-Arc, Create Stakes, Create Conflict.

Format: Physical.

Audience: Novice.

Useful things: Case Study, Exercises.

Corbett offers a plethora of exercises on characterisation. Additionally, this manual covers every detail to creating characters, to formatting the script, and what to include in describing the character (Corbett, 2013). Furthermore, this manual is easy to read and comprehend for and level of the screenwriter. Moreover, Corbett satisfyingly covers all aspects of defining a character, developing character-arc, and raising the stakes for a character, and creating conflict. The exercises are beneficial, and the 
depth of discussion on characterisation in scripts is impressive, considering that Corbett designed the format for better readability.

Cowgill, L. J. (2008). The art of plotting: How to add emotion, excitement, and depth to your writing [Electronic resource]. Back Stage Books. http://excerpts.cdn.overdrive.com/FormatType- 410/0111-1/406/071/7B/ ArtofPlottingAddEmotionSuspenseandDep9780307875136.epub

Subject: Define Hero, Develop Character-Arc, Create Stakes, Create Conflict.

Format: E-Book.

Audience: Novice.

Useful things: Case Study.

Cowgill believes the character conflict and desire are interdependent. Therefore, knowing the character's goal is crucial to creating obstacles that prevent that character from reaching that goal. Furthermore, conflict reveals character, and this is where a screenwriter can externalise and define who the main character is, and chart their character arc (Cowgill, 2008). This manual is excellent at finding solutions to character problems and strikes a balance between plotting and characterisation. However, it could do more with exercises, so that screenwriters could use them to find problems in their scripts.

Cron, L. (2016). Story genius: How to use brain science to go beyond outlining and write a riveting novel (before you waste three years writing 327 pages that go nowhere) (First edition) [Electronic resource]. Ten Speed Press. http://samples.overdrive.com/?crid=825acba2- 5676-4cdd-b52c697102dd5a43\&.epub-sample.overdrive.com

Subject: Define Hero, Develop Character-Arc, Create Stakes.

Format: E-Book.

Audience: Novice. 
Useful things: Case Study, Exercises.

Cron's manual focuses on Fiction Authorship more than screenwriting. However, the same principles and problems exist in both disciplines. Cron argues that character comes first, and plot acts as a framework for that character progression through their character-arc (Cron, 2016). Cron also touches on the issue of multiple protagonists but insists that there is always one character favoured as the main character. The manual has simple exercises at the end of each chapter prompting the writer to delve into their characters. The organisation of the manual is easy to follow and navigate.

Cron, L. (2012). Wired for story: The writer's guide to using brain science to hook readers from the very first sentence (1st ed) [Electronic resource]. Ten Speed Press. http://excerpts.cdn.overdrive.com/FormatType- 410/0111-1/973/3AE/4B/ WiredforStoryTheWritersGuidetoUsingBr9781607742463.epub

Subject: Define Hero, Develop Character-Arc, Create Stakes, Create Conflict.

Format: E-Book.

Audience: Novice.

Useful things: Case Study, Exercises.

Cron's manual focuses on fiction authorship. However, a screenwriter can still use ideas in characterisation in their scripts. The section, in particular regarding character goals, is comprehensive and covers a lot of characterisation problems (Cron, 2012). Cron's manual is easy to navigate to exciting chapters but also generally good advice on creative writing matters. It delves into character problems and their possible solutions using exercises and case studies.

Davis, R. (2016). Creating compelling characters for film, TV, theatre and radio (2nd edition). Bloomsbury Academic.

Subject: Define Hero, Develop Character-Arc, Create Stakes, Create Conflict.

Format: Physical. 
Audience: Intermediate.

Useful things: Case Study.

Davis delves into character on a writing level but also offers an understanding of how an actor interprets the script with various acting methods. It is written for the novice to understand relatively complex issues regarding characterisation in stories. It is a good starting point in understanding what shapes characters and what motivates characters to propel the story. Davis provides a manual that covers characterisation indepth and encompasses many examples of how characters move the plot. The plethora of entertaining and intriguing choices a character must make, which makes a story interesting. Lastly, Davis explores how screenwriters can use secondary characters to make the main character's journey more attractive to the audience (Davis, 2016).

De Paul, G. (2017). Bring the funny: The essential companion for the comedy screenwriter. Routledge.

Subject: Define Hero, Create Stakes, Create Conflict.

Format: Physical.

Audience: Novice.

Useful things: Case Study.

DePaul does offer solutions to character development problems. DePaul injects humour into this manual. However, this can be time-consuming. De Paul provides a necessary lesson to any screenwriter, and that is to learn scriptwriting by deconstructing or analysing existing film and scripts (De Paul, 2017). De Paul also has a section on the screenwriter and how to keep on track with writing and keep motivated to produce a final draft.

Diamond, D., \& Weissman, D. (2019). Bulletproof: Writing scripts that don't get shot down. Michael Wiese Productions.

Subject: Define Hero, Develop Character-Arc, Create Stakes. 
Format: Physical.

Audience: Novice.

Useful things: Case Study, Exercises.

Diamond \& Weissman believe a screenplay centres on the three C's: concept, character, and context (Diamond \& Weissman, 2019). The manual provides useful insights into the creative process from logline to finished script and in an easy to read format. The contents page is easy to navigate for users that are unfamiliar with film terms. It provides summary points to all the chapters in the manual. However, it does not offer a comprehensive look into solving characterisation problems. The manual promises to help maximise screenwriting talent and increase the odds of producer picking up the script. The manual provides straightforward and time-tested advice on characterisation.

Duncan, S. V. (2008). Genre screenwriting: How to write popular screenplays that sell. Continuum.

Subject: Define Hero, Develop Character-Arc, Create Stakes, Create Conflict.

Format: Physical.

Audience: Novice, Intermediate.

Useful things: Case Study, Exercises, Diagrams.

Duncan provides a comprehensive manual on the rules of genre writing: Actionadventure, thriller, sci-fi and fantasy, horror-fantasy, Romantic comedies, and popgenre (Duncan, 2008). It defines characters through the use of relationship triangles. It also touches on character-arc and also how it relates to subtext. Duncan treats suspense for thrillers as screenwriters can apply the same methods to other genres. An exciting book that sufficiently answers characterisation questions within the genre's Duncan mentions. 
Edelstein, L. N. (2004). The writer's guide to character traits: Includes profiles of human behaviors and personality types. Writer's Digest; David \& Charles.

Subject: Define Hero, Develop Character-Arc, Create Stakes, Create Conflict.

Format: Physical.

Audience: Intermediate.

Useful things: Case Study.

Edelstein studies character traits in-depth to provide screenwriters with the tools to create convincing characters. Edelstein delves into criminal types, sexual issues, relationships, family, past trauma, body disorders, influences, career choices, and physical appearances (Edelstein, 2004). This manual is useful for developing empathy in a character, or hero. Additionally, this manual can help create a vile antagonist, and give convincing character traits that explain why that character is a villain. Edelstein's manual is comprehensive and exciting for screenwriters wanting to develop their character and engage the audience with exciting character traits and backstory. On account of this, navigating is made more comfortable with the detailed index.

Eszterhas, J. (2006). The devil's guide to Hollywood: The screenwriter as God! (1st ed). St. Martin's Press.

Subject: Define Hero, Develop Character-Arc, Create Stakes, Create Conflict.

Format: Physical.

Audience: Novice.

Useful things: Case Study.

Eszterhas has some practical advice, and exercises, on writer's block, which could help with character development ideas. Eszterhas has an alternative take on letting the characters develop overwriting the plot, and the choices that they make should be interesting. It is better to reveal character than to have significant exposition explaining backstory; in fact, the backstory is a hindrance and not necessary (Eszterhas, 2006). He also recognises that conflict is at the heart of a compelling 
script. The advice he gives is almost conversational but does deliver on common problems that he has faced that a screenwriter would inevitably experience with character development.

Evenson, J. M. (2013). Shakespeare for screenwriters: timeless writing tips from the master of drama. Michael Wiese Productions.

Subject: Define Hero, Create Stakes, Create Conflict.

Format: Physical.

Audience: Intermediate.

Useful things: Case Study, Exercises.

Evenson uses Shakespeare as a framework for understanding and creating a film script. Evenson uses the psychology of Hamlet to understand how to construct a threedimensional character (Evenson, 2013). Evenson provides exercises, case studies, and a summary of the chapter, which helps screenwriters digest what they have learned in every chapter.

Fancher, H., \& Lethem, J. (2019). The wall will tell you: The forensics of screenwriting. Melville House.

Subject: Define Hero, Create Stakes, Create Conflict.

Format: Physical.

Audience: Novice.

Useful things: None.

Fancher \& Lethem have constructed a short and concise book that reveals much in its economy of words and pages (Fancher \& Lethem, 2019). It is more contemplative borderline philosophical than practical as the answer to character development problems are dispersed throughout the text in what appears to be a random order of free thought. 
Field, S. (2005). Screenplay: The foundations of screenwriting (Rev. ed.). Delta Trade Paperbacks.

Subject: Define Hero, Develop Character-Arc, Create Stakes, Create Conflict.

Format: Physical.

Audience: Novice.

Useful things: Case Study.

Field explores character problems in script with exercises, case studies, and diagrams to illustrates his points. The design and format prevent the screenwriter from navigating quickly to solve particular character problems unless they use index. However, Field's manual is comprehensive in exploring the problems in characterisation that a screenwriter would encounter. Field's manual centres on the three-act structure in conjunction with three sections on creating and building character, and story and character (Field, 2005).

Frey, J. N. (2010). How to write a damn good thriller: A step-by-step guide for novelists and screenwriters (1st ed). St. Martin's Press.

Subject: Define Hero, Develop Character-Arc, Create Stakes, Create Conflict.

Format: Physical.

Audience: Novice.

Useful things: Case Study.

According to Frey, a good character is one that has an impossible task and the wit to overcome it (Frey, 2010). Additionally, a character should stand to lose a lot if they cannot overcome their obstacles, and a ticking clock to compound tension in a story. Furthermore, the hero must face a moral dilemma at every turn to demonstrate the complexity of the character. Frey's manual is easy to navigate and have exciting sections for screenwriters interested in developing both character and plot specifically for crime thrillers. However, it could benefit from exercises. 
Gallo, G. (2012). The screenwriter's compass: Character as true North. Focal Press.

Subject: Define Hero, Develop Character-Arc, Create Stakes, Create Conflict.

Format: Physical.

Audience: Novice.

Useful things: Case Study.

Gallo believes that the audience is not seduced by plot but by characters (Gallo, 2012b). Subsequently, Gallo believes that character development problems are tied to plot problems. Gallo provides case studies on how to structure a script. However, this manual does not have enough exercises for a writer to work out complex character development-problems.

Garant, R. B., \& Lennon, T. (2011). Writing movies for fun and profit! How we made a billion dollars at the box office and you can, too! Touchstone.

Subject: Define Hero, Develop Character-Arc, Create Stakes, Create Conflict.

Format: Physical.

Audience: Intermediate.

Useful things: Case Study.

Garant and Lennon advise on how to be successful in screenwriting and attract attention from producers (Garant \& Lennon, 2011). However, the manual's format is more akin to reading a magazine, and navigating through the book is cumbersome at times. Garant and Lennon delve into characterisation problems briefly but not sufficiently enough for a screenwriter with serious characterisation problems in their script.

Hauge, M. (2011). Writing screenplays that sell (New twentieth anniversary ed). Methuen Drama.

Subject: Define Hero, Develop Character-Arc, Create Stakes, Create Conflict.

Format: Physical. 
Audience: Novice.

Useful things: Case Study, Exercises, Diagrams.

Hauge has an interesting take in that a character flaw could play as the main obstacle to achieving a story goal. Hauge also details how a screenwriter gets the audience to empathise with a character by putting them in jeopardy. Hauge also demonstrates that a protagonist needs inner motivation for every action or in-action they have. Hauge gives case studies to illustrate how conflict is made either by the character or other supporting characters. Therefore, a character must have outer motivation and conflict to create a definable character that an audience can follow (Hauge, 2011). Hauge's manual is suitable for the intermediate screenwriter interested in re-learning crucial characterisation points.

Hay, L. V. (2017). Writing diverse characters for fiction, TV or film [Electronic resource]. Kamera Books. https://samples.overdrive.com/?crid=a4f88304-2f10-45c3-abfd269b4df98fce\&.epub-sample.overdrive.com

Subject: Define Hero, Develop Character-Arc, Create Stakes, Create Conflict.

Format: E-Book.

Audience: Novice.

Useful things: Case Study, Exercises.

Hay talks about diversity in television and film and the inclusion of different ethnicities and religions in screenwriting. Hay defines good characterisation as characters having flaws and complications regardless of their diverse background (Hay, 2017). Hay believes that good characters do not have to change like characters that inspire other characters to change but not necessarily the hero of the story. In general, this manual is excellent at identifying stereotypes, tropes, and cliches. Furthermore, this manual is a good start for any novice screenwriter has it explains why they exist and how to subvert expectations. 
Horne, J. (2018). Dramatic techniques for creative writers: Turbo-charge your writing (1st ed). Method Writing.

Subject: Define Hero, Create Stakes, Create Conflict.

Format: Physical.

Audience: Novice.

Useful things: Case Study, Exercises.

Horne suggests that there are dramatic guidelines that a screenwriter must follow and that characterisation in terms of conflict and tension are interrelated (Horne, 2018). The manual provides fair use of exercises and case studies. However, the manual is not comprehensive in covering the problems of characterisation.

Howard, D. (2005). How to build a great screenplay: A master class in storytelling for film. Souvenir.

Subject: Define Hero, Develop Character-Arc, Create Stakes, Create Conflict.

Format: Physical.

Audience: Novice.

Useful things: Case Study.

Howard's approach is to tie the theme of the screenplay closely with the hero; in other words, the theme defines the hero. It mentions that whatever weakness is inherent in the hero, are flaws that are exploited by the antagonist or strengths that they possess, which create conflict. Howard also explains how tension captures audience attention and retains it through the story (Howard, 2005). It provides examples of how to overcome problems with tension, conflict, and stakes through case studies of other films. Howard asks the questions of where the hero should be by the end of the film to create and convincing character arc. Pivotal actions can be as simple as decisions, and this is what involves an audience to care about the character development in the story. Howard's book delves deeply into all facets of the screenplay, and character development is no exception. 
Hoxter, J. (2011). Write what you don't know: An accessible manual for screenwriters. Continuum.

Subject: Define Hero, Develop Character-Arc, Create Stakes, Create Conflict.

Format: Physical.

Audience: Novice.

Useful things: Case Study, Diagrams.

Hoxter covers many relevant topics to screenwriters, such as gathering ideas, cinematic storytelling, the writing process, and character development. Hoxter offers an alternative to just using checklists and background exercises as it becomes irrelevant if the character does not match up with the cinematic theme. Therefore, it is better to come up with a theme that will oppose the character (Hoxter, 2011). Hoxter provides a few generic choices and action that a hero and a villain or antihero will make during their character arc, which could be useful to the screenwriter.

Hurbis-Cherrier, M., \& Rabiger, M. (2013). Directing: Film techniques and aesthetics $\left(5^{\text {th }}\right.$ ed). Focal Press.

Subject: Define Hero, Develop Character-Arc, Create Stakes, Create Conflict.

Format: Physical.

Audience: Novice.

Useful things: Case Study, Diagrams.

Hurbis-Cherrier \& Rabiger have crafter a manual that is comprehensive from gathering ideas to writing the script, to planning production, post-production (HurbisCherrier \& Rabiger, 2013). In terms of scriptwriting, it covers most facets of screenwriting, including all of the character development problems of defining, character-arc, stakes, and conflict. A must-read for any screenwriter and it is easy to use and in a logical arrangement. 
Iglesias, K. (2005). Writing for emotional impact: Advanced dramatic techniques to attract, engage, and fascinate the reader from beginning to end (1st ed). WingSpan Press.

Subject: Define Hero, Develop Character-Arc, Create Stakes, Create Conflict.

Format: Physical.

Audience: Novice.

Useful things: Case Study.

Iglesias cares more about the emotional impact a script can have than the usual by the numbers script development process provided in most screenwriting manuals. In character development chapter, Iglesias talks about character flaw as a need that should be fulfilled, or not, by the end, which creates character arc. Including what is at stake for the hero if they fail and Iglesias provides case studies to show how character wants and needs can develop character arc, tension, and stakes. It also delves into how to make a character appealing through the use of being recognisable, fascinating, and being a mystery, which usually captures an audience (Iglesias, 2005). Iglesias Manual is an easy read and covers the basics, and also the norm for professional screenwriters.

Indick, W. (2004). Psychology for screenwriters: Building conflict in your script. Michael Wiese Productions.

Subject: Define Hero, Develop Character-Arc, Create Stakes, Create Conflict.

Format: Physical.

Audience: Intermediate.

Useful things: Case Study, Exercises, Diagrams.

Indick uses notable figures in psychology: Freud, Erikson, and Jung and other notable figures to explain the psychology behind constructing characters and creating conflict (Indick, 2004). Indick uses the neurotic complex to explore a character's inner and outer conflict. Additionally. An exciting read for the novice screenwriter to delve more profound than any other book on externalising the inner workings of a character, and developing a deeper understanding of how to form such complex characters. 
Indick addresses most of the character development problems with such depth that this manual might be more suitable for an advanced screenwriter.

Jessup, L. Z. (2014). Getting it write: An insider's guide to a screenwriting career. Michael Wiese Productions.

Subject: Define Hero, Create Stakes, Create Conflict.

Format: Physical.

Audience: Novice.

Useful things: None.

Jessup has practical advice for writers, but there is not enough to fully explain how to develop characterisation to a particular problem a screenwriter would encounter. However, the book provides tips on how to make screenwriting career, and what to expect. Additionally, Jessup offers tips on the process of starting and selling as a script than on the craft itself (Jessup, 2014). Jessup offers a practical guide on surviving a screenwriting career.

Klick, T. (2016). Beat by beat: A cheat sheet for screenwriters. Michael Wiese Productions. Subject: Define Hero, Develop Character-Arc, Create Stakes, Create Conflict.

Format: Physical.

Audience: Intermediate.

Useful things: Case Study, Exercises, Diagrams.

Klick organises sections that follow a four-act structure and lists the requirements for each act. It provides a comprehensive checklist for a screenwriter to keep track of essential beats in the story that are crucial for a coherent script. Its emphasis on a visual checklist is constructive for a writer to navigate and consume information, especially in a pinch. It uses six different movies: Skyfall, Avengers, Hangover, Beautiful Mind, Conjuring, and Gone Girl (Klick, 2016). Klick tackles all character development problems and emphasises the visual form. 
Landau, N. (2013). The screenwriter's roadmap: 21 ways to jumpstart your story. Focal Press.

Subject: Define Hero, Develop Character-Arc, Create Stakes, Create Conflict.

Format: Physical.

Audience: Intermediate.

Useful things: Case Study, Exercises.

Landau's manual is very comprehensive in dealing with a character as its primary focus. The contents page is convenient, and the headings are designed for quick access for any screenwriter regardless of their working knowledge of the screenwriter's language or terminology. Landau acknowledges that there can be alternatives to the three-act structure (Landau, 2013). However, the fundamental focus of any story is on the character. It provides excellent case studies and exercises in overcoming various character development problems.

Lazarus, T. (2012). The last word: Definitive answers to all your screenwriting questions. Michael Wiese Productions.

Subject: Define Hero, Develop Character-Arc, Create Stakes, Create Conflict.

Format: Physical.

Audience: Intermediate.

Useful things: Case Study, Exercises.

Lazarus has developed a convenient manual for screenwriters. A screenwriter can look for solutions to specific problems by looking at the contents page. Lazarus' writing style is easy to follow and is organised in alphabetical order by theme. The manual is straightforward and provides some exercises for the screenwriter. It has information for a novice screenwriter to advance to more intermediate or advance. Lazarus provides advice on what producers are looking for in a script; if the 
screenwriter is an amateur or professional screenwriter (Lazarus, 2012). It provides adequate coverage on character development problems a screenwriter will face.

McBride, J. (2012). Writing in pictures: Screenwriting made (mostly) painless. Vintage Books.

Subject: Create Stakes, Create Conflict.

Format: Physical.

Audience: Novice.

Useful things: None.

McBride believes action is character and character is conflict and conflict is the plot. Additionally, McBride believes the character does not have to be likeable. However, the character needs to drive the action and have clear motives that the audience can understand why the hero wants to accomplish their goal. McBride emphasises the use of word-economy, showing more than telling and does touch on subtext in terms of dialogue and images (McBride, 2012). Sometimes the character development problems encountered by a screenwriter have to do how they have defined character, raised the stakes, created conflict through the use of secondary characters.

Neipris, J. (2016). A master class in dramatic writing: Theater, film, and television. Routledge.

Subject: Define Hero, Develop Character-Arc, Create Stakes, Create Conflict.

Format: Physical.

Audience: Novice.

Useful things: Case Study.

Neipris has a short but concise look into creating complex characters by providing a checklist of questions for the screenwriter to answer for their particular character problem. Additionally, it tells a screenwriter how to show this complexity through action and interactions with other characters (Neipris, 2016). It also touches on how to 
raise stakes through the character journey. It also provides exercises on escalating conflicts. However, the manual shines with its section on how to rewrite to refine a script.

Obstfeld, R. (2002). Fiction first aid: Instant remedies for novels, stories and scripts. Writer's Digest Books.

Subject: Define Hero, Develop Character-Arc, Create Stakes, Create Conflict.

Format: Physical.

Audience: Novice.

Useful things: Case Study, Exercises.

Obstfeld believes that increasing the stakes for the hero means having a goal and subtasks to achieve that goal (Obstfeld, 2002). Additionally, the hero must face unimaginable odds that the audience knows it is close to impossible to overcome. Moreover, Obstfeld believes a character does not have to be likeable. In conclusion, this manual is easy to navigate. It has finding aids inside that will help the user skip to relevant chapters or pages. Furthermore, Obstfeld asks relevant questions that are common problems in characterisation.

Rosenfeld, J. E. (2016). Writing the intimate character: Create unique, compelling characters through mastery of point of view. Writer's Digest Books.

Subject: Define Hero, Develop Character-Arc, Create Stakes.

Format: Physical.

Audience: Intermediate.

Useful things: Case Study, Exercises.

Rosenfeld suggests that screenwriters should put the main character in a situation that is beyond their control to create tension (Rosenfeld, 2016). Rosenfeld's manual is for authors rather than screenwriters. However, the principles of mystery, and developing the character-arc, and creating tension remain the same. The book is not easy to navigate for a novice, mostly a user not used to fictional writing jargon. However, 
there are essential aspects of writing, such as handling exposition, or extraneous background information to understand the narrative or character, which a screenwriter can use.

Russin, R. U., \& Downs, W. M. (2012). Screenplay: Writing the picture (2nd ed. rev. \& updated). Silman-James Press.

Subject: Define Hero, Develop Character-Arc, Create Stakes, Create Conflict.

Format: Physical.

Audience: Novice.

Useful things: Case Study, Exercises, Diagrams.

Russin \& Down's delves into character development and provides an adequate explanation into character, character arc, conflict, and stakes. Additionally, Russin and Down reference films that have done well, or not well, in developing characters (Russin \& Downs, 2012). The section on stakes is clearly defined and elaborated on, in terms of how to up the stakes. It also provides snapshots of how it would appear in an actual script which is extremely helpful to screenwriters. An exciting chapter on power and conflict provides solutions to creating conflict and developing characterarc. Russin \& Down provide advice on smaller things such as formatting that some screenwriting books leave out. Formatting is essential and usually what tells a reader, or producer if the script is worth reading.

Schimmel, J. (2014). Screenwriting behind enemy lines: Lessons from inside the studio gates. Michael Wiese Productions.

Subject: Define Hero, Develop Character-Arc, Create Stakes, Create Conflict.

Format: Physical.

Audience: Intermediate.

Useful things: Case Study, Exercises. 
Schimmel offers a pragmatic look into characterisation (Schimmel, 2014). Schimmel analyses how to define a character and how a character's arc should develop over a standard three-act structure of a script. The exercises force the screenwriter to analyse a film and to identify critical elements of characterisation to figure out solutions to their character development problems.

Seger, L. (2011). Writing subtext: What lies beneath. Michael Wiese Productions.

Subject: Define Hero, Develop Character-Arc, Create Stakes, Create Conflict.

Format: Physical.

Audience: Novice.

Useful things: Case Study, Exercises.

Seger deals with writing dialogue and characterisation in scripts. Moreover, Seger explores subtext: words or gestures that we see that may refer, or infer, a different meaning than the one that a screenwriter wishes to convey (Seger, 2011). Seger offers case studies and exercises for the screenwriter to help develop the use of subtext.

Selbo, J. (2008). Gardner's guide to screenplay: The rewrite. GGC Pub.

Subject: Define Hero, Develop Character-Arc, Create Stakes, Create Conflict.

Format: Physical.

Audience: Novice.

Useful things: Case Study, Exercises.

Selbo provides useful sections on the basics of rewriting and genre expectations (Selbo, 2008). Selbo delivers great coverage on characterisation and provides numerous checklists of questions, and exercises, to overcome most character development problems. The screenwriter can easily navigate through chapters or use the index to find solutions to their specific needs. Additionally, there are great case studies to demonstrate what Selbo is explaining as well, which is helpful. 
Smith, P. J. (2008). The power of the dark side: Creating great villains, dangerous situations, \& dramatic conflict. Michael Wiese Productions.

Subject: Define Hero, Develop Character-Arc, Create Stakes, Create Conflict.

Format: Physical.

Audience: Novice.

Useful things: Case Study.

Smith understands that conflict is at the heart of a story. Smith focuses on villains, but the screenwriter can apply the concept to any genre. Smith has a good understanding of archetypes found in antagonist and explores how a screenwriter can avoid cliches and why they work in a script. However, Smith's manual design prevents the screenwriter from effortlessly navigating the manual to solve their particular character problem. Smith provides a manual that illustrates the importance of conflict being the centre of a good story, and screenwriters need uncompromising characters to ensure characters are in conflict (P. J. Smith, 2008).

Street, K. L. (2013). Writing and selling crime film screenplays. Creative Essentials.

Subject: Define Hero, Develop Character-Arc, Create Stakes, Create Conflict.

Format: Physical.

Audience: Novice.

Useful things: Case Study, Exercises.

Street has dedicated her manual to the crime screenwriter and touches on many popular sub-genres within crime: whodunnit, Prison films, Gangster films, and more (Street, 2013). Street uses Joseph Campbell's mono-myth to construct the hero's journey. Additionally, using a checklist for the antihero journey. Street provides a plethora of exercises, examples, and case studies that are useful. 
Sublett, S. W. (2014). Screenwriting for neurotics: A beginner's guide to writing a featurelength screenplay from start to finish. University of Iowa Press.

Subject: Define Hero, Create Stakes, Create Conflict.

Format: Physical.

Audience: Novice.

Useful things: Case Study.

Sublett emphasises character conflict where there is a clash of ideologies or competing goals between two or more characters. It talks about external conflict, either environment or secondary characters that oppose the hero, or inner conflict inside the hero with doubts of accomplishing their goals (Sublett, 2014). Sublet provides coverage on externalising conflict. It does well to answer all four-character development problems. However, Sublett disperses the solutions throughout the book, and the screenwriter must consult with the index to find the sections that are relevant to their specific character development problem.

Sykes, C. P. (2012). How to craft a great story: Creating perfect plot and structure. Teach Yourself.

Subject: Define Hero, Create Conflict.

Format: Physical and E-Book.

Audience: Novice.

Useful things: Exercises.

Sykes provides diagrams, case studies, and exercises to illustrate his points. Sykes uses a character ladder diagram to illustrate how a character moves through their journey from one emotional state to another by the end of the script (Sykes, 2012). Sykes offers more tips on creating conflict and tension better than most manuals. Sykes succeeds in providing everything a screenwriter needs to solve complex character development problems. 
Trottier, D. (2014). The screenwriter's bible: A complete guide to writing, formatting, and selling your script (6th edition). Silman-James Press.

Subject: Define Hero, Develop Character-Arc, Create Stakes, Create Conflict.

Format: Physical.

Audience: Novice.

Useful things: Case Study.

Trottier provides a comprehensive manual on screenwriting. Trottier covers the mental process and motivation to complete a script, the technical formatting of a script to look aesthetically pleasing to a producer or filmmaker, revising a script, and how to sell it (Trottier, 2014). Trottier provides more than sufficient amount of depth in character development solutions and overall coverage of issues arising in scripts. However, Trottier does not provide exercises; instead, it raises awareness of issues and potential solutions by using questions. However, a screenwriter can efficiently traverse to relevant sections to find solutions.

Truby, J. (2007). The anatomy of story: 22 steps to becoming a master storyteller. Faber and Faber.

Subject: Define Hero, Develop Character-Arc, Create Stakes, Create Conflict.

Format: Physical \& E-Book.

Audience: Novice.

Useful things: Case Study, Exercises, Diagrams.

Truby argues that secondary characters often define great characters. Additionally, all characters serve a purpose. Therefore, a screenwriter should write all characters in a script like an interconnected web. Truby also argues that any opposition or conflict should be necessary for the growth of the character-arc (Truby, 2007). Truby's manual is well-formatted and designed to be easy to read. A screenwriter can navigate between chapters easily, and there are learning aids such as exercises, case studies, and diagrams that help a reader understand the concepts that underlie characterisation. 
Vogler, C., \& Montez, M. (2007). The writer's journey: Mythic structure for writers (3rd ed). Michael Wiese Productions.

Subject: Define Hero, Develop Character-Arc, Create Stakes, Create Conflict.

Format: Physical.

Audience: Novice.

Useful things: Case Study, Exercises, Diagrams.

Vogler is a seminal text for screenwriters as it uses Joseph Campbell's mythic structure and makes it more accessible to screenwriters (Vogler \& Montez, 2007). It gives case studies, checklists, diagrams, and exercises for novice screenwriters to explore the mythic structure. It delves into defining a character, character arc, character stakes, and conflict and more. Film studio executives, creatives, screenwriters and producers in Hollywood use Vogler's manual.

Weiland, K. M. (2017). Creating character arcs: The masterful author's guide to uniting story structure, plot, and character development [Electronic resource]. Smashwords Edition. https://samples.overdrive.com/?crid=5c0105b2- 3acb-4c91-8322c3b909acd72c\&.epub-sample.overdrive.com

Subject: Define Hero, Develop Character-Arc, Create Stakes, Create Conflict.

Format: E-book.

Audience: Novice.

Useful things: Case Study, Exercises.

Weiland offers a manual that marries story structure and character arc seamlessly. Weiland believes there are three types of character-arcs: Positive change, Flat arc, and negative change (Weiland, 2017). Firstly, Positive arc is when a character is unfulfilled and ends in triumph. The changes to the hero are positive. Secondly, the Flat arc is when a character is unchanged from the start to the end, and they usually spark change in other characters in the narrative. Lastly, negative change is the 
opposite of positive change. This manual is easy to follow and delves into problems with characterisation very well and offers straight to the point exercises to remedy problems.

Wendig, C. (2017). Damn fine story: Mastering the tools of a powerful narrative. Writer's Digest Books.

Subject: Define Hero, Develop Character-Arc, Create Stakes, Create Conflict.

Format: Physical.

Audience: Intermediate.

Useful things: Case Study.

Wendig believes superficial aspects of the character are meaningless and that what is the most important is the character problem because it defines who they are (Wendig, 2017). The actions they take to solve it and provides narrative beats to answering that character problem. Moreover, both external and internal complications prevent the character from finding a solution to that character problem which creates more threedimensional characters. Therefore, complications raise the stakes on completing the journey to solving that character problem. Wendig puts together an essential overview of what to do with characterisation but also why it is necessary. Wendig presents his ideas in an entertaining and easy to consume way. However, Wendig has a poorly designed contents page. Therefore, making a screenwriter would have difficulty navigating to characterisation problems. However, this manual is perfect for the novice writer as the content is entertaining and relevant to most characterisation problems. 


\section{Creating Character Conflict}

Abushwesha, F. (2014). Rocliffe notes: A professional approach for screenwriters \& writerdirectors. Kamera Books.

Subject: Define Hero, Create Conflict.

Format: Physical.

Audience: Intermediate.

Useful things: Case Study, Exercises

Abushwesha interviews various filmmakers on how they approach problems with character development (Abushwesha, 2014). Moreover, this manual provides the screenwriter with multiple real-world perspectives on solving a character development problem in their script, such as defining the hero and creating conflict. It provides a checklist, exercises, and case studies to understand the ideas present in the chapters. The manual touches on various topics that are essential learning for screenwriters, such as what is the writing process, and gives tips in finding a producer. Additionally, the manual serves as a quick reference to professional writers stuck or have come across specific development problems with their characters. Furthermore, this manual offers advice on how to overcome procrastination.

Ackerman, A., Puglisi, B., \& Kaufman, C. (2013). The negative trait thesaurus: A writer's guide to character flaws (First print edition). JADD Publishing.

Subject: Define Hero, Develop Character-Arc, Create Stakes, Create Conflict.

Format: Physical.

Audience: Novice.

Useful things: Case Study, Exercises.

Ackerman argues that character flaws are just as crucial in defining a character and making them memorable (A. Ackerman et al., 2013). Character flaws are traits that can damage character relationships. Character flaws develop through the character- 
arc. Therefore, it is the flaws of the hero and other secondary characters that can cause conflict. Subsequently, Ackerman provides a thesaurus of character traits and behaviours and character flaws of certain characters to aid a screenwriter in forming believable, credibly, three-dimensional characters. This manual is unlike other screenwriting books as it gives a plethora of character types in detail for the screenwriter to choose and explore.

Ackerman, H. (2017). Write screenplays that sell: The Ackerman way (Revised updated edition). Tallfellow Press.

Subject: Define Hero, Develop Character-Arc, Create Stakes, Create Conflict.

Format: Physical.

Audience: Intermediate-Advanced.

Useful things: Case Study, Exercises, Diagrams.

Ackerman demonstrates how a screenwriter introduces a character to the audience by actions, such as introducing them through a scene showing their occupation $(\mathrm{H}$. Ackerman, 2017). It provides examples of how to overcome character and narrative problems by using scene-cards to map out how a character grows and drives the narrative. It also provides exercises for the screenwriter to practice their craft. Ackerman also answers frequently asked questions a screenwriter by exploring why a screenwriter writes or does not write. Additionally, this manual offers a glimpse into the practicality of generating ideas by using scene, or index cards, to create an exciting scene.

Alderson, M., \& Rosenfeld, J. E. (2015). Writing deep scenes: Plotting your story scene by scene through action, emotion, and theme [Electronic resource]. Writer's Digest. http://samples.overdrive.com/?crid=72bc4d2e- ec05-44f1-832f49f366150333\&.epub-sample.overdrive.com

Subject: Define Hero, Develop Character-Arc, Create Stakes, Create Conflict.

Format: Physical \& E-Book. 
Audience: Novice.

Useful things: Case Study, Exercises.

Alderson \& Rosenfeld believes that character problem must propel the hero to achieving a concrete goal which leads to smaller goals (Alderson \& Rosenfeld, 2015). Moreover, a character can change how they achieve smaller goals to complete their primary objective. The book is not easy to navigate and requires the screenwriter to flip through pages to find relevant chapters. However, the manual is logical and easy to read and provides plenty of case studies and exercises for the screenwriter.

Aronson, L. (2000). Scriptwriting updated: New and conventional ways of writing for the screen. Australian Film Television \& Radio School; Allen \& Unwin.

Subject: Define Hero, Develop Character-Arc, Create Stakes, Create Conflict.

Format: Physical.

Audience: Intermediate-Advanced.

Useful things: Case Study, Exercises, Diagrams.

Aronson has been a screenwriter for twenty years, but more importantly, she has been a script assessor and teacher (Aronson, 2000). She has a checklist for identifying who the protagonist is in the story, and it is helpful to any screenwriter to follow and answer, the questions provided to define their main character. The manual is easy to follow, and Aronson organises the manual in a user-friendly way for navigating. It has checklists, exercises, and diagrams and case studies that will illuminate most characterisation problems a screenwriter will encounter. The manual relates ideas about the character to the main beats of a three-act structure. The best part of the book is that it makes use of diagrams to follow.

Aronson, L. (2010). The 21 st century screenplay: A comprehensive guide to writing tomorrow's films. Allen \& Unwin.

Subject: Define Hero, Develop Character-Arc, Create Conflict. 
Format: Physical.

Audience: Novice.

Useful things: Case Study, Diagrams.

Aronson provides obvious development strategies and explores these strategies with exercises which are helpful for character development problems inherent in a screenwriter's script. Additionally, Aronson has visual strategies and checklists on how to create and develop ideas when a screenwriter has writer's block. It provides conventional and alternative methods to narrative structure and how to break out of cliches. It also tackles double protagonist or ensemble casting, like no other screenwriting manual. She tackles innovative narrative designs, such as writing for an anthology film (Aronson, 2010). It is a book that can help novice and professional writers with ordering their ideas into real scripts. Furthermore, the manual aligns how to solve character problems with a strong emphasis on narrative conventions.

Bailey, S., \& Blake, M. (2013). Writing the horror movie. Bloomsbury.

Subject: Define Hero, Develop Character-Arc, Create Stakes, Create Conflict.

Format: Physical.

Audience: Novice-Intermediate.

Useful things: Case Study, Exercises.

Bailey \& Blake give direction in how to structure the character's journey but also on how to create tension through the use of 5 tropes: unease, dread, terror, horror, and disgust (Bailey \& Blake, 2013). It provides a checklist for screenwriters to check that their story is on track and writing exercises, interviews with directors and writers on horror films. The manual is an exemplar in defining the antagonist that will be a cause of conflict with a screenwriter's central character. Furthermore, it gives good advice on creating conflict, raising the stakes for the main character, and sustaining tension. Although the manual focuses on writing horror films, a screenwriter can use the same principles in different genres. The style and layout of the manual are easy to follow and navigate and has an appealing readable style. 
Batty, C., \& Waldeback, Z. (2012). The creative screenwriter: Exercises to expand your craft. Methuen Drama.

Subject: Define Hero, Develop Character-Arc, Create Stakes, Create Conflict.

Format: Physical.

Audience: Novice.

Useful things: Exercises.

Batty and Waldeback provide a useful checklist on pinpointing the main character that a story follows (Batty \& Waldeback, 2012). Additionally, Batty and Waldeback explore how screenwriters generate ideas. The manual emphasises that understanding the characters and their relationship to one another is useful in defining characters and developing their character-arc. It also provides a section on strengthening visual storytelling which is a critical element of scriptwriting. The manual offers exercises to help build solutions to character development problems.

Additionally, there are some checklists for a screenwriter to work through to develop a good character arc. The manual also provides advice post scriptwriting process of pitching an idea, or writing outlines and treatments to distribute to producers. There are extensive exercises provided at the conclusion to help with common story problems, and they list an index to direct the screenwriter to writing exercises found through the beneficial book.

Bell, J. S. (2011). Conflict \& suspense [Electronic resource]. Writers Digest Books. http://excerpts.cdn.overdrive.com/FormatType- 410/1705-1/715/9B4/61/ ElementsofFictionWritingConflictandSu9781599632759.epub

Subject: Develop Character-Arc, Create Stakes, Create Conflict.

Format: E-Book.

Audience: Intermediate.

Useful things: Exercises, Diagrams. 
Bell's manual focuses on fiction-authorship. However, Bell offers tips on characterisation that a screenwriter can use. Bell provides a comprehensive look into character and conflict. Moreover, Bell also uses the narrative structure to frame characterisation and conflict and lets the screenwriter know when and where conflict should appear (Bell, 2011). In conclusion, this manual is useful to screenwriters as it explores conflict very well. However, more case studies could help the reader know what examples of good and bad writing in terms of characterisation are. Additionally, this manual is easy to read and easy to navigate due to the design.

Bennett, T. (2014). Showrunners: The art of running a TV show / Tara Bennett. Titan Books. Subject: Create Conflict.

Format: Physical.

Audience: Novice.

Useful things: Case Study.

Bennett interviews various show-runners such as Joss Whedon, Damon Lindelof, and Terence Winter (Bennett, 2014). Bennett comments on character conflict and how some tv shows have dealt with creating conflict but does not necessarily give solutions to screenwriters with their problems. However, it is still an interesting read on the process from script to screen.

Bernhardt, W., \& Bernhardt, W. (2017). Creating Character: Bringing Your Story to Life [Electronic resource]. Babylon Books. https://samples.overdrive.com/?crid=134b427a-3b68-4522-97290a449f836c65\&.epub-sample.overdrive.com

Subject: Define Hero, Develop Character-Arc, Create Stakes, Create Conflict.

Format: Physical \& E-Book.

Audience: Novice.

Useful things: Case Study, Exercises. 
Bernhardt believes all stories are character-driven, and all stories are about conflict, and all conflict develops over a character-arc (Bernhardt \& Bernhardt, 2017). This manual provides helpful exercises at the end of every chapter. Therefore, navigating each chapter for a particular characterisation problem will inevitably lead a screenwriter to exercises they can use. This manual's focus is on fiction authorship. However, a screenwriter can use this manual for screenwriting as well.

Bishop, L. S. (2016). Sell your story in a single sentence: Advice from the front lines of Hollywood. The Countryman Press, a division of W.W. Norton \& Company.

Subject: Define Hero, Create Stakes, Create Conflict.

Format: Physical.

Audience: Intermediate.

Useful things: Exercises.

Bishop talks about how the motivation of the hero, drives the story and character arc and creates conflict (Bishop, 2016). Bishop shows examples of how she initially writes things, and then how she would redo a section in her script. Additionally, Bishop emphasises the use of word-economy in writing loglines and screenplays. Therefore, every word counts and to be succinct as possible, which will also help identify character development problems as there is less clutter on the page. In general, the manual provides tips on character development. However, the manual is more focused on finalising and selling a script to a producer.

Brooks, L., \& Hauge, M. (2015). Story fix: Transform your novel from broken to brilliant. Writer's Digest Books.

Subject: Define Hero, Develop Character-Arc, Create Stakes, Create Conflict.

Format: Physical \& E-Book.

Audience: Intermediate.

Useful things: Case Study, Exercises. 
Brooks believes there are two reasons why a story does not work: the story concept is not strong enough; and, or, the delivery of the story is ineffective (Brooks \& Hauge, 2015). This manual is a study in revising the concept and the delivery and honing the screenwriter's analytical skills in identifying where a narrative has failed, and the process of fixing it. Brooks believes that conflict is at the heart of a good story, and that means having characters with purpose, which is achieved by a screenwriter creating dramatic tension. Dramatic tension is when the hero's goals, or quest, is in jeopardy by other characters, or an antagonistic force. Therefore, increasing audience empathy with the character. Additionally, there are three dimensions to character: backstory, the hero's world view, and the decisions the hero makes under tension. This manual is a laid out, and direct to the point, and easily readable, which makes it a reliably useful tool to any screenwriter.

Callaghan, D. (2012). Script tease: Today's hottest screenwriters bare all. Adams Media. Subject: Define Hero, Develop Character-Arc, Create Stakes, Create Conflict.

Format: Physical.

Audience: Novice.

Useful things: Case Study.

Callaghan's manual is a collection of interviews from sessions held for the writer's guild of America and include: Darren Aronofsky, Sofia Coppola, Elmore Leonard and many more (Callaghan, 2012). The book provides some insight into characterisation, but there is no continuity to the questions Callaghan asks, so there are varying degrees of answers from the interviewees. The interview snippets on each guest speaker are also concise. An exciting light read for those interested in the interviewees. However, the manual lacks the necessary sections on characterisation. Moreover, there is a lack of finding aids to help a screenwriter navigate the interviews to find answers to specific questions.

Chamberlain, J. (2016). The nutshell technique: Crack the secret of successful screenwriting (First edition) [Electronic resource]. University of Texas Press. 
http://samples.overdrive.com/?crid=e97d148d- 9672-4113-be10-

fc5de8d4393f\&.epub-sample.overdrive.com

Subject: Define Hero, Develop Character-Arc, Create Stakes, Create Conflict.

Format: E-Book.

Audience: Novice.

Useful things: Case Study, Exercises, Diagrams.

Chamberlain argues that most scripts fail because screenwriters base their narration on a situation rather than a story (Chamberlain, 2016b). Additionally, it is the use of reversals, in which a character's path leads one way and then completely turns around. Therefore, making the story less predictable and more entertaining. Screenwriters can use the nutshell technique as a worksheet to identify their hero and eight essential story elements required for that protagonist. The manual uses case studies different type of protagonist and the story elements that a screenwriter needs to include for the hero to progress with their character arc. The manual is straight to the point with what a screenwriter is required to do to have a satisfying story and interesting characters.

Chitlik, P. (2013). Rewrite: A step-by-step guide to strengthen structure, characters, and drama in your screenplay (Second edition). Michael Wiese Productions.

Subject: Define Hero, Develop Character-Arc, Create Stakes, Create Conflict.

Format: Physical.

Audience: Novice.

Useful things: Case Study, Exercises, Diagrams.

Chitlik believes in matching the character with the premise or dramatic theme (Chitlik, 2013). The character needs a goal to drive the story. Chitlik demonstrates how characters can be more three dimensional with fatal flaws that stop them from reaching their goals. Therefore, to develop a good character-arc, the audience needs to follow the hero in attaining, or not, their intended purpose. Chitlik provides a detailed checklist for the screenwriter to create a good character arc. Moreover, there is a 
checklist for a screenwriter to create tension and conflict. The book is well used in US film schools and is a practical manual for revealing the hidden structures in scenes, stories, characters, and scripts.

Cooper, P., \& Dancyger, K. (2005). Writing the short film (3rd ed). Elsevier/Focal Press. Subject: Define Hero, Create Conflict.

Format: Physical.

Audience: Novice.

Useful things: Case Study, Exercises.

Cooper \& Dancyger comment on behaviour defining the character from character ticks, appearance, but more importantly, on actions and motivations. It also talks about dramatic action and how that motivates character and creates stakes and conflict with the antagonist of the story (Cooper \& Dancyger, 2005). It gives various exercises for the screenwriter to learn and develop a strategy for tackling most character development problems. This manual covers the entire process of screenwriting, and although its main focus is on short film making the same principles can be applied to a feature-length film.

Corbett, D. (2013). The art of character: Creating memorable characters for fiction, film, and $T V$.

Subject: Define Hero, Develop Character-Arc, Create Stakes, Create Conflict.

Format: Physical.

Audience: Novice.

Useful things: Case Study, Exercises.

Corbett offers a plethora of exercises on characterisation. Additionally, this manual covers every detail to creating characters, to formatting the script, and what to include in describing the character (Corbett, 2013). Furthermore, this manual is easy to read and comprehend for and level of the screenwriter. Moreover, Corbett satisfyingly 
covers all aspects of defining a character, developing character-arc, and raising the stakes for a character, and creating conflict. The exercises are beneficial, and the depth of discussion on characterisation in scripts is impressive, considering that Corbett designed the format for better readability.

Corder, N. (2014). Creating convincing characters. Compass Books.

Subject: Define Hero, Develop Character-Arc, Create Conflict.

Format: Physical.

Audience: Novice.

Useful things: Case Study, Exercises.

Corder offers an excellent introductory overview into creating characters for creative writing which a screenwriter can use. Corder provides and end of chapter summary and set of exercises for the writer to practice what they have learned in each chapter. On account of this, the screenwriter can practice their craft. However, more could be done in solving particular characterisation problems found in scripts. One of the most exciting aspects of Corder's manual is the treatment of info-dumping and the use of psychological profiles. Corder advises the screenwriter to slowly reveal character rather than info-dumping everything about that character in one scene (Corder, 2014). Furthermore, the psychological profiles, help provide a more convincing character with ticks, and traits, that are interesting and may play a part in the overall narrative of the script.

Cowgill, L. J. (2008). The art of plotting: How to add emotion, excitement, and depth to your writing [Electronic resource]. Back Stage Books. http://excerpts.cdn.overdrive.com/FormatType- 410/0111-1/406/071/7B/ ArtofPlottingAddEmotionSuspenseandDep9780307875136.epub

Subject: Define Hero, Develop Character-Arc, Create Stakes, Create Conflict.

Format: E-Book. 
Audience: Novice.

Useful things: Case Study.

Cowgill believes the character conflict and desire are interdependent. Therefore, knowing the character's goal is crucial to creating obstacles that prevent that character from reaching that goal. Furthermore, conflict reveals character, and this is where a screenwriter can externalise and define who the main character is, and chart their character arc (Cowgill, 2008). This manual is excellent at finding solutions to character problems and strikes a balance between plotting and characterisation. However, it could do more with exercises, so that screenwriters could use them to find problems in their scripts.

Cron, L. (2012). Wired for story: The writer's guide to using brain science to hook readers from the very first sentence (1st ed) [Electronic resource]. Ten Speed Press. http://excerpts.cdn.overdrive.com/FormatType- 410/0111-1/973/3AE/4B/ WiredforStoryTheWritersGuidetoUsingBr9781607742463.epub

Subject: Define Hero, Develop Character-Arc, Create Stakes, Create Conflict.

Format: E-Book.

Audience: Novice.

Useful things: Case Study, Exercises.

Cron's manual focuses on fiction authorship. However, a screenwriter can still use ideas in characterisation in their scripts. The section, in particular regarding character goals, is comprehensive and covers a lot of characterisation problems (Cron, 2012). Cron's manual is easy to navigate to exciting chapters but also generally good advice on creative writing matters. It delves into character problems and their possible solutions using exercises and case studies. 
Davis, R. (2016). Creating compelling characters for film, TV, theatre and radio (2nd edition). Bloomsbury Academic.

Subject: Define Hero, Develop Character-Arc, Create Stakes, Create Conflict.

Format: Physical.

Audience: Intermediate.

Useful things: Case Study.

Davis delves into character on a writing level but also offers an understanding of how an actor interprets the script with various acting methods. It is written for the novice to understand relatively complex issues regarding characterisation in stories. It is a good starting point in understanding what shapes characters and what motivates characters to propel the story. Davis provides a manual that covers characterisation indepth and encompasses many examples of how characters move the plot. The plethora of entertaining and intriguing choices a character must make, which makes a story interesting. Lastly, Davis explores how screenwriters can use secondary characters to make the main character's journey more attractive to the audience (Davis, 2016).

De Paul, G. (2017). Bring the funny: The essential companion for the comedy screenwriter. Routledge.

Subject: Define Hero, Create Stakes, Create Conflict.

Format: Physical.

Audience: Novice.

Useful things: Case Study.

DePaul does offer solutions to character development problems. DePaul injects humour into this manual. However, this can be time-consuming. De Paul provides a necessary lesson to any screenwriter, and that is to learn scriptwriting by deconstructing or analysing existing film and scripts (De Paul, 2017). De Paul also has a section on the screenwriter and how to keep on track with writing and keep motivated to produce a final draft. 
Diamond, D., \& Weissman, D. (2019). Bulletproof: Writing scripts that don't get shot down. Michael Wiese Productions.

Subject: Define Hero, Develop Character-Arc, Create Stakes.

Format: Physical.

Audience: Novice.

Useful things: Case Study, Exercises.

Diamond \& Weissman believe a screenplay centres on the three C's: concept, character, and context (Diamond \& Weissman, 2019). The manual provides useful insights into the creative process from logline to finished script and in an easy to read format. The contents page is easy to navigate for users that are unfamiliar with film terms. It provides summary points to all the chapters in the manual. However, it does not offer a comprehensive look into solving characterisation problems. The manual promises to help maximise screenwriting talent and increase the odds of producer picking up the script. The manual provides straightforward and time-tested advice on characterisation.

Duncan, S. V. (2008). Genre screenwriting: How to write popular screenplays that sell. Continuum.

Subject: Define Hero, Develop Character-Arc, Create Stakes, Create Conflict.

Format: Physical.

Audience: Novice, Intermediate.

Useful things: Case Study, Exercises, Diagrams.

Duncan provides a comprehensive manual on the rules of genre writing: Actionadventure, thriller, sci-fi and fantasy, horror-fantasy, Romantic comedies, and popgenre (Duncan, 2008). It defines characters through the use of relationship triangles. It also touches on character-arc and also how it relates to subtext. Duncan treats suspense for thrillers as screenwriters can apply the same methods to other genres. An 
exciting book that sufficiently answers characterisation questions within the genre's Duncan mentions.

Dunnigan, B. (2019). Screenwriting is filmmaking: The theory and practice of writing for the screen. The Crowood Press.

Subject: Define Hero, Develop Character-Arc, Create Conflict.

Format: Physical.

Audience: Novice.

Useful things: Case Study, Exercises.

Dunnigan provides an excellent overview of most of the character problems that a screenwriter would encounter. The manual is easy to navigate to relevant sections such as chapters on character, structure, scene writing and dialogue, and development. Dunnigan provides exercises at the end of each chapter for convenience. It is an excellent resource for the complete novice screenwriter. Dunnigan encourages the screenwriter to find their voice and incorporate their beliefs in their writing (Dunnigan, 2019). The most important sections this manual gives is on subtext and how characters can be revealed by what they say, and do not say. Secondly, the manual provides insight on how to keep a script visually appealing through the use of words rather than intellectual exercises more commonly associated with novel writing.

Edelstein, L. N. (2004). The writer's guide to character traits: Includes profiles of human behaviors and personality types. Writer's Digest; David \& Charles.

Subject: Define Hero, Develop Character-Arc, Create Stakes, Create Conflict.

Format: Physical.

Audience: Intermediate.

Useful things: Case Study. 
Edelstein studies character traits in-depth to provide screenwriters with the tools to create convincing characters. Edelstein delves into criminal types, sexual issues, relationships, family, past trauma, body disorders, influences, career choices, and physical appearances (Edelstein, 2004). This manual is useful for developing empathy in a character, or hero. Additionally, this manual can help create a vile antagonist, and give convincing character traits that explain why that character is a villain. Edelstein's manual is comprehensive and exciting for screenwriters wanting to develop their character and engage the audience with exciting character traits and backstory. On account of this, navigating is made more comfortable with the detailed index.

Egri, L. (2009). The art of dramatic writing: Its basis in the creative interpretation of human motives. Wildside $\mathrm{P}$

Subject: Define Hero, Develop Character-Arc, Create Conflict.

Format: Physical \& E-Book.

Audience: Intermediate.

Useful things: Case Study, Exercises.

Egri believes that all good writing stems from human motives. Therefore, characterisation is essential to novels and screenplays. Egri covers all aspects of characterisation: physiology, sociology, psychology. Additionally, Egri believes that a screenwriter can reveal a character-arc through conflict, and decisions on how to handle that conflict (Egri, 2009). Egri focuses on literary and writing for plays rather than screenwriting.

Moreover, the case studies, and examples, come from a literary and theatrical background and can be jarring for a screenwriter that may be more familiar with films. Therefore, it would take an intermediate screenwriter to learn more from the examples given in this manual than an amateur knew to storytelling. Egri writes little to no jargon, and the contents page makes it easy to navigate to relevant sections. 
Eszterhas, J. (2006). The devil's guide to Hollywood: The screenwriter as God! (1st ed). St. Martin's Press.

Subject: Define Hero, Develop Character-Arc, Create Stakes, Create Conflict.

Format: Physical.

Audience: Novice.

Useful things: Case Study.

Eszterhas has some practical advice, and exercises, on writer's block, which could help with character development ideas. Eszterhas has an alternative take on letting the characters develop overwriting the plot, and the choices that they make should be interesting. It is better to reveal character than to have significant exposition explaining backstory; in fact, the backstory is a hindrance and not necessary (Eszterhas, 2006). He also recognises that conflict is at the heart of a compelling script. The advice he gives is almost conversational but does deliver on common problems that he has faced that a screenwriter would inevitably experience with character development.

Evenson, J. M. (2013). Shakespeare for screenwriters: timeless writing tips from the master of drama. Michael Wiese Productions.

Subject: Define Hero, Create Stakes, Create Conflict.

Format: Physical.

Audience: Intermediate.

Useful things: Case Study, Exercises.

Evenson uses Shakespeare as a framework for understanding and creating a film script. Evenson uses the psychology of Hamlet to understand how to construct a threedimensional character (Evenson, 2013). Evenson provides exercises, case studies, and a summary of the chapter, which helps screenwriters digest what they have learned in every chapter. 
Fancher, H., \& Lethem, J. (2019). The wall will tell you: The forensics of screenwriting. Melville House.

Subject: Define Hero, Create Stakes, Create Conflict.

Format: Physical.

Audience: Novice.

Useful things: None.

Fancher \& Lethem have constructed a short and concise book that reveals much in its economy of words and pages (Fancher \& Lethem, 2019). It is more contemplative borderline philosophical than practical as the answer to character development problems are dispersed throughout the text in what appears to be a random order of free thought.

Field, S. (2005). Screenplay: The foundations of screenwriting (Rev. ed.). Delta Trade Paperbacks.

Subject: Define Hero, Develop Character-Arc, Create Stakes, Create Conflict.

Format: Physical.

Audience: Novice.

Useful things: Case Study.

Field explores character problems in script with exercises, case studies, and diagrams to illustrates his points. The design and format prevent the screenwriter from navigating quickly to solve particular character problems unless they use index. However, Field's manual is comprehensive in exploring the problems in characterisation that a screenwriter would encounter. Field's manual centres on the three-act structure in conjunction with three sections on creating and building character, and story and character (Field, 2005).

Fink, E. J. (2014). Dramatic story structure: A primer for screenwriters. Routledge. Subject: Define Hero, Develop Character-Arc, Create Conflict. 
Format: Physical.

Audience: Novice.

Useful things: Case Study, Exercises, Diagrams.

Fink clearly defines the main hero as the one that undergoes the most change from the start to the end of the script. Fink uses case studies from films to illustrate his point. Fink argues that a screenwriter needs to create narratives that are about an extraordinary person in an ordinary situation and an ordinary person in an extraordinary world (Fink, 2014). Additionally, Fink explores conflict and other significant character development problems and uses diagrams, case studies, and a checklist of exercises to perform. Fink's manual provides the building blocks of screenwriting but also a refresher for intermediate screenwriters.

Frey, J. N. (2010). How to write a damn good thriller: A step-by-step guide for novelists and screenwriters (1st ed). St. Martin's Press.

Subject: Define Hero, Develop Character-Arc, Create Stakes, Create Conflict.

Format: Physical.

Audience: Novice.

Useful things: Case Study.

According to Frey, a good character is one that has an impossible task and the wit to overcome it (Frey, 2010). Additionally, a character should stand to lose a lot if they cannot overcome their obstacles, and a ticking clock to compound tension in a story. Furthermore, the hero must face a moral dilemma at every turn to demonstrate the complexity of the character. Frey's manual is easy to navigate and have exciting sections for screenwriters interested in developing both character and plot specifically for crime thrillers. However, it could benefit from exercises.

Gallo, G. (2012). The screenwriter's compass: Character as true North. Focal Press. Subject: Define Hero, Develop Character-Arc, Create Stakes, Create Conflict. 
Format: Physical.

Audience: Novice.

Useful things: Case Study.

Gallo believes that the audience is not seduced by plot but by characters (Gallo,

2012b). Subsequently, Gallo believes that character development problems are tied to plot problems. Gallo provides case studies on how to structure a script. However, this manual does not have enough exercises for a writer to work out complex character development-problems.

Garant, R. B., \& Lennon, T. (2011). Writing movies for fun and profit! How we made a billion dollars at the box office and you can, too! Touchstone.

Subject: Define Hero, Develop Character-Arc, Create Stakes, Create Conflict.

Format: Physical.

Audience: Intermediate.

Useful things: Case Study.

Garant and Lennon advise on how to be successful in screenwriting and attract attention from producers (Garant \& Lennon, 2011). However, the manual's format is more akin to reading a magazine, and navigating through the book is cumbersome at times. Garant and Lennon delve into characterisation problems briefly but not sufficiently enough for a screenwriter with serious characterisation problems in their script.

Gilford, J. (2015). Why does the screenwriter cross the road? + other screenwriting secrets. Michael Wiese Productions.

Subject: Define Hero, Develop Character-Arc, Create Conflict.

Format: Physical.

Audience: Novice. 
Useful things: Case Study, Exercises.

Gilford talks about character arc as being the plot. The character both enters an unfamiliar world or learns a less by the end of it, which sums up what character arc is for a screenwriter (Gilford, 2015). Additionally, Gilford provides exercises for the screenwriter to follow to help develop a better character arc in their scripts. This manual is for teachers, students, and screenwriters. Furthermore, Gilford provides exercises for screenwriters to overcome writer's block, and how to manage self-doubt that prevents scripts from being finished.

Grove, E. (2009). Beginning filmmaking: 100 easy steps from script to screen (1st ed). Methuen Drama.

Subject: Define Hero, Develop Character-Arc, Create Conflict.

Format: Physical.

Audience: Novice.

Useful things: Exercises.

Grove gives a comprehensive overview of filmmaking to introduce concepts to filmmakers (Grove, 2009). There is a small section dedicated to screenwriting that dives into characterisation. However, they are more prompts to get a complete novice to think about characterisation. Although there are some exercises to help the screenwriter to come up with solutions, and to begin writing, they are not of the quality or quantity expected in a screenwriting manual. Moreover, the manual is fundamental and more informative of the entire process of filmmaking that on the craft of screenwriting.

Hamand, M. (2009). Creative writing for dummies [Electronic resource]. Wiley. http://link.overdrive.com/?websiteID=262\&titleID=531571

Subject: Define Hero, Create Conflict.

Format: Physical \& E-Book. 
Audience: Novice.

Useful things: Exercises.

Hamand provides a manual geared more towards literary than screenwriting. However, a screenwriter can still use Hamand's principles in both disciplines. The most exciting aspect of this manual is its focus on revealing the characters through actions. However, the section on characterisation is short and is suitable for any writer regardless of ability (Hamand, 2009).

Hauge, M. (2011). Writing screenplays that sell (New twentieth anniversary ed). Methuen Drama.

Subject: Define Hero, Develop Character-Arc, Create Stakes, Create Conflict.

Format: Physical.

Audience: Novice.

Useful things: Case Study, Exercises, Diagrams.

Hauge has an interesting take in that a character flaw could play as the main obstacle to achieving a story goal. Hauge also details how a screenwriter gets the audience to empathise with a character by putting them in jeopardy. Hauge also demonstrates that a protagonist needs inner motivation for every action or in-action they have. Hauge gives case studies to illustrate how conflict is made either by the character or other supporting characters. Therefore, a character must have outer motivation and conflict to create a definable character that an audience can follow (Hauge, 2011). Hauge's manual is suitable for the intermediate screenwriter interested in re-learning crucial characterisation points.

Hay, L. V. (2017). Writing diverse characters for fiction, TV or film [Electronic resource]. Kamera Books. https://samples.overdrive.com/?crid=a4f88304-2f10-45c3-abfd269b4df98fce\&.epub-sample.overdrive.com

Subject: Define Hero, Develop Character-Arc, Create Stakes, Create Conflict. 


\section{Format: E-Book.}

Audience: Novice.

Useful things: Case Study, Exercises.

Hay talks about diversity in television and film and the inclusion of different ethnicities and religions in screenwriting. Hay defines good characterisation as characters having flaws and complications regardless of their diverse background (Hay, 2017). Hay believes that good characters do not have to change like characters that inspire other characters to change but not necessarily the hero of the story. In general, this manual is excellent at identifying stereotypes, tropes, and cliches. Furthermore, this manual is a good start for any novice screenwriter has it explains why they exist and how to subvert expectations.

Hockrow, R. (2014). Storytelling techniques for digital filmmakers: Plot structure, camera movement, lens selection, and more [Electronic resource]. Amherst Media Press. http://link.overdrive.com/?websiteID=262\& titleID=1408846

Subject: Define Hero, Create Conflict.

Format: Physical and E-Book.

Audience: Novice.

Useful things: Case Study.

Hockrow has a concise passage on character development. It illustrates the importance of character but does not delve deeply into answering questions on how to circumvent character development problems. However, it does give an overview of different types of conflict: relational, situational, inner, paranormal, cosmic, and social (Hockrow, 2014), that a story can have.

Horne, J. (2018). Dramatic techniques for creative writers: Turbo-charge your writing (1st ed). Method Writing.

Subject: Define Hero, Create Stakes, Create Conflict. 
Format: Physical.

Audience: Novice.

Useful things: Case Study, Exercises.

Horne suggests that there are dramatic guidelines that a screenwriter must follow and that characterisation in terms of conflict and tension are interrelated (Horne, 2018). The manual provides fair use of exercises and case studies. However, the manual is not comprehensive in covering the problems of characterisation.

Howard, D. (2005). How to build a great screenplay: A master class in storytelling for film. Souvenir.

Subject: Define Hero, Develop Character-Arc, Create Stakes, Create Conflict.

Format: Physical.

Audience: Novice.

Useful things: Case Study.

Howard's approach is to tie the theme of the screenplay closely with the hero; in other words, the theme defines the hero. It mentions that whatever weakness is inherent in the hero, are flaws that are exploited by the antagonist or strengths that they possess, which create conflict. Howard also explains how tension captures audience attention and retains it through the story (Howard, 2005). It provides examples of how to overcome problems with tension, conflict, and stakes through case studies of other films. Howard asks the questions of where the hero should be by the end of the film to create and convincing character arc. Pivotal actions can be as simple as decisions, and this is what involves an audience to care about the character development in the story. Howard's book delves deeply into all facets of the screenplay, and character development is no exception. 
Hoxter, J. (2011). Write what you don't know: An accessible manual for screenwriters. Continuum.

Subject: Define Hero, Develop Character-Arc, Create Stakes, Create Conflict.

Format: Physical.

Audience: Novice.

Useful things: Case Study, Diagrams.

Hoxter covers many relevant topics to screenwriters, such as gathering ideas, cinematic storytelling, the writing process, and character development. Hoxter offers an alternative to just using checklists and background exercises as it becomes irrelevant if the character does not match up with the cinematic theme. Therefore, it is better to come up with a theme that will oppose the character (Hoxter, 2011). Hoxter provides a few generic choices and action that a hero and a villain or antihero will make during their character arc, which could be useful to the screenwriter.

Hurbis-Cherrier, M., \& Rabiger, M. (2013). Directing: Film techniques and aesthetics $\left(5^{\text {th }}\right.$ ed). Focal Press.

Subject: Define Hero, Develop Character-Arc, Create Stakes, Create Conflict.

Format: Physical.

Audience: Novice.

Useful things: Case Study, Diagrams.

Hurbis-Cherrier \& Rabiger have crafter a manual that is comprehensive from gathering ideas to writing the script, to planning production, post-production (HurbisCherrier \& Rabiger, 2013). In terms of scriptwriting, it covers most facets of screenwriting, including all of the character development problems of defining, character-arc, stakes, and conflict. A must-read for any screenwriter and it is easy to use and in a logical arrangement. 
Iglesias, K. (2005). Writing for emotional impact: Advanced dramatic techniques to attract, engage, and fascinate the reader from beginning to end (1st ed). WingSpan Press.

Subject: Define Hero, Develop Character-Arc, Create Stakes, Create Conflict.

Format: Physical.

Audience: Novice.

Useful things: Case Study.

Iglesias cares more about the emotional impact a script can have than the usual by the numbers script development process provided in most screenwriting manuals. In character development chapter, Iglesias talks about character flaw as a need that should be fulfilled, or not, by the end, which creates character arc. Including what is at stake for the hero if they fail and Iglesias provides case studies to show how character wants and needs can develop character arc, tension, and stakes. It also delves into how to make a character appealing through the use of being recognisable, fascinating, and being a mystery, which usually captures an audience (Iglesias, 2005). Iglesias Manual is an easy read and covers the basics, and also the norm for professional screenwriters.

Indick, W. (2004). Psychology for screenwriters: Building conflict in your script. Michael Wiese Productions.

Subject: Define Hero, Develop Character-Arc, Create Stakes, Create Conflict.

Format: Physical.

Audience: Intermediate.

Useful things: Case Study, Exercises, Diagrams.

Indick uses notable figures in psychology: Freud, Erikson, and Jung and other notable figures to explain the psychology behind constructing characters and creating conflict (Indick, 2004). Indick uses the neurotic complex to explore a character's inner and outer conflict. Additionally. An exciting read for the novice screenwriter to delve more profound than any other book on externalising the inner workings of a character, and developing a deeper understanding of how to form such complex characters. 
Indick addresses most of the character development problems with such depth that this manual might be more suitable for an advanced screenwriter.

Jessup, L. Z. (2014). Getting it write: An insider's guide to a screenwriting career. Michael Wiese Productions.

Subject: Define Hero, Create Stakes, Create Conflict.

Format: Physical.

Audience: Novice.

Useful things: None.

Jessup has practical advice for writers, but there is not enough to fully explain how to develop characterisation to a particular problem a screenwriter would encounter. However, the book provides tips on how to make screenwriting career, and what to expect. Additionally, Jessup offers tips on the process of starting and selling as a script than on the craft itself (Jessup, 2014). Jessup offers a practical guide on surviving a screenwriting career.

Klick, T. (2016). Beat by beat: A cheat sheet for screenwriters. Michael Wiese Productions. Subject: Define Hero, Develop Character-Arc, Create Stakes, Create Conflict.

Format: Physical.

Audience: Intermediate.

Useful things: Case Study, Exercises, Diagrams.

Klick organises sections that follow a four-act structure and lists the requirements for each act. It provides a comprehensive checklist for a screenwriter to keep track of essential beats in the story that are crucial for a coherent script. Its emphasis on a visual checklist is constructive for a writer to navigate and consume information, especially in a pinch. It uses six different movies: Skyfall, Avengers, Hangover, Beautiful Mind, Conjuring, and Gone Girl (Klick, 2016). Klick tackles all character development problems and emphasises the visual form. 
Kress, N. (2005). Characters, emotion, \& viewpoint: Techniques and exercises for creating dynamic characters and effective viewpoints (1st ed). Writer's Digest Books.

Subject: Define Hero, Develop Character-Arc, Create Conflict.

Format: Physical.

Audience: Novice.

Useful things: Case Study, Exercises, Diagrams.

Kress believes that character motivation is key to the narrative structure. Kress advises the screenwriter to write characters with more than one goal. Furthermore, a screenwriter should include smaller goals that the character may want to achieve towards their primary objective. For example, a small goal could include repairing a character flaw, or a relationship, or getting revenge, as long as the smaller goals apply to the main objective and narrative structure (Kress, 2005). Furthermore, Kress delves into revealing information slowly through the narrative and not info-dumping exposition, which is information crucial to understanding the plot or character. This manual is a good start for a novice screenwriter in understanding how to construct characters and how to reveal their objectives naturally.

Landau, N. (2013). The screenwriter's roadmap: 21 ways to jumpstart your story. Focal Press.

Subject: Define Hero, Develop Character-Arc, Create Stakes, Create Conflict.

Format: Physical.

Audience: Intermediate.

Useful things: Case Study, Exercises.

Landau's manual is very comprehensive in dealing with a character as its primary focus. The contents page is convenient, and the headings are designed for quick access for any screenwriter regardless of their working knowledge of the screenwriter's language or terminology. Landau acknowledges that there can be 
alternatives to the three-act structure (Landau, 2013). However, the fundamental focus of any story is on the character. It provides excellent case studies and exercises in overcoming various character development problems.

Lazarus, T. (2012). The last word: Definitive answers to all your screenwriting questions. Michael Wiese Productions.

Subject: Define Hero, Develop Character-Arc, Create Stakes, Create Conflict.

Format: Physical.

Audience: Intermediate.

Useful things: Case Study, Exercises.

Lazarus has developed a convenient manual for screenwriters. A screenwriter can look for solutions to specific problems by looking at the contents page. Lazarus' writing style is easy to follow and is organised in alphabetical order by theme. The manual is straightforward and provides some exercises for the screenwriter. It has information for a novice screenwriter to advance to more intermediate or advance. Lazarus provides advice on what producers are looking for in a script; if the screenwriter is an amateur or professional screenwriter (Lazarus, 2012). It provides adequate coverage on character development problems a screenwriter will face.

McBride, J. (2012). Writing in pictures: Screenwriting made (mostly) painless. Vintage Books.

Subject: Create Stakes, Create Conflict.

Format: Physical.

Audience: Novice.

Useful things: None.

McBride believes action is character and character is conflict and conflict is the plot. Additionally, McBride believes the character does not have to be likeable. However, the character needs to drive the action and have clear motives that the audience can 
understand why the hero wants to accomplish their goal. McBride emphasises the use of word-economy, showing more than telling and does touch on subtext in terms of dialogue and images (McBride, 2012). Sometimes the character development problems encountered by a screenwriter have to do how they have defined character, raised the stakes, created conflict through the use of secondary characters.

McKee, R. (2016). Dialogue: The art of verbal action for page, stage, screen (First edition). Twelve, an imprint of Grand Central Publishing.

Subject: Define Hero, Develop Character-Arc, Create Conflict.

Format: Physical.

Audience: Novice.

Useful things: Case Study, Exercises.

McKee believes that every character is a walking dictionary with their unique phrases and words (McKee, 2016). McKee offers solutions to creating three-dimensional characters and defining characters using dialogue as a framework. Additionally, McKee explains that there are three types of conflict: social, personal, and inner. Moreover, Social conflict derives from institutional forces. Furthermore, personal conflict arises from relationships, and inner conflict derives from the main character. Therefore, it is essential to fluctuate between the three to create exciting obstacles for the hero to overcome or not overcome. McKee's manual is a seminal work in dialogue for films. It offers comprehensive coverage in all matters of building characters through dialogue.

Munier, P. (2014). Plot Perfect: How to Build Unforgettable Stories Scene by Scene [Electronic resource]. F+W Media. http://auckland.lib.overdrive.com/ ContentDetails.htm?ID=9C683762-4FBF-49F1-9648-643934BDF270

Subject: Define Hero, Develop Character-Arc, Create Conflict.

Format: Physical \& E-Book. 
Audience: Novice.

Useful things: Case Study, Exercises, Diagrams.

Munier provides a manual that is very simplistic in design and some ways content. However, the content that is there is crucial for any novice writer to understand. Additionally, Munier asks the screenwriter a series of questions to both let the screenwriter identify and characterisation problem, and also solve it. Furthermore, Munier encourages the screenwriter to ask questions about their scripts regularly (Munier, 2014). Munier covers areas of defining the hero and structuring the narrative with the character-arc to achieve a character-driven story.

Neipris, J. (2016). A master class in dramatic writing: Theater, film, and television. Routledge.

Subject: Define Hero, Develop Character-Arc, Create Stakes, Create Conflict.

Format: Physical.

Audience: Novice.

Useful things: Case Study.

Neipris has a short but concise look into creating complex characters by providing a checklist of questions for the screenwriter to answer for their particular character problem. Additionally, it tells a screenwriter how to show this complexity through action and interactions with other characters (Neipris, 2016). It also touches on how to raise stakes through the character journey. It also provides exercises on escalating conflicts. However, the manual shines with its section on how to rewrite to refine a script.

Obstfeld, R. (2002). Fiction first aid: Instant remedies for novels, stories and scripts. Writer's Digest Books.

Subject: Define Hero, Develop Character-Arc, Create Stakes, Create Conflict.

Format: Physical. 
Audience: Novice.

Useful things: Case Study, Exercises.

Obstfeld believes that increasing the stakes for the hero means having a goal and subtasks to achieve that goal (Obstfeld, 2002). Additionally, the hero must face unimaginable odds that the audience knows it is close to impossible to overcome. Moreover, Obstfeld believes a character does not have to be likeable. In conclusion, this manual is easy to navigate. It has finding aids inside that will help the user skip to relevant chapters or pages. Furthermore, Obstfeld asks relevant questions that are common problems in characterisation.

Patz, D. S. (2017). Write! Shoot! Edit! The complete guide to filmmaking for teens. Michael Wiese Productions.

Subject: Define Hero, Develop Character-Arc, Create Conflict.

Format: Physical.

Audience: Novice.

Useful things: Diagrams.

Patz' manual aims to deliver practicable information for teenagers to make films. An example is different strategies such as brainstorming, the use of index cards. It also provides a simple overview of character archetypes, such as the villain and the hero. However, it does touch upon how events or activities that affect a screenwriter's character should either be an emotional up or and emotional downer to show character arc, struggle, and resolution (Patz, 2017). Although it is primarily for short films, the principles can be applied to feature films.

Robinson, J., \& Mungovan, T. (2003). The screenplay workbook: The writing before the writing [Electronic resource]. Lone Eagle. http://auckland.lib.overdrive.com/ ContentDetails.htm?ID=DECC7971-16B0-4648-862C-A9F00653DD2C

Subject: Define Hero, Develop Character-Arc, Create Conflict.

Format: E-Book.

Audience: Novice. 
Useful things: Case Study, Exercises.

Robinson and Mungovan provide a very simple and easy to use manual. The manual offers sound advice on character development and character arcs. Furthermore, Robinson \& Mungovan provide worksheets for screenwriters to use to flesh out their characters and understand what drives their actions through the narrative structure (Robinson \& Mungovan, 2003). However, the worksheets are very small and hard to look at; it would be beneficial to screenwriters if there were a PDF or a link to download. Despite this, the manual does make an effort to ask the screenwriter questions so the screenwriter can find solutions to their characterisation problems. This manual offers brilliant resources in the appendix.

Russin, R. U., \& Downs, W. M. (2012). Screenplay: Writing the picture (2nd ed. rev. \& updated). Silman-James Press.

Subject: Define Hero, Develop Character-Arc, Create Stakes, Create Conflict.

Format: Physical.

Audience: Novice.

Useful things: Case Study, Exercises, Diagrams.

Russin \& Down's delves into character development and provides an adequate explanation into character, character arc, conflict, and stakes. Additionally, Russin and Down reference films that have done well, or not well, in developing characters (Russin \& Downs, 2012). The section on stakes is clearly defined and elaborated on, in terms of how to up the stakes. It also provides snapshots of how it would appear in an actual script which is extremely helpful to screenwriters. An exciting chapter on power and conflict provides solutions to creating conflict and developing characterarc. Russin \& Down provide advice on smaller things such as formatting that some screenwriting books leave out. Formatting is essential and usually what tells a reader, or producer if the script is worth reading. 
Schimmel, J. (2014). Screenwriting behind enemy lines: Lessons from inside the studio gates. Michael Wiese Productions.

Subject: Define Hero, Develop Character-Arc, Create Stakes, Create Conflict.

Format: Physical.

Audience: Intermediate.

Useful things: Case Study, Exercises.

Schimmel offers a pragmatic look into characterisation (Schimmel, 2014). Schimmel analyses how to define a character and how a character's arc should develop over a standard three-act structure of a script. The exercises force the screenwriter to analyse a film and to identify critical elements of characterisation to figure out solutions to their character development problems.

Schmidt, V. (2012). 45 master characters: Mythic models for creating original characters (2nd ed). Writer's Digest Books.

Subject: Define Hero, Develop Character-Arc, Create Conflict.

Format: Physical.

Audience: Intermediate.

Useful things: Exercises.

Schmidt helps writers explore character archetypes using the mythic journeys of heroes and heroines (Schmidt, 2012). The difference with this manual is that it splits up its characterisation by gender. Furthermore, Schmidt believes that the character's goal closely defines character-arc. This manual is an interesting read in terms of archetypes, and the overall design is easy to follow. However, there are terms used in there that a novice would think twice about making it hard to navigate in the contents page. 
Seger, L. (2011). Writing subtext: What lies beneath. Michael Wiese Productions.

Subject: Define Hero, Develop Character-Arc, Create Stakes, Create Conflict.

Format: Physical.

Audience: Novice.

Useful things: Case Study, Exercises.

Seger deals with writing dialogue and characterisation in scripts. Moreover, Seger explores subtext: words or gestures that we see that may refer, or infer, a different meaning than the one that a screenwriter wishes to convey (Seger, 2011). Seger offers case studies and exercises for the screenwriter to help develop the use of subtext.

Selbo, J. (2008). Gardner's guide to screenplay: The rewrite. GGC Pub.

Subject: Define Hero, Develop Character-Arc, Create Stakes, Create Conflict.

Format: Physical.

Audience: Novice.

Useful things: Case Study, Exercises.

Selbo provides useful sections on the basics of rewriting and genre expectations (Selbo, 2008). Selbo delivers great coverage on characterisation and provides numerous checklists of questions, and exercises, to overcome most character development problems. The screenwriter can easily navigate through chapters or use the index to find solutions to their specific needs. Additionally, there are great case studies to demonstrate what Selbo is explaining as well, which is helpful.

Smith, P. J. (2008). The power of the dark side: Creating great villains, dangerous situations, \& dramatic conflict. Michael Wiese Productions.

Subject: Define Hero, Develop Character-Arc, Create Stakes, Create Conflict.

Format: Physical.

Audience: Novice. 
Useful things: Case Study.

Smith understands that conflict is at the heart of a story. Smith focuses on villains, but the screenwriter can apply the concept to any genre. Smith has a good understanding of archetypes found in antagonist and explores how a screenwriter can avoid cliches and why they work in a script. However, Smith's manual design prevents the screenwriter from effortlessly navigating the manual to solve their particular character problem. Smith provides a manual that illustrates the importance of conflict being the centre of a good story, and screenwriters need uncompromising characters to ensure characters are in conflict (P. J. Smith, 2008).

Snyder, B. (2005). Save the cat! The last book on screenwriting you'll ever need. Michael Wiese Productions.

Subject: Define Hero, Develop Character-Arc, Create Conflict.

Format: Physical Book, E-Book.

Audience: Intermediate.

Useful things: Case Study.

Snyder provides a transparent 15-point beat sheet on how a story is structured. He also writes the manual in a manner that asks questions to the screenwriter for them to come up with a solution to their particular script. Snyder demonstrates how to develop a character arc by using his 'transformational machine' diagram, which plots the 15point beats and when and where a character's arc encounters an emotional shift (Snyder, 2005). Snyder provides a useful checklist of questions about the hero's journey.

Street, K. L. (2013). Writing and selling crime film screenplays. Creative Essentials.

Subject: Define Hero, Develop Character-Arc, Create Stakes, Create Conflict.

Format: Physical.

Audience: Novice. 
Useful things: Case Study, Exercises.

Street has dedicated her manual to the crime screenwriter and touches on many popular sub-genres within crime: whodunnit, Prison films, Gangster films, and more (Street, 2013). Street uses Joseph Campbell's mono-myth to construct the hero's journey. Additionally, using a checklist for the antihero journey. Street provides a plethora of exercises, examples, and case studies that are useful.

Sublett, S. W. (2014). Screenwriting for neurotics: A beginner's guide to writing a featurelength screenplay from start to finish. University of Iowa Press.

Subject: Define Hero, Create Stakes, Create Conflict.

Format: Physical.

Audience: Novice.

Useful things: Case Study.

Sublett emphasises character conflict where there is a clash of ideologies or competing goals between two or more characters. It talks about external conflict, either environment or secondary characters that oppose the hero, or inner conflict inside the hero with doubts of accomplishing their goals (Sublett, 2014). Sublet provides coverage on externalising conflict. It does well to answer all four-character development problems. However, Sublett disperses the solutions throughout the book, and the screenwriter must consult with the index to find the sections that are relevant to their specific character development problem.

Sykes, C. P. (2012). How to craft a great story: Creating perfect plot and structure. Teach Yourself.

Subject: Define Hero, Create Conflict.

Format: Physical and E-Book.

Audience: Novice.

Useful things: Exercises. 
Sykes provides diagrams, case studies, and exercises to illustrate his points. Sykes uses a character ladder diagram to illustrate how a character moves through their journey from one emotional state to another by the end of the script (Sykes, 2012). Sykes offers more tips on creating conflict and tension better than most manuals. Sykes succeeds in providing everything a screenwriter needs to solve complex character development problems.

Sykes, C. P. (2014). Complete creative writing course. Teach Yourself, John Murray Learning.

Subject: Define Hero, Create Stakes, Create Conflict.

Format: Physical and E-Book.

Audience: Novice.

Useful things: Case Study, Exercises, Diagrams.

Sykes Manual is for writing fiction and provides tools and exercises to stimulate creativity (Sykes, 2014). However, it does provide useful checklists for character biographies that a screenwriter can use and does touch upon essential topics of defining a character and creating conflict between characters. However, the manual is more suitable for writing novels than scripts.

Trottier, D. (2014). The screenwriter's bible: A complete guide to writing, formatting, and selling your script (6th edition). Silman-James Press.

Subject: Define Hero, Develop Character-Arc, Create Stakes, Create Conflict.

Format: Physical.

Audience: Novice.

Useful things: Case Study.

Trottier provides a comprehensive manual on screenwriting. Trottier covers the mental process and motivation to complete a script, the technical formatting of a script to look aesthetically pleasing to a producer or filmmaker, revising a script, and 
how to sell it (Trottier, 2014). Trottier provides more than sufficient amount of depth in character development solutions and overall coverage of issues arising in scripts. However, Trottier does not provide exercises; instead, it raises awareness of issues and potential solutions by using questions. However, a screenwriter can efficiently traverse to relevant sections to find solutions.

Truby, J. (2007). The anatomy of story: 22 steps to becoming a master storyteller. Faber and Faber.

Subject: Define Hero, Develop Character-Arc, Create Stakes, Create Conflict.

Format: Physical \& E-Book.

Audience: Novice.

Useful things: Case Study, Exercises, Diagrams.

Truby argues that secondary characters often define great characters. Additionally, all characters serve a purpose. Therefore, a screenwriter should write all characters in a script like an interconnected web. Truby also argues that any opposition or conflict should be necessary for the growth of the character-arc (Truby, 2007). Truby's manual is well-formatted and designed to be easy to read. A screenwriter can navigate between chapters easily, and there are learning aids such as exercises, case studies, and diagrams that help a reader understand the concepts that underlie characterisation.

Vogler, C., \& Montez, M. (2007). The writer's journey: Mythic structure for writers (3rd ed). Michael Wiese Productions.

Subject: Define Hero, Develop Character-Arc, Create Stakes, Create Conflict.

Format: Physical.

Audience: Novice.

Useful things: Case Study, Exercises, Diagrams.

Vogler is a seminal text for screenwriters as it uses Joseph Campbell's mythic structure and makes it more accessible to screenwriters (Vogler \& Montez, 2007). It 
gives case studies, checklists, diagrams, and exercises for novice screenwriters to explore the mythic structure. It delves into defining a character, character arc, character stakes, and conflict and more. Film studio executives, creatives, screenwriters and producers in Hollywood use Vogler's manual.

Walker, S. J. (2012). Romantic screenplays 101 [Electronic resource]. Fiction Works. http://auckland.lib.overdrive.com/ ContentDetails.htm?ID=D0961FBB-00E7-4CF6AE53-F5CEC5BCDB52

Subject: Define Hero, Develop Character-Arc, Create Conflict.

Format: E-Book.

Audience: Novice.

Useful things: Case Study, Exercises, Diagrams.

Walker analyses the principles of romantic fiction and romance's characterisation requirement. Walker recognises that there is a clear narrative progression from a romantic couple going from trust, acceptance, and permission (Walker, 2012). Walker recognises that conflict is handled differently in romance and that complication in the relationship between characters, and jealousy is a crucial device in creating conflict. Walker's account on characterisation does not seem comprehensive. However, a screenwriter can learn archetypes and why they are essential to this particular genre of filmmaking.

Weiland, K. M. (2017). Creating character arcs: The masterful author's guide to uniting story structure, plot, and character development [Electronic resource]. Smashwords Edition. https://samples.overdrive.com/?crid=5c0105b2- 3acb-4c91-8322c3b909acd72c\&.epub-sample.overdrive.com

Subject: Define Hero, Develop Character-Arc, Create Stakes, Create Conflict.

Format: E-book.

Audience: Novice. 
Useful things: Case Study, Exercises.

Weiland offers a manual that marries story structure and character arc seamlessly. Weiland believes there are three types of character-arcs: Positive change, Flat arc, and negative change (Weiland, 2017). Firstly, Positive arc is when a character is unfulfilled and ends in triumph. The changes to the hero are positive. Secondly, the Flat arc is when a character is unchanged from the start to the end, and they usually spark change in other characters in the narrative. Lastly, negative change is the opposite of positive change. This manual is easy to follow and delves into problems with characterisation very well and offers straight to the point exercises to remedy problems.

Wendig, C. (2017). Damn fine story: Mastering the tools of a powerful narrative. Writer's Digest Books.

Subject: Define Hero, Develop Character-Arc, Create Stakes, Create Conflict.

Format: Physical.

Audience: Intermediate.

Useful things: Case Study.

Wendig believes superficial aspects of the character are meaningless and that what is the most important is the character problem because it defines who they are (Wendig, 2017). The actions they take to solve it and provides narrative beats to answering that character problem. Moreover, both external and internal complications prevent the character from finding a solution to that character problem which creates more threedimensional characters. Therefore, complications raise the stakes on completing the journey to solving that character problem. Wendig puts together an essential overview of what to do with characterisation but also why it is necessary. Wendig presents his ideas in an entertaining and easy to consume way. However, Wendig has a poorly designed contents page. Therefore, making a screenwriter would have difficulty navigating to characterisation problems. However, this manual is perfect for the novice writer as the content is entertaining and relevant to most characterisation problems. 


\section{References}

Abushwesha, F. (2014). Rocliffe notes: A professional approach for screenwriters \& writerdirectors. Kamera Books.

Ackerman, A., Puglisi, B., \& Kaufman, C. (2013). The negative trait thesaurus: A writer's guide to character flaws (First print edition). JADD Publishing.

Ackerman, H. (2017). Write screenplays that sell: The Ackerman way (Revised updated edition). Tallfellow Press.

Alderson, M., \& Rosenfeld, J. E. (2015). Writing deep scenes: Plotting your story scene by scene through action, emotion, and theme [Electronic resource]. Writer's Digest. http://samples.overdrive.com/?crid=72bc4d2e- ec05-44f1-832f49f366150333\&.epub-sample.overdrive.com

Aronson, L. (2000). Scriptwriting updated: New and conventional ways of writing for the screen. Australian Film Television \& Radio School ; Allen \& Unwin.

Aronson, L. (2010). The 21st century screenplay: A comprehensive guide to writing tomorrow's films. Allen \& Unwin.

Axelrod, M. (2014). Constructing dialogue: From Citizen Kane to Midnight in Paris. Bloomsbury Academic.

Azlant, E. (1997). Screenwriting for the early silent film: Forgotten pioneers, 1897-1911. Film History, 9(3), 228-256.

Bailey, S., \& Blake, M. (2013). Writing the horror movie. Bloomsbury.

Ballon, R. (2005). Blueprint for Screenwriting: A Complete Writer's Guide to Story Structure and Character Development (Rev.ed.). Mahwah, N.J: Lawrence Erlbaum Associates. https://doi.org/10.4324/9781410611123 
Batty, C. (2011). Movies That Move Us Screenwriting and the Power of the Protagonist's Journey (1st ed. 2011.). Palgrave Macmillan UK.

https://doi.org/10.1057/9780230348158

Batty, C. (2012). Screenplays: How to write and sell them. Creative Essentials.

Batty, C. (2016). Screenwriting studies, screenwriting practice and the screenwriting manual. New Writing (Clevedon, England), 13(1), 59-70. https://doi.org/10.1080/14790726.2015.1134579

Batty, C., \& Baker, D. J. (2018). Screenwriting as a Mode of Research, and the Screenplay as a Research Artefact. In C. Batty \& S. Kerrigan (Eds.), Screen Production Research: Creative Practice as a Mode of Enquiry (pp. 67-83). Springer International Publishing. https://doi.org/10.1007/978-3-319-62837-0_5

Batty, C., \& Kerrigan, S. (2018). Screenwriting as a Mode of Research, and the Screenplay as a Research Artefact. In C. Batty \& S. Kerrigan (Eds.), Screen Production Research: Creative Practice as a Mode of Enquiry (1st ed.2018., pp. 67-83). Springer International Publishing. https://doi.org/10.1007/978-3-319-62837-0_5

Batty, C., \& Waldeback, Z. (2012). The creative screenwriter: Exercises to expand your craft. Methuen Drama.

Bauer, I., \& Bauer, V. (2017). Screenwriting fundamentals: The art and craft of visual writing. Routledge.

Bell, J. S. (2011). Conflict \& suspense [Electronic resource]. Writers Digest Books. http://excerpts.cdn.overdrive.com/FormatType- 410/1705-1/715/9B4/61/ ElementsofFictionWritingConflictandSu9781599632759.epub

Bennett, T. (2014). Showrunners: The art of running a TV show / Tara Bennett. Titan Books. Bernhardt, W., \& Bernhardt, W. (2017). Creating Character: Bringing Your Story to Life [Electronic resource]. Bablyon Books. 
https://samples.overdrive.com/?crid=134b427a- 3b68-4522-9729-

0a449f836c65\&.epub-sample.overdrive.com

Bishop, L. S. (2016). Sell your story in a single sentence: Advice from the front lines of Hollywood. The Countryman Press, a division of W.W. Norton \& Company.

Branton, M. (2013). The Creative Writing Workbook [Electronic resource]. Hodder \& Stoughton. http://auckland.lib.overdrive.com/ ContentDetails.htm?ID=6ECFE41B5E99-44FC-9470-8BA8C899F757

Brooks, L., \& Hauge, M. (2015). Story fix: Transform your novel from broken to brilliant. Writer's Digest Books.

Callaghan, D. (2012). Script tease: Today's hottest screenwriters bare all. Adams Media.

Chamberlain, J. (2016a). The nutshell technique: Crack the secret of successful screenwriting (First edition.). University of Texas Press.

Chamberlain, J. (2016b). The nutshell technique: Crack the secret of successful screenwriting (First edition) [Electronic resource]. University of Texas Press. http://samples.overdrive.com/?crid=e97d148d- 9672-4113-be10fc5de8d4393f\&.epub-sample.overdrive.com

Cheng, J., Wicks, J., \& Noguchi, S. (2016). An annotated bibliography for Taiwan film studies. Columbia University Press.

Chitlik, P. (2013). Rewrite: A step-by-step guide to strengthen structure, characters, and drama in your screenplay (Second edition). Michael Wiese Productions.

Coleman, J. J., \& Peditto, P. (2012). Writing screenplays. Self-Counsel Press.

Conor, B. (2014). Gurus and Oscar Winners: How-To Screenwriting Manuals in the New Cultural Economy. Television \& New Media, 15(2), 121-138. https://doi.org/10.1177/1527476412452798

Cooper, P., \& Dancyger, K. (2005). Writing the short film (3rd ed). Elsevier/Focal Press. 
Corbett, D. (2013). The art of character: Creating memorable characters for fiction, film, and TV. Penguin Books.

Corder, N. (2014). Creating convincing characters. Compass Books.

Cowgill, L. J. (2008). The art of plotting: How to add emotion, excitement, and depth to your writing [Electronic resource]. Back Stage Books.

http://excerpts.cdn.overdrive.com/FormatType- 410/0111-1/406/071/7B/

ArtofPlottingAddEmotionSuspenseandDep9780307875136.epub

Cron, L. (2012). Wired for story: The writer's guide to using brain science to hook readers from the very first sentence (1st ed) [Electronic resource]. Ten Speed Press. http://excerpts.cdn.overdrive.com/FormatType- 410/0111-1/973/3AE/4B/ WiredforStoryTheWritersGuidetoUsingBr9781607742463.epub

Cron, L. (2016). Story genius: How to use brain science to go beyond outlining and write a riveting novel (before you waste three years writing 327 pages that go nowhere) (First edition) [Electronic resource]. Ten Speed Press. http://samples.overdrive.com/?crid=825acba2- 5676-4cdd-b52c697102dd5a43\&.epub-sample.overdrive.com

Dale, E. (1951). Motion picture discrimination: An annotated bibliography. Bureau of Educational Research, Ohio State University. http://hdl.handle.net/2027/uc1.b3227230

Dancyger, K. (2013). Alternative Scriptwriting, 5th Edition (5th edition). Routledge.

Davis, R. (2016). Creating compelling characters for film, TV, theatre and radio (2nd edition). Bloomsbury Academic.

De Paul, G. (2017). Bring the funny: The essential companion for the comedy screenwriter. Routledge. 
Diamond, D., \& Weissman, D. (2019). Bulletproof: Writing scripts that don't get shot down. Michael Wiese Productions.

Duncan, S. V. (2008). Genre screenwriting: How to write popular screenplays that sell. Continuum.

Dunnigan, B. (2019). Screenwriting is filmmaking: The theory and practice of writing for the screen. The Crowood Press.

Edelstein, L. N. (2004). The writer's guide to character traits: Includes profiles of human behaviors and personality types. Writer's Digest; David \& Charles.

Egri, L. (2009). The art of dramatic writing: Its basis in the creative interpretation of human motives. Wildside Press.

Eszterhas, J. (2006). The devil's guide to Hollywood: The screenwriter as God! (1st ed). St. Martin's Press.

Evenson, J. M. (2013). Shakespeare for screenwriters: Timeless writing tips from the master of drama. Michael Wiese Productions.

Fancher, H., \& Lethem, J. (2019). The wall will tell you: The forensics of screenwriting. Melville House.

Field, S. (2005). Screenplay: The foundations of screenwriting (Rev. ed.). Delta Trade Paperbacks.

Fink, E. J. (2014). Dramatic story structure: A primer for screenwriters. Routledge.

Finnegan, J. (2016). The screenplay and the spectator: Exploring audience identification in narrative structure. Journal of Screenwriting, 7(3), 319-330. https://doi.org/10.1386/josc.7.3.319_1

Foster, S. E. (2002). Streets were dark with something more than night: An annotated bibliography of film noir and neo-noir. http://restrictedarchive.vuw.ac.nz//handle/123456789/7934 
Frayne, C. (2019, May 28). The Worst Mistake a Screenwriter Can Make. Script Magazine. https://scriptmag.com/screenplays/the-worst-mistake-a-screenwriter-can-make

Frey, J. N. (2010). How to write a damn good thriller: A step-by-step guide for novelists and screenwriters (1st ed). St. Martin's Press.

Gaines, T. (2017). So you want to write a screenplay: A step-by-step guide to writing for film, video, and television. Atlantic Publishing Group, Inc.

Gallo, G. (2012a). Screenwriter's Compass (1st edition). Routledge.

Gallo, G. (2012b). The screenwriter's compass: Character as true North. Focal Press.

Garant, R. B., \& Lennon, T. (2011). Writing movies for fun and profit! How we made a billion dollars at the box office and you can, too! Touchstone.

Gilford, J. (2015). Why does the screenwriter cross the road? + other screenwriting secrets. Michael Wiese Productions.

Grace, J. (2013). Directing your destiny: How to become the writer, producer, and director of your dreams (1st edition). Hay House, Inc.

Grace, Y. (2014). Writing for television: Series, serials and soaps. Kamera Books, an imprint of Oldcastle Books.

Grierson, T. (2013). FilmCraft: Screenwriting (1st edition). Focal Press.

Grove, E. (2009). Beginning filmmaking: 100 easy steps from script to screen (1st ed). Methuen Drama.

Hamand, M. (2009). Creative writing for dummies [Electronic resource]. Wiley. http://link.overdrive.com/?websiteID=262\&titleID=531571

Hauge, M. (2011). Writing screenplays that sell (New twentieth anniversary ed). Methuen Drama. 
Hay, L. V. (2017). Writing diverse characters for fiction, TV or film [Electronic resource]. Kamera Books. https://samples.overdrive.com/?crid=a4f88304- 2f10-45c3-abfd269b4df98fce\&.epub-sample.overdrive.com

Hockrow, R. (2014). Storytelling techniques for digital filmmakers: Plot structure, camera movement, lens selection, and more [Electronic resource]. Amherst Media Press. http://link.overdrive.com/?websiteID=262\&titleID=1408846

Horne, J. (2018). Dramatic techniques for creative writers: Turbo-charge your writing (1st ed). Method Writing.

Howard, D. (2005). How to build a great screenplay: A master class in storytelling for film. Souvenir.

Hoxter, J. (2011). Write what you don't know: An accessible manual for screenwriters. Continuum.

Hurbis-Cherrier, M., \& Rabiger, M. (2013). Directing: Film techniques and aesthetics (5th ed). Focal Press.

Iglesias, K. (2005). Writing for emotional impact: Advanced dramatic techniques to attract, engage, and fascinate the reader from beginning to end (1st ed). WingSpan Press.

Indick, W. (2004). Psychology for screenwriters: Building conflict in your script. Michael Wiese Productions.

Jacey, H. J. (2010). Journey to nowhere: The writing of Loy and Christopher Vogler's screenwriting paradigm [Ph.D., University of the Arts London]. https://ualresearchonline.arts.ac.uk/id/eprint/5211/

Jessup, L. Z. (2014). Getting it write: An insider's guide to a screenwriting career. Michael Wiese Productions.

Johnson, C. (2010). Crafting short screenplays that connect (3rd ed., rev.expanded). Focal Press. 
Johnson, C., \& Stevens, M. (2002). Script partners: What makes film and TV writing teams work. Michael Wiese Productions.

Klick, T. (2016). Beat by beat: A cheat sheet for screenwriters. Michael Wiese Productions.

Kress, N. (2005). Characters, emotion, \& viewpoint: Techniques and exercises for creating dynamic characters and effective viewpoints (1st ed). Writer's Digest Books.

Lake, D. (2017). The screenwriter's path: From idea to script to sale. Focal Press.

Landau, N. (2013). The screenwriter's roadmap: 21 ways to jumpstart your story. Focal Press.

Lazarus, T. (2012). The last word: Definitive answers to all your screenwriting questions. Michael Wiese Productions.

Lee, L. (2001). A Poetics for Screenwriters (1st ed.). University of Texas Press.

Lee, S.-J. S., Lomdahl, A.-M., Sawtell, L., Sculley, S., \& Taylor, S. (2016). Screenwriting and the higher degree by research: Writing a screenplay for a creative practice $\mathrm{PhD}$. New Writing, 13(1), 85-97. https://doi.org/10.1080/14790726.2015.1135964

Leff, L. J. (1984). Resources for the screenwriting teacher. Journal of Film and Video, 36(3), 6-14. JSTOR.

Lyons, J. (2016). Anatomy of a premise line: How to master premise and story development for writing success. Focal Press.

Marlow, J. R. (2012). Make your story a movie: Adapting your book or idea for Hollywood (1st ed). St. Martin's Griffin.

McBride, J. (2012). Writing in pictures: Screenwriting made (mostly) painless. Vintage Books.

McKee, R. (2016). Dialogue: The art of verbal action for page, stage, screen (First edition). Twelve, an imprint of Grand Central Publishing. 
Mernit, B. (2020). Writing the romantic comedy: The art of crafting funny love stories for the screen (Twentieth anniversary expanded and updated edition). Harper.

Mukherjee, R. (2014). The art of screenplays: A writers guide. Kamera Books, an imprint of Oldcastle Books.

Munier, P. (2014). Plot Perfect: How to Build Unforgettable Stories Scene by Scene [Electronic resource]. F+W Media. http://auckland.lib.overdrive.com/ ContentDetails.htm?ID=9C683762-4FBF-49F1-9648-643934BDF270

Nannicelli, T. (2013). A philosophy of the screenplay. Routledge.

Neipris, J. (2016). A master class in dramatic writing: Theater, film, and television. Routledge.

Nelmes, J. (2010). Analysing the screenplay. Routledge.

Nicolosi, B. R., \& Peterson, V. (2015). Notes to screenwriters: Advancing your story, screenplay, and career with whatever Hollywood throws at you. Michael Wiese Productions.

Nornes, M. (2009). Research guide to Japanese film studies. Center for Japanese Studies, The University of Michigan.

NZ Writers Guild-Professional Association of Script Writers. (2020). Nzwritersguild. https://www.nzwg.org.nz

NZFC Scriptwriting. (2020). New Zealand Film Commission. https://www.nzfilm.co.nz/resources/scriptwriting

Obstfeld, R. (2002). Fiction first aid: Instant remedies for novels, stories and scripts. Writer's Digest Books.

Patz, D. S. (2017). Write! Shoot! Edit! The complete guide to filmmaking for teens. Michael Wiese Productions. 
Robinson, J., \& Mungovan, T. (2003). The screenplay workbook: The writing before the writing [Electronic resource]. Lone Eagle. http://auckland.lib.overdrive.com/ ContentDetails.htm?ID=DECC7971-16B0-4648-862C-A9F00653DD2C

Rosenfeld, J. E. (2016). Writing the intimate character: Create unique, compelling characters through mastery of point of view. Writer's Digest Books.

Russin, R. U., \& Downs, W. M. (2012). Screenplay: Writing the picture (2nd ed. rev. \& updated). Silman-James Press.

Samaroo, M. (2015). The complete guide to writing a successful screenplay: Everything you need to know to write and sell a winning script. Atlantic Publishing Group.

Schimmel, J. (2014). Screenwriting behind enemy lines: Lessons from inside the studio gates. Michael Wiese Productions.

Schmidt, V. (2012). 45 master characters: Mythic models for creating original characters (2nd ed). Writer's Digest Books.

Seger, L. (1990). Creating unforgettable characters (1st ed.). HHolt.

Seger, L. (2011). Writing subtext: What lies beneath. Michael Wiese Productions.

Selbo, J. (2008). Gardner's guide to screenplay: The rewrite. GGC Pub.

Smethurst, W. (2016). How to write for television (7th edition). Robinson.

Smith, N. J. (1999). Tracking the changes: The impact of end-user searching on the reference librarian's role. Victoria University of Wellington.

Smith, P. J. (2008). The power of the dark side: Creating great villains, dangerous situations, \& dramatic conflict. Michael Wiese Productions.

Snyder, B. (2005). Save the cat! The last book on screenwriting you'll ever need. Michael Wiese Productions.

Steele, A., \& Gotham Writers' Workshop (Eds.). (2006). Writing movies: The practical guide to creating stellar screenplays (1st U.S. ed). Bloomsbury. 
Street, K. L. (2013). Writing and selling crime film screenplays. Creative Essentials.

Sublett, S. W. (01). Screenwriting for Neurotics-A Beginner's Guide to Writing a FeatureLength Screenplay from Start to Finish. University of Iowa Press.

Sublett, S. W. (2014). Screenwriting for neurotics: A beginner's guide to writing a featurelength screenplay from start to finish. University of Iowa Press.

Sykes, C. P. (2012). How to craft a great story: Creating perfect plot and structure. Teach Yourself.

Sykes, C. P. (2014). Complete creative writing course. Teach Yourself, John Murray Learning.

The Library of Congress. (2020). LC Linked Data Service: Authorities and Vocabularies (Library of Congress) [Webpage]. Library of Congress. http://id.loc.gov/authorities/subjects/sh85088030.html

Trottier, D. (2014). The screenwriter's bible: A complete guide to writing, formatting, and selling your script (6th edition). Silman-James Press.

Truby, J. (2007). The anatomy of story: 22 steps to becoming a master storyteller. Faber and Faber.

Vogler, C., \& Montez, M. (2007). The writer's journey: Mythic structure for writers (3rd ed). Michael Wiese Productions.

Walker, S. J. (2012). Romantic screenplays 101 [Electronic resource]. Fiction Works. http://auckland.lib.overdrive.com/ ContentDetails.htm?ID=D0961FBB-00E7-4CF6AE53-F5CEC5BCDB52

Weiland, K. M. (2017). Creating character arcs: The masterful author's guide to uniting story structure, plot, and character development [Electronic resource]. Smashwords Edition. https://samples.overdrive.com/?crid=5c0105b2- 3acb-4c91-8322c3b909acd72c\&.epub-sample.overdrive.com 
Wendig, C. (2017). Damn fine story: Mastering the tools of a powerful narrative. Writer's Digest Books.

Yorke, J. (2014). Into the woods: How stories work and why we tell them [Electronic resource]. Penguin Books. https://samples.overdrive.com/into-the-woodsacd02d?.epub-sample.overdrive.com 


\section{Glossary of Terms}

\begin{tabular}{|c|c|}
\hline Terms & Defii \\
\hline Antagonist & $\begin{array}{l}\text { An antagonist is a character that opposes the main character, or } \\
\text { hero, or protagonist in the narrative. }\end{array}$ \\
\hline Antihero & $\begin{array}{l}\text { The main character, or protagonist, that lacks heroic attributes but } \\
\text { an audience can empathise with their motives. }\end{array}$ \\
\hline Character Conflict & $\begin{array}{l}\text { Two characters have motivations that oppose each other that } \\
\text { naturally cause confrontation. }\end{array}$ \\
\hline Character Flaw & $\begin{array}{l}\text { An attribute of a character's personality that makes the character } \\
\text { complex, imperfect, and can be an obstacle for a character wanting } \\
\text { change. }\end{array}$ \\
\hline $\begin{array}{l}\text { Character goal } \\
\text { (motivation) }\end{array}$ & $\begin{array}{l}\text { A character's main objective that determines their actions, or in- } \\
\text { action, in accomplishing that objective. }\end{array}$ \\
\hline Character-Arc & $\begin{array}{l}\text { Follows a character's journey of transformation from one emotional } \\
\text { state to another, which an audience can track character growth and } \\
\text { change from the start of the narrative to the end. }\end{array}$ \\
\hline Conflict & $\begin{array}{l}\text { Conflict can be both internal and external to the character. Internal } \\
\text { conflict could be associated with psychological attributes that can } \\
\text { hinder a character. Additionally, an external conflict could come } \\
\text { from other characters, institutions, or a force of nature. }\end{array}$ \\
\hline Exposition & $\begin{array}{l}\text { Background information that is crucial for the audience to } \\
\text { understand the world and the character's motivation in a narrative. } \\
\text { Compelling exposition is embedded in a screenplay. Ineffective } \\
\text { exposition can dramatically slow the pace of a film. }\end{array}$ \\
\hline Logline & $\begin{array}{l}\text { A logline is a one-sentence summary of the characters, the general } \\
\text { plot, and the main problem faced by the character. }\end{array}$ \\
\hline Obstacles & $\begin{array}{l}\text { Obstacles can be other characters, or a force of nature, institution, } \\
\text { or complication that oppose the main character from accomplishing } \\
\text { their goals. }\end{array}$ \\
\hline Outline & $\begin{array}{l}\text { An outline is a breakdown of the plot in sequential order. The } \\
\text { outline can range between } 5-10 \text { pages. }\end{array}$ \\
\hline Pitching & $\begin{array}{l}\text { Pitching is the verbal presentation of a film concept or script in } \\
\text { order to gain confidence from collaborators or producers. }\end{array}$ \\
\hline Premise & The premise is a 1-3 paragraph-long summary of the plot. \\
\hline Protagonist & $\begin{array}{l}\text { The main character the audience follows through the narrative. The } \\
\text { character is usually an agent of change, and the audience identifies } \\
\text { or empathises with more than other characters. }\end{array}$ \\
\hline Reveal & $\begin{array}{l}\text { A plot device that reveals information either to the audience, or the } \\
\text { main character, that has implications on the main character's goals. }\end{array}$ \\
\hline Scene & $\begin{array}{l}\text { A narrative building block usually denoted by a change of location, } \\
\text { and each scene builds upon the previous scene and reveals } \\
\text { character, drives the plot, or reveals background information crucial } \\
\text { to understanding the narrative. }\end{array}$ \\
\hline $\begin{array}{l}\text { Scene-Cards (Index- } \\
\text { Cards) }\end{array}$ & $\begin{array}{l}\text { A screenwriting tool used to write essential plot points, scenes, or } \\
\text { characters that a screenwriter writes on cards, in order to re- } \\
\text { arrange, add, or discard scenes crucial to building the narrative. }\end{array}$ \\
\hline
\end{tabular}




\begin{tabular}{|l|l|}
\hline \multicolumn{1}{|c|}{ Terms } & \multicolumn{1}{c|}{ Definition } \\
\hline Screenplay (Script) & $\begin{array}{l}\text { A blueprint for film collaborators. Additionally, a highly formatted } \\
\text { body of writing that details the entire narrative and sequence of } \\
\text { events. A page of a script is equivalent to one minute of screen- } \\
\text { time. Therefore, it can range between 90-120 pages, which is the } \\
\text { standard length of films. }\end{array}$ \\
\hline $\begin{array}{l}\text { Screenwriter } \\
\text { (Scriptwriter) }\end{array}$ & The screenwriter is the author of the screenplay or script. \\
\hline Stakes & $\begin{array}{l}\text { The negative outcome that will happen if the main character does } \\
\text { not accomplish their goal. Raising the stakes can elicit audience } \\
\text { empathy. }\end{array}$ \\
\hline Story Beat & $\begin{array}{l}\text { A narrative note, or checkpoint in the narrative. A helpful } \\
\text { screenwriting tool to track the character journey. }\end{array}$ \\
\hline Subtext & $\begin{array}{l}\text { Content that is implied but not explicitly, or dialogue that has a } \\
\text { deeper meaning than its surface-level reading. }\end{array}$ \\
\hline $\begin{array}{l}\text { Supporting } \\
\text { (Secondary) }\end{array}$ & $\begin{array}{l}\text { Characters that are not the main character, or hero, that aid, or } \\
\text { hinder, the main character on their journey. A plot device to reveal } \\
\text { character through conversation. }\end{array}$ \\
\hline Three-Act Structure & $\begin{array}{l}\text { A standard narrative structure in three parts: setup, confrontation, } \\
\text { resolution, and includes points between each part that denote a } \\
\text { significant change in the narrative. }\end{array}$ \\
\hline Treatment & $\begin{array}{l}\text { A script document that charts the entire narrative of the script and } \\
\text { contains elements of a final script except for dialogue. Usually, the } \\
\text { last step before the first draft. Therefore, treatment can range } \\
\text { between 90-120 pages describing each scene. }\end{array}$ \\
\hline Word Economy & $\begin{array}{l}\text { Word Economy is the craft of writing with little to no words to } \\
\text { increase the readability of a script. }\end{array}$ \\
\hline $\begin{array}{l}\text { Writer's Block is a condition that prevents a writer from completing } \\
\text { the script due to perfectionism and, or, procrastination. }\end{array}$ \\
\hline
\end{tabular}




\section{Index}

2

21st century screenplay: A comprehensive guide to writing tomorrow's films, The.

18,69

4

45 master characters: Mythic models for creating original characters 57

A

Abushwesha, Farah 16,143

Ackerman, Angela. 16, 67, 112, 143

Ackerman, $\mathrm{Hal}$ $.17,67,112,144$

Alderson, Martha $.17,68,113,144$

Anatomy of a premise line: How to master premise and story development for writing success .... 48

Anatomy of story: 22 steps to becoming a master storyteller. 62

Aronson, Linda. 18, 68, 69, 113, 145

Art of character: Creating memorable characters for fiction, film, and TV, The 27

Art of dramatic writing: Its basis in the creative interpretation of human motives, The 33

Art of plotting: How to add emotion, excitement, and depth to your writing, The 28

Art of screenplays: A writer's guide, The ............ 51

Axelrod, Mark 19, 69

B

Bailey, Sara

20, 70, 114, 146

Batty, Craig $20,21,71,114,147$

Bauer, Irv.

21,72

Bauer, Vimi

21, 72

Beat by beat: A cheat sheet for screenwriters .... 45

Beginning filmmaking: 100 easy steps from script to screen 38

Bell, James Scott 72, 115, 147

Bennett, Tara .148

Bernhardt, William

$.22,73,116,148$

Bishop, Lane Shefter $23,116,149$

Blake, Marc

$20,70,114,146$

Branton, Matthew 23,74

Bring the funny: The essential companion for the comedy screenwriter

31

Brooks, Larry $.24,74,117,149$

Bulletproof: Writing scripts that don't get shot down
C

Callaghan, Dylan

$24,75,117,150$

Chamberlain, Jill

$25,75,118,150$

Character

Actions 17, 27, 39, 42, 50, 53, 54, 65, 67, 91, 99, $101,111,112,129,142,144,152,164,166$, 175,183

Antagonist. 20, 27, 33, 42, 49, 59, 60, 70, 83, 90, $97,105,107,114,124,129,138,146,152$, $158,166,178$

Antihero 26,77

Background .34, 40, 42, 55, 83, 90, 91, 102, 128, $130,136,158,165,167$

Backstory ..24, 33, 34, 75, 83, 84, 117, 124, 150, 158, 159

Character-driven story..22, 52, 73, 98, 116, 149, 173

Diversity. $40,90,128,165$

Exposition 34, 46, 55, 84, 95, 102, 124, 136, 159, 170

Flaw .. 40, 43, 46, 89, 92, 95, 128, 131, 164, 168, 170

Flaws.... 16, 17, 26, 40, 42, 67, 76, 90, 112, 119, $128,129,143,144,151,165,166$

goal 18, 26, 29, 40, 46, 49, 53, 57, 68, 76, 79, 89, $94,95,99,100,104,113,119,120,128,134$, 135, 145, 151, 154, 164, 170, 172, 174, 176

goals.... 18, 24, 26, 30, 46, 61, 68, 75, 76, 80, 94, $95,113,117,119,121,139,145,150,151$, $154,170,179$

Info-Dumping ..............28, 46, 78, 95, 153, 170 Journey $20,21,23,26,31,52,59,60,61,63,65$, 70, 71, 74, 77, 81, 99, 106, 107, 109, 111, $114,122,135,138,139,141,142,146,155$, $173,178,179,180,181,183$

Motivation 23, 27, 30, 40, 46, 49, 62, 80, 88, 89, $94,97,108,116,122,128,140,149,152$, $155,164,170,180$

Multiple Protagonists $29,79,121$

Psychological Profile.......... 28, 65, 78, 111, 153

Psychology ..... 34, 35, 44, 83, 93, 125, 131, 158, 159, 168

Relationships...21, 32, 46, 49, 64, 71, 81, 95, 97, $109,115,123,147,156,170,182$

Reveal ... 28, 34, 46, 58, 78, 83, 84, 95, 105, 124, $153,158,159,170$ 
Reversal

23,74

Stereotypes

$40,90,128,165$

Supporting (Secondary).

$40,89,128,164$

Sympathetic.

$26,51,77$

three-dimensional $17,21,35,45,50,60,65,67$,

$71,93,98,107,111,112,125,142,144,159$, 172,183

Traits .....16, 17, 28, 33, 67, 78, 82, 83, 112, 124, $143,144,153,157,158$

Tropes $20,40,70,90,114,128,146,165$

unsympathetic. 26,77

Villain ......33, 42, 54, 83, 91, 100, 124, 130, 158, 167,174

Wants....21, 22, 43, 49, 51, 71, 72, 92, 131, 134, 168,172

Character Conflict. 13

Character flaws 4

Character goal 3

Character-Arc

Flat Arc

$64,110,141,183$

Negative Change

$64,110,141,183$

Positive change.

$64,110,141,183$

Characters, emotion, \& viewpoint: Techniques and exercises for creating dynamic characters and effective viewpoints 46

Chitlik, Paul. $.26,76,119,151$

Coleman, Jessie J 26, 77

Complete creative writing..... 61

Complete guide to writing a successful screenplay: Everything you need to know to write and sell a winning script. 56

Conflict \& suspense 72

Constructing dialogue: From Citizen Kane to Midnight in Paris.. 69

Constructing dialogue: From Citizen Kane to Midnight in Paris. 19

Cooper, Pat. 27, 152

Corbett, David $.27,77,119,152$

Corder, Nicholas $28,78,153$

Cowgill, Linda J $.28,78,120,153$

Crafting short screenplays that connect ............. 45 Creating Character: Bringing Your Story to Life.. 22, 73

Creating compelling characters for film, TV, theatre and radio 30

Creating convincing characters. ........................ 28

Creative screenwriter, The ............................. 21 creative writing ... 28, 30, 61, 78, 80, 121, 153, 154, 180

Creative writing for dummies. 39,163

Creative Writing Workbook, The ... 23
Cron, Lisa $29,30,79,80,120,121,154$

D

Damn fine story: Mastering the tools of a powerful narrative .64

Dancyger, Ken 27, 152

Davis, Rib $30,80,121,155$

De Paul, Greg. 31, 122, 155

deconstructing films $31,122,155$

Devil's guide to Hollywood: The screenwriter as God, The. 34

Dialogue .. 19, 32, 49, 50, 51, 57, 58, 69, 70, 82, 98, 104, 105, 134, 137, 157, 172, 177

Dialogue: The art of verbal action for page, stage, screen. 50

Diamond, David 31, 81, 122, 156

Directing your destiny: How to become the writer, producer, and director of your dreams ...........88

Directing: Film techniques and aesthetics ..........42

Downs, William Missouri........... 55, 102, 136, 175

Dramatic story structure: A primer for screenwriters 36

Dramatic techniques for creative writers: Turbocharge your writing .41

Duncan, Stephen V 32, 81, 123, 156

Dunnigan, Brian $.32,82,157$

E

Edelstein, Linda $\mathbf{N}$

$33,82,124,157$

Egri, Lajos

33, 83, 158

Emotional state.

Eszterhas, Joe

34, 84, 124, 159

Evenson, J. M.

35, 125, 159

$\boldsymbol{F}$

Fancher, Hampton

$35,125,160$

feature-length $27,60,139,152,179$

Fiction first aid: Instant remedies for novels, stories and scripts. $6,9,11$

Fictional authorship

Fictional Authorship.. 22, 29, 30, 34, 39, 73, 80, 83, 115, 116, 121, 148, 149, 154, 158, 164

Field, Syd $35,84,126,160$ filmmaking process ... 32, 38, 39, 53, 58, 64, 82, 89, 100, 105, 110, 157, 163, 174, 182

Fink, Edward J.

$36,85,160$

first draft 22,72

Format

Physical Book .13

formatting the script. $27,56,62,77,102,108,119$, $136,140,152,175,180$ 
Frey, James $\mathbf{N}$

$.36,85,126,161$

G

Gaines, Taylor 86

Gallo, Guy 37, 86, 127, 161

Garant, Robert Ben $.37,87,127,162$

Gardner's guide to screenplay: The rewrite....... 58

Genre screenwriting: How to write popular screenplays that sell. 32

Genre writing 6

Getting it write: An insider's guide to a screenwriting career 44

Gilford, Joe $38,87,162$

Grace, Jennifer. 88

Grace, Yvonne 88

Grove, Elliot $38,89,163$

H

Hamand, Maggie 39, 163

Hauge, Michael.. 24, 39, 74, 89, 117, 127, 149, 164 Hay, Lucy V $40,90,128,164$

Hockrow, Ross 40, 165

Horne, Jules 41, 129, 165

How to build a great screenplay: A master class in storytelling for film. 41

How to craft a great story: Creating perfect plot and structure.

How to write a damn good thriller: A step-by-step guide for novelists and screenwriters............. 36

How to write for television ............................. 58

Howard, David

41, 90, 129, 166

Hoxter, Julian

$.42,91,130,167$

Hurbis-Cherrier, Mick.

$.42,91,130,167$

I

Iglesias, Karl

.43, 92, 131, 168

index cards $17,54,68,100,113,144,174$

Indick, William 44, 92, 131, 168

Interviews with writers, directors, and producers

$. .16,20,25,70,75,114,118,143,146,148,150$ Into the woods: How stories work and why we tell them. 65 J

Jessup, Lee Zahavi. $44,132,169$ Johnson, Claudia Hunter..... 45, 93 $\kappa$

Kaufman, Carolyn $16,67,112,143$ Klick, Todd $45,94,132,169$ Kress, Nancy 46, 94, 170
$L$

Lake, Dianne .46, 95

Landau, Neil $47,95,133,170$

Last word: Definitive answers to all your screenwriting questions, The. Lazarus, Tom $47,96,133,171$

Lennon, Thomas

.37, 87, 127, 162

Lethem, Jonathan $35,125,160$

Lyons, Jeff. .48, 96

M

Make your story a movie: Adapting your book or idea for Hollywood . .48

Marlow, John Robert ............................... 48, 97

Master class in dramatic writing: Theater, film, and television, A.

. .52

McBride, Joseph 49, 134, 171

McKee, Robert. $.50,97,172$

Mernit, Billy..... .50

Montez, M. $63,109,141,181$

Mukherjee, Robin .51

Mungovan, Tom $54,101,174$

Munier, Paula $.51,98,172$

N

Narrative

Alternative 19, 34, 42, 69, 84, 91, 114, 124, 130, $146,159,167$

Anthology Genre $19,69,114,146$

Concept...24, 31, 59, 74, 81, 105, 117, 123, 138, $150,156,178$

Conventional ........ 18, 19, 68, 69, 114, 145, 146

Dramatic Theme $26,76,119,151$

Four-Act Structure. $46,94,132,169$ Genre 32, 58, 59, 64, 81, 82, 104, 105, 110, 123, 137, 138, 156, 157, 177, 178, 182

Logline (Writing) $31,81,123,156$

Loglines (Writing) $23,117,149$

Obstacles......29, 37, 47, 50, 79, 85, 95, 98, 120, 126, 154, 161, 172

Outline (Writing) $21,72,115,147$

Premise $26,48,76,96,97,119,151$

Seven-Step Structure . 47, 95 Theme42, 48, 68, 90, 91, 96, 113, 129, 130, 133, 144, 166, 167, 171

Three Act Structure .... 18, 36, 47, 56, 69, 84, 96, 103, 126, 133, 137, 145, 160, 171, 176

Treatments (Writing) $21,72,115,147$

Negative trait thesaurus: $A$ writer's guide to character flaws, The 16 Neipris, Janet $52,99,134,173$ 
Nicolosi, Barbara $.52,99$

Notes to screenwriters: Advancing your story, screenplay, and career with whatever Hollywood throws at you. 52

Nutshell technique: Crack the secret of successful screenwriting, The

0

Obstfeld, Raymond $53,100,135,173$

$\boldsymbol{P}$

Patz, Deborah S $53,100,174$

Peditto, Paul .26, 77

Peterson, Vicki

52,99

Pitching an Idea $21,72,115,147$

Plot Perfect: How to Build Unforgettable Stories Scene by Scene. 51

Power of the dark side: Creating great villains, dangerous situations, \& dramatic conflict. .... 58

Protagonist....18, 19, 25, 40, 48, 60, 69, 76, 89, 97, $106,114,118,128,145,146,151,164$

Psychology for screenwriters: Building conflict in your script.

$.16,67,112,143$

Puglisi, Becca

$\boldsymbol{R}$

Rabiger, Michael

$.42,91,130,167$

Rewrite: A step-by-step guide to strengthen structure, characters, and drama in your screenplay

Robinson, Jeremy 54, 101, 174

Rocliffe notes: A professional approach for screenwriters \& writer-directors. 16

Romantic screenplays 101 63

Rosenfeld, Jordan E .17, 55, 68, 101, 113, 135, 144 Russin, Robin U. $55,102,136,175$

$S$

Samaroo, Melissa

56,102

Save the cat! The last book on screenwriting you'll

ever need.

scene-cards

$.17,67,112,144$

Schimmel, John $56,103,136,176$

Schmidt, Victoria $57,103,176$

Screenplay workbook: The writing before the writing, The 54

Screenplay: The foundations of screenwriting .... 35

Screenplay: Writing the picture ......................... 55

Screenplays: How to write and sell them ............ 20

Screenwriter's compass: Character as true North, The 37
Screenwriter's path: From idea to script to sale, The 46

Screenwriter's roadmap: 21 ways to jumpstart your story, The. .47

Screenwriting behind enemy lines: Lessons from inside the studio gates. .56

Screenwriting for neurotics: A beginner's guide to writing a feature-length screenplay from start to finish. 60

Screenwriting fundamentals: The art and craft of visual writing. 21,72

Screenwriting is filmmaking: The theory and practice of writing for the screen. 32

Script partners: What makes film and TV writing teams work

Script tease: Today's hottest screen writers bare all. .24

Scriptwriting updated: New and conventional ways of writing for the screen.... 68

Scriptwriting updated: New and conventional ways of writing for the screen. .18

Seger, Linda $57,104,137,177$

Selbo, Julie $58,104,137,177$

Sell your story in a single sentence: Advice from the front lines of Hollywood. .23

Selling tips......23, 27, 44, 60, 62, 77, 107, 108, 117, 132, 138, 140, 149, 169, 178, 180

Shakespeare for screenwriters: timeless writing tips from the master of drama 35 short film ................................................ 27, 152 Showrunners: The art of running a TV show......148 Smethurst, William 58,105 Smith, Pamela Jaye $58,105,138,177$

Snyder, Blake 59, 106, 178

So you want to write a screenplay: A step-by-step guide to writing for film, video, and television $\mathbf{8 6}$

Steele, Alexander 59, 106

Stevens, Matt 45,93

Story fix: Transform your novel from broken to brilliant. .24

Story genius: How to use brain science to go beyond outlining and write a riveting novel....29

Storytelling techniques for digital filmmakers: Plot structure, camera movement, lens selection, and more .40

Street, Karen Lee $60,107,138,178$

Sublett, Scott Winfield $60,139,179$ Sykes, Chris $\mathbf{P}$. $61,107,139,179,180$ 


\section{$T$}

Tension .... 20, 21, 24, 26, 37, 41, 42, 43, 49, 55, 60, $61,70,71,75,76,85,91,92,97,102,107,114$, $117,119,126,129,131,135,139,146,150$, $152,161,166,168,180$

The negative trait thesaurus: $A$ writer's guide to character flaws

The screenwriter's bible: A complete guide to writing, formatting, and selling your script .... 62 The writer's guide to character traits 33 The writer's journey: Mythic structure for writers 63 Theme 12

Trottier, David $62,108,140,180$ Truby, John $62,108,140,181$

V

Vogler, Christopher $63,109,141,181$

W

Waldeback, Zara

$.21,71,114,147$

Walker, Sally J $63,109,182$

Wall will tell you: The forensics of screenwriting, The

31, 81, 122, 156

Weissman, David $64,110,142,183$

Wendig, Chuck.

$38,87,162$

screen writing secrets
sc...

Wired for story: The writer's guide to using brain science to hook readers from the very first sentence. 30

Word-economy ... 20, 23, 35, 49, 70, 117, 125, 134, $149,160,172$

Write screenplays that sell: The Ackerman way. 17, 67
Write what you don't know: An accessible manual

for screenwriters 42

Write! Shoot! Edit! The complete guide to

filmmaking for teens. 53

writer's block $19,38,69,87,114,146,163$

Writing and selling crime film screenplays. 60

Writing deep scenes: Plotting your story scene by scene through action, emotion, and theme ...17, 68

Writing diverse characters for fiction, TV or film .40 Writing for emotional impact: Advanced dramatic techniques to attract, engage, and fascinate the reader from beginning to end .43

Writing for television: Series, serials and soaps ...88 Writing in pictures: Screenwriting made (mostly) painless 49

Writing movies for fun and profit! How we made a billion dollars at the box office and you can, too!

Writing movies: The practical guide to creating stellar screenplays ...................................59

Writing process............................................... writing process, The ... 16, 42, 88, 91, 130, 143, 167 Writing screenplays.......................................26

Writing screenplays that sell.............................39

Writing subtext: What lies beneath. ....................57

Writing the horror movie..................................20

Writing the intimate character: Create unique, compelling characters through mastery of point of view .55

Writing the romantic comedy: The art of crafting funny love stories for the screen....................50 Writing the short film

$\boldsymbol{Y}$

Yorke, John. 65,111 


\section{Thematic/ Subject Index}

C

Creating Character Conflict

Case Study.... 143, 144, 145, 146, 148, 149, 150, $151,152,153,154,155,156,157,158,159$,

$160,161,162,163,164,165,166,167,168$,

$169,170,171,172,173,174,175,176,177$, $178,179,180,181,182,183$

Case Study $\backslash \mathrm{b}$. 152

Diagrams144, 145, 146, 147, 151, 156, 161, 164, $167,168,169,170,173,174,175,180,181$, 182

E-Book...144, 147, 148, 149, 151, 153, 154, 158, $163,165,172,174,178,179,180,181,182$

Exercises143, 144, 145, 146, 147, 148, 149, 151, $152,153,154,156,157,158,159,161,163$, $164,165,166,168,169,170,171,172,173$, $174,175,176,177,179,180,181,182,183$

Physical Book 143, 144, 145, 146, 147, 148, 149, $150,151,152,153,155,156,157,158,159$, $160,161,162,163,164,165,166,167,168$, $169,170,171,172,173,174,175,176,177$, $178,179,180,181,183$

D

Define the Main Character (Or Hero)

Case Study.16, 17, 18, 19, 20, 22, 23, 24, 25, 26, $27,28,29,30,31,32,33,34,35,36,37,38$, $39,40,41,42,43,44,45,46,47,48,49,50$, $52,53,54,55,56,57,58,59,60,61,62,63$, 64,65

Diagrams ...17, 18, 19, 22, 25, 26, 32, 36, 39, 42, $43,44,46,47,48,51,52,54,55,62,63,65$

E-Book. 18, 22, 23, 24, 25, 28, 29, 30, 33, 39, 40, $41,47,51,54,59,61,62,63,64$

Exercises. 18

Exercises....16, 17, 18, 19, 20, 21, 22, 23, 24, 25, $26,27,28,29,30,31,32,34,35,36,38,39$, $40,41,44,45,46,47,48,50,51,52,53,54$, $55,56,57,58,60,61,62,63,64$

Physical Book.. 16, 17, 18, 19, 20, 21, 22, 23, 24, $26,27,28,30,31,32,33,34,35,36,37,38$,
$39,41,42,43,44,45,46,47,48,49,50,51$, $52,53,54,55,56,57,58,59,60,61,62,63$, 65

Developing the Character-Arc

Case Study. 67, 68, 69, 70, 73, 74, 75, 76, 77, 78, $79,80,81,82,83,84,85,86,87,89,90,91$, $92,93,94,95,96,97,98,99,100,101,102$, $103,104,105,106,107,108,109,110,111$

Diagrams...67, 68, 69, 72, 73, 76, 81, 85, 86, 89, $91,92,93,94,95,97,98,100,102,108,109$, 111

E-book73, 74, 75, 78, 79, 80, 83, 90, 95, 98, 101, 106, 107, 108, 109, 110

E-Book. 68,73

Exercises ... 67, 68, 70, 71, 72, 73, 74, 76, 77, 78, $79,80,81,82,83,85,87,88,89,90,93,94$, $95,96,97,98,99,100,101,102,103,104$, $107,108,109,110$

Physical book...67, 68, 69, 70, 71, 72, 73, 74, 75, $76,77,78,80,81,82,83,84,85,86,87,88$, $89,90,91,92,93,94,95,96,97,98,99,100$, $101,102,103,104,105,106,107,108,109$, 110,111

$R$

Raising the Stakes

Case Study.... 112, 113, 114, 116, 117, 118, 119, $120,121,122,123,124,125,126,127,128$, $129,130,131,132,133,134,135,136,137$, $138,139,140,141,142$

Diagrams112, 113, 115, 118, 119, 123, 128, 130 , $131,132,136,140,141$

E-Book...113, 115, 116, 117, 118, 120, 121, 128, 139, 140, 141

Exercises112, 113, 114, 115, 116, 117, 118, 119, $121,123,125,128,129,131,132,133,135$, $136,137,138,139,140,141$

Physical Book 112, 113, 114, 115, 116, 117, 119, $121,122,123,124,125,126,127,129,130$, $131,132,133,134,135,136,137,138,139$, $140,141,142$ 
Word Count excluding title \& contents page, reference list and indices: 44,144

Lene Aiono

INFO580 